NISTIR 7749

\title{
Model Based Enterprise Technical Data Package Requirements
}

Simon Frechette

Paul Huang

Mark Carlisle 


\title{
Model Based Enterprise Technical Data Package Requirements
}

\author{
Simon Frechette \\ Systems Integration Division \\ Engineering Laboratory \\ Paul Huang \\ Department of the Army \\ Army Research Laboratory \\ Mark Carlisle \\ Systems Integration Division \\ Engineering Laboratory
}

February 2011

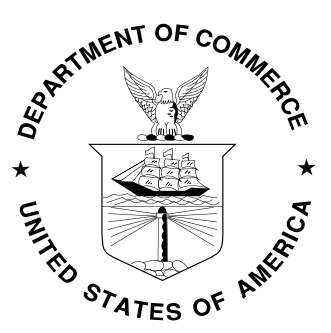

U.S. Department of Commerce Gary Locke, Secretary

National Institute of Standards and Technology Patrick D. Gallagher, Director 


\section{Contents}

Executive Summary $\quad 1$

1 Introduction $\quad 4$

1.1 What is a TDP? $\quad 4$

1.2 What is Changing? 4

1.3 DoD Engineering, Drawing, and Modeling Working Group (DEDMWG) 5

1.4 MBE/TDP Summit $\quad 5$

2 Background $\quad 6$

2.1 Challenge $\quad 6$

2.2 Workshop 6

3 TDP Workshop Results $\quad 9$

3.1 Group A - Acquisition $\quad 9$

3.1.1 Deficiencies or Barriers $\quad 9$

$\begin{array}{lll}3.1 .2 & \text { Vision Statement } & 15\end{array}$

3.1.3 Issues and Solutions 16

3.2 Group B - Production, Planning, and Design 21

3.2.1 Deficiencies or Barriers $\quad 22$

3.2.2 Vision Statement 36

$\begin{array}{lll}\text { 3.2.3 Issues and Solutions } & 37\end{array}$

3.3 Group C - Provisioning, Logistics, and Sustainment 44

3.3.1 Deficiencies or Barriers $\quad 46$

3.3.2 Vision $\quad 52$

3.3.3 Issues and Solutions $\quad 53$

3.4 Group D - Policy Management $\quad 56$

3.4.1 Deficiencies or Barriers $\quad 57$

$\begin{array}{lll}3.4 .2 & \text { Vision } & 59\end{array}$

$\begin{array}{lll}\text { 3.4.3 Issues and Solutions } & 60\end{array}$

4 Full Group Prioritization and Resulting Nuggets $\quad 65$

$\begin{array}{lll}4.1 & \text { Analysis } & 68\end{array}$

A-1 Group A. Acquisition Issues and Solutions Table $\quad 71$

A-2 Group B. Production, Planning, and Design Table 76

A-3 Group C. Provisioning, Logistics, and Sustainment Table 82

A-4 Group D. Policy Management Table

A-5 Summit Agenda $\quad 90$

A-6 Participants

A-7 Wiring Diagrams $\quad 96$ 


\section{Executive Summary}

\section{Workshop Summary}

The Department of Defense and the National Institute of Standards and Technology held a Model Based Enterprise Summit and Technical Data Package (TDP) Workshop December 15-17, 2009 in Gaithersburg, MD. The TDP workshop gathered subject matter experts to make recommendations for changes to DoD technical data package specifications. These changes are needed to support DoD transition to total lifecycle management based on digital models rather than 2D drawings.

77 subject matter experts from government and industry identified 46 critical issues affecting adoption of model based technical data packages during the day and a half workshop. Issues were separated into four categories: acquisition, production, sustainment, and policy. The attendees developed 148 proposed actions needed to address the critical issues. Each of four breakout sessions identified solutions and presented them in a final large group setting. The full assembly then prioritized the actions in order to provide a basis for a model based TDP implementation roadmap.

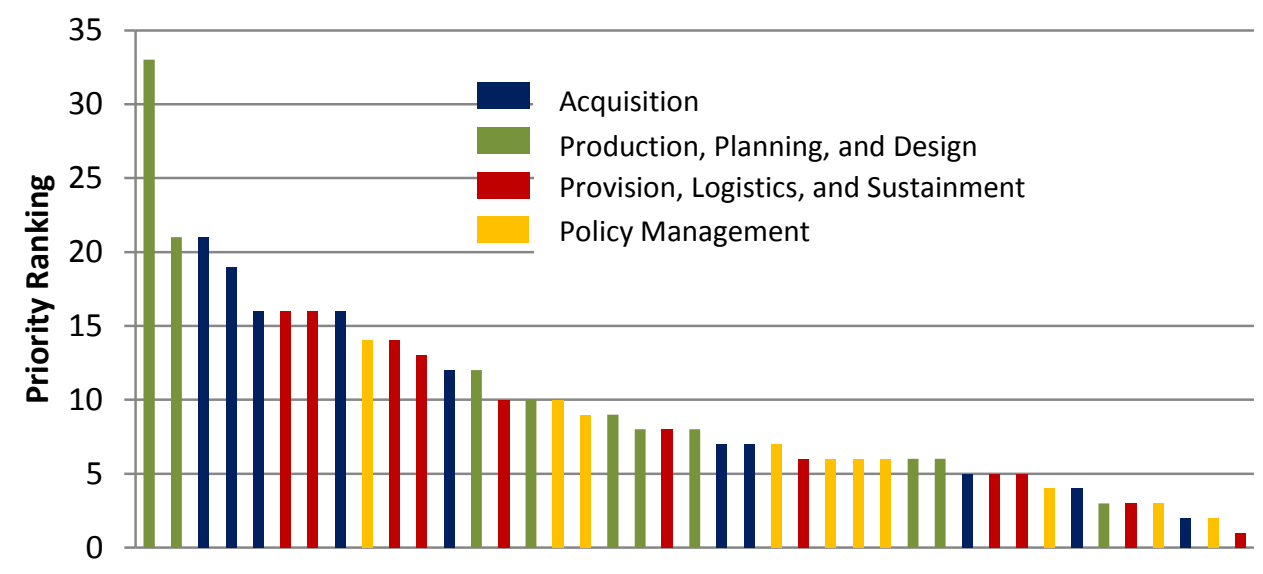

Activites Proposed to Support Model Based Technical Data Packages

Figure 1. Prioritization of Proposed Activities

\section{Importance of Technical Data}

The Technical Data Package delivered with a defense system contains all the engineering data and descriptive documentation required to support the system throughout its lifecycle. The information in the TDP is initially used to support the operation of the system - provisioning, logistics, training, and maintenance. For maintenance operations, production of interactive technical manuals directly from the product data has proven to be very effective. Later in the system life, the TDP is used to support repair, refit, and re-engineering of the system. The TDP provides the basis for modifying the system and supports competitive re-procurement of system components.

A technical data package includes applicable engineering data such as models, drawings, associated lists, specifications, standards, quality assurance, performance, and operational requirements. TDP completeness varies with each system procurement. Most major defense system support contracts are unique. Some systems have been delivered with fairly comprehensive data packages, while others have been delivered with very little technical data. In the cases where no technical data is delivered, the government must rely on the system prime manufacturer for support. Support provided by prime 
contracts may or may not be cost effective and in the case of increased operational tempo, the prime contractor may not be willing or may not be able to provide support or critical components in a timely manner. In some cases, government personnel have had to resort to reverse-engineering systems components in order to manufacture needed replacement parts. This is especially true of orphaned systems whose original manufacturers no longer exist.

Supporting advanced defense systems with little or no access to technical data adds significant costs and reduces system availability. Over $70 \%$ of the lifecycle cost of a system is incurred during the maintenance, support, and refit portion of the system lifecycle. Reverse engineering system components is a complex and error prone process. Reverse engineered component data and manufacturing processes must be completely re-certified prior to production. This process is potentially an order of magnitude more expensive than producing a component directly from the original data.

Robust, accessible technical data is vital for long term system support, but there are barriers to acquiring this data.

\section{Barriers to Acquisition of Technical Data}

The U.S. Department of Defense (DoD) has recently implemented policies that encourage DoD program managers (PMs) to consider a program's life cycle during initial system acquisition. PMs are encouraged to acquire a complete TDP with major system acquisitions and system upgrades. Despite policies that stress the importance of technical data, there are several factors that inhibit the acquisition and delivery of adequate technical data. Major factors are cost, perceived competitive advantage, data rights, and TDP delivery.

TDPs are considered expensive to acquire, which reduces the funding available for the system itself. With defense systems, the main concern is system delivery and initial cost control versus reducing long term sustainment costs. Program Managers often respond by obtaining only the minimal TDP to manage initial costs.

Technical data is considered a competitive advantage for the manufacturer. Most prime manufacturers do not consider it in their best interest to deliver complete technical data packages. Most primes would rather "lock in" future business as the only entity capable of providing the sustainment support and spare parts for the system. This exposes the government to the risk of the sole supplier not having sufficient capacity during critical times in the system's life-cycle.

Data rights are sometimes not clearly asserted. Uncertainty about technical data rights - what development was paid for by the government and what belongs to the manufacturer - has made the acquisition of technical data difficult in the past. The government can clearly assert its rights and data requirements in a well understood TDP framework.

Modern technical data package requirements are not sufficiently specified. The Office of the Secretary of Defense (OSD), as well as the individual services, have implemented directives that require acquisition of technical data, but with little, if any, direction as to what constitutes an adequate TDP, its format, or how it must be handled. Currently, nearly all TDPs are based upon centuries old methods limited to two-dimension (2D) drawings and associated documentation files. Industry, including most small businesses, has adopted a model based enterprise (MBE) approach where system data is captured as digital product models (e.g., computer aided design applications) and managed in a centralized database.

MBE technology has matured to the point where there is significant opportunity to dramatically improve defense systems operations and reduce support costs. By moving from the 2D drawing world into the digital 3D model world, the full product description can not only be captured in a digital product model 
but the information becomes reusable throughout the system lifecycle. Improved access to data enables all manner of automation and cost savings. Industry's migration to the model based enterprise should significantly ease the production of TDPs and make acquisition of adequate documentation more viable - but only if DoD TDP specifications are complete, well understood, and developed in partnership with industry.

\section{Recommended Actions}

Proposed actions from the workshop breakout sessions were consolidated and grouped into four distinct areas of need:

- Actions needed to completely define DoD TDP content requirements and delivery requirements.

- Actions needed to improve direction, instructions, and policy to better articulate the necessity for acquiring adequate technical data.

- Improvements in technology needed to fully enable more efficient use of the 3D product description.

- Actions needed to improve acquisition processes and provide more uniform contract language.

Workshop actions were formulated to provide a basis to move forward with planning, support, and execution of TDP-related projects. The central action identified by the workshop was the revision of MILSTDs and other specifications to support model based technical data packages. Even when prime contractors are willing to provide system technical data, there are significant questions regarding how the data will be transmitted, in what format, and how the government will organize this data in its own data management systems.

The top actions in each category are listed below.

\section{TDP Definition for MBE}

- Create a comprehensive description of the data required in a TDP.

- Define requirements for completely annotated models.

- Revise current MIL-STDs and related documents to consolidate requirements for distinct TDP levels and 3D model based product representations.

\section{Acquisition Policies and Directives}

- Mandate participation of all stakeholders and subject matter experts at Data Call and throughout the program, including IP attorneys experienced in data acquisition contractual issues.

- Make accountability of decisions made by PM extend beyond tenure for acquisition, such as practiced by the UK Defense Department.

- Revisit DODI 5000.02 to better address TDP policy.

\section{Technology Development}

- Identify acceptable native, neutral, and viewable data formats and ensure that standards are in place to support these formats.

- Identify TDP repository requirements and repository architecture options.

- Develop a validated translation process for delivering TDP information to the government and establish independent TDP validation processes.

\section{Acquisition Workforce and Processes}

- Establish training, certification, and knowledge capture to address declining workforce issues for acquisition data management professionals.

- Expand use of automated acquisition and contract development tools, i.e., SYSPARS \& SMART-T.

- Ensure that transportable, shareable, usable, and clearly identifiable data formats are established at Data Call. 


\section{Introduction}

\subsection{What is a Technical Data Package?}

A technical data package (TDP) contains a technical description of an item adequate for supporting an acquisition strategy, production, engineering, and logistics support. The description defines the required design configuration or performance requirements, and procedures required to ensure adequacy of item performance. It consists of applicable technical data such as models, drawings, associated lists, specifications, standards, and performance requirements. ${ }^{1,2,3}$ Lastly, as echoed by Ric Norton's large group presentation "Contracting for Data; a DLIS/DLA Perspective" - a Technical Data Package (TDP) should provide not only sufficient data to procure "up front" but re-procure later in the product lifecycle.

\subsection{What is Changing?}

We now have the opportunity to advance the state of product definition and its use. By moving from the 2D printed world into the 3D digital universe, the full product description is not only archived in a digital product model but the information becomes reusable without manual reentry. Figure 2 offers an example of the kind of clear graphic that can be easily and automatically extracted from a 3D computer model of an assembly.

The computer sensible information enables automation that leads to both speed and accuracy of data manipulation. Development of the Model Based Enterprise (MBE) is causing this technology to have tremendous value to the production of TDPs. Taking full advantage of the 3D product definition that an MBE will enable will be met sooner and with more coherent results if the steps required for fully effective use in TDPs are identified and then addressed in the appropriate order and timeliness.

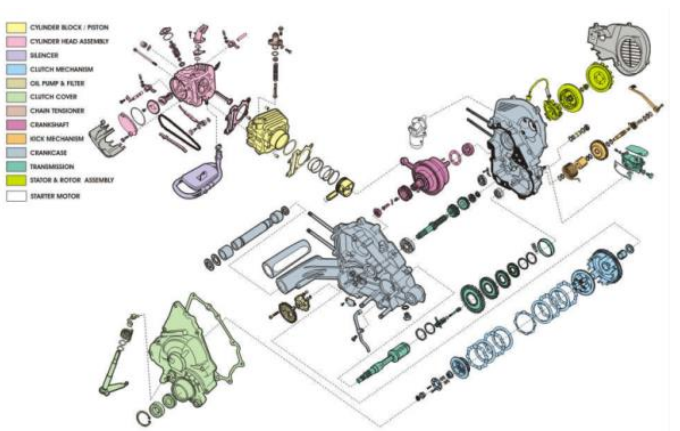

Figure 1 Example of an automated drawing generated by a 3D model

\footnotetext{
1 MIL-STD-31000 found at https://assist.daps.dla.mil/online/start/

2 The acronym 'TDP' for Technical Data Package is NOT found in Joint Publication 1-02, DoD Dictionary of Military and Associated Terms, as amended through 310ctober 2009 located at http://www.dtic.mil/doctrine/dod dictionary/

${ }^{3}$ From DoD Replenishment Parts Purchase or Borrow (DoD RPPOB) Program per Department of Defense INSTRUCTION NUMBER 4140.57, May 30, 2008 at http://www.dtic.mil/whs/directives/corres/pdf/414057p.pdf
} 


\subsection{DoD Engineering, Drawing, and Modeling Working Group (DEDMWG)}

The DEDMWG, currently co-chaired by Paul Huang (Army) and Ric Norton (DLIS), involves participation by individuals from the DoD Services plus NIST, Coast Guard, DOE, and interested industrial and academia personnel. The group works in two areas:

- Looking for methods to encourage acquisition managers to require an adequate TDP, and

- Modifying the definition of an adequate TDP to anticipate and/or encourage the use of 3D product models in TDP packages.

The DoD Engineering, Drawing, and Modeling Working Group (DEDMWG) charter calls for the group to lead efforts for technical coordination and policy guidance on technical data for product design, analysis, simulation, manufacturing, provisioning and other product lifecycle management functions. This includes guidance on technical data requirements for computeraided design, engineering, manufacturing, data tools for archival and retrieval, and related applications for total product lifecycle management.

This group's current accomplishments include highlighting the need to focus on understanding data rights and how to use them in the acquisition process, highlighting the benefits of a completely adequate TDP, and are actively seeking support for developing improved training for acquisition managers in collaboration with Defense Acquisition University.

Their main vehicle used to modify the requirements for

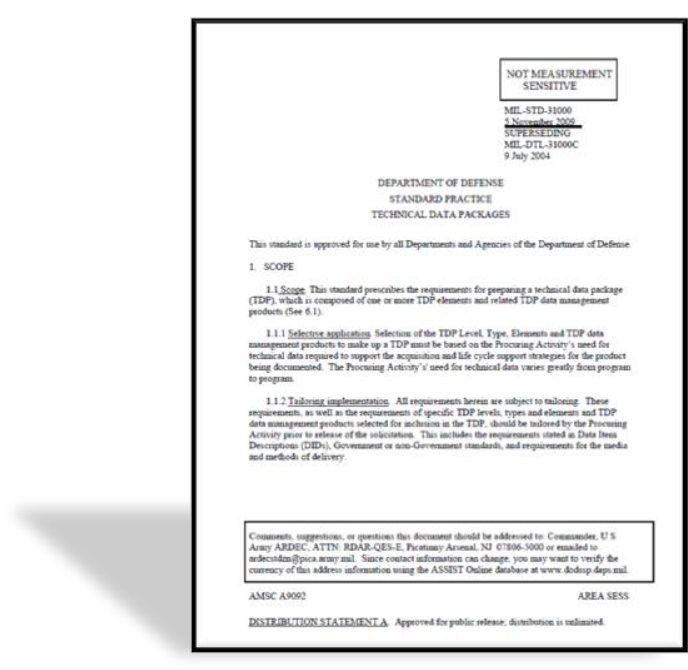

Figure 2. MIL-STD-31000 Revised by the DEDMWG. a TDP has been the creation of MIL-STD-31000 (to include several features compatible with a 3D product description's use (Figure 5).

\subsection{MBE/TDP Summit}

To further advance this work, the MBE/TDP Summit was designed to present current efforts dealing with MBE selected applications. Subject matter experts could then share their expertise on what should happen next with respect to TDPs in a secondary workshop.

On December $15-17^{\text {th }}$ at the NIST facilities in Gaithersburg, MD, the DoD sponsored the Model Based Enterprise \& Technical Data Package Summit.

On December $15^{\text {th }}$ and the first half of December $16^{\text {th }}$ the summit offered 18 presentations of selected Model Based Enterprise (MBE) efforts where models have been applied successfully in new ways to benefit our Warfighters. Participates contributed in a workshop (facilitated by $I M T I^{4}$ ) to gather focused input from on what data a Technical Data Package (TDP) should contain when embodied in a 3D Model definition. This report focuses on the findings of the workshop portion of the Summit.

4 IMTI - Integrated Manufacturing Technology Initiative is a non-for-profit Technology Management company headquartered in Knoxville, TN 


\section{Background}

The evolving model-based product realization process will produce a 3D product definition as a natural course of producing the product. This is because in a model based enterprise the execution of product and process models to realize the product will naturally produce a virtual product as well. Companies are beginning to realize that integrating the various models with collaborating applications that assist the various functions throughout the enterprise can provide untold benefits not only to the enterprise but to all downstream customers. This includes those needing a TDP to enable provisioning, provide logistics, and sustain the real product. One recently revealed example documented time and cost savings of 25 to 1 when model-based techniques are compared to conventional engineering practice. Further, savings and time compression of a factor of 5 were found in the change management process. ${ }^{5}$

\subsection{Challenge}

Technical information about a defense acquisition is required as part of the acquisition process, especially for major systems. According to Department of Defense Instruction DODI 5000.02 program managers for ACAT I and II programs, ${ }^{6}$ regardless of planned sustainment approach, shall assess the long-term technical data needs of their systems, and reflect that assessment in a Data Management Strategy (DMS). The DMS shall (1) be integrated with other life-cycle sustainment planning and included in the acquisition strategy; (2) assess the data required to design, manufacture, and sustain the system, as well as to support re-competition for production, sustainment, or upgrades; and (3) address the merits of including a priced contract option for the future delivery of technical data and intellectual property rights not acquired upon initial contract award considering the contractor's responsibility to verify any assertion of restricted use and release of data. ${ }^{7}$

The DFARS ${ }^{8}$ further strengthen this requirement by stipulating that, for major acquisitions, the acquisition manager shall establish acquisition strategies that provide for the TDP. These strategies are usually embodied in a technical data package and associated license rights needed to sustain those systems and subsystems over their life cycle. ${ }^{9}$

Containing sufficient information to sustain equipment throughout its useful life-cycle places stiff requirements on the TDP that should be acquired with each piece of major equipment. Current TDPs often fall short in providing the needed information for product use, provisioning, repair, and modification. The challenge is to use the emerging MBE to enrich the TDP to its fully required level of detail in as automated way as possible.

\subsection{Workshop}

During the workshop portion of this summit, representatives from government (primarily DoD), industry, and academia worked together to answer questions that will lead to the most effective

\footnotetext{
${ }^{5}$ BAE Systems U.S. Combat Systems Benchmarking Notes. October 20, 2009, IMTI2010001

6 Acquisition Categories costing greater than approximately $\$ 140 \mathrm{M}$ for research, development, and evaluation or procurement greater than $\$ 300 \mathrm{M}$ in FY1996 constant dollars

7 Department of Defense Instruction No. 5000.02 (December 8, 2008)

8 Defense Federal Acquisition Regulation Supplement (DFARS)

9 DFARS SubPart 207.1 - Acquisition Plans (S-70)(1)(ii)
} 
investment strategy required to advance the technology, the manufacturing readiness, and the state of the industry. By reviewing the current state, envisioning the perfect future, articulating the issues, and proposing a suite of solutions for their resolution the participants outlined a plan for moving forward. The results from this workshop, presented herein, will lead to the strategic investments needed to achieve the needed TDP maturation.

To facilitate the discussion the summit participants were divided themselves into four groups to discuss the topic from different viewpoints. The four subtopic areas were:
A. Acquisition;
B. Production, Planning, and Design(PP\&D);
C. Provisioning, Logistics, \& Sustainment (PL\&S); and
D. Policy Management.

The functional diagram for this structure is provided in Figure 3.

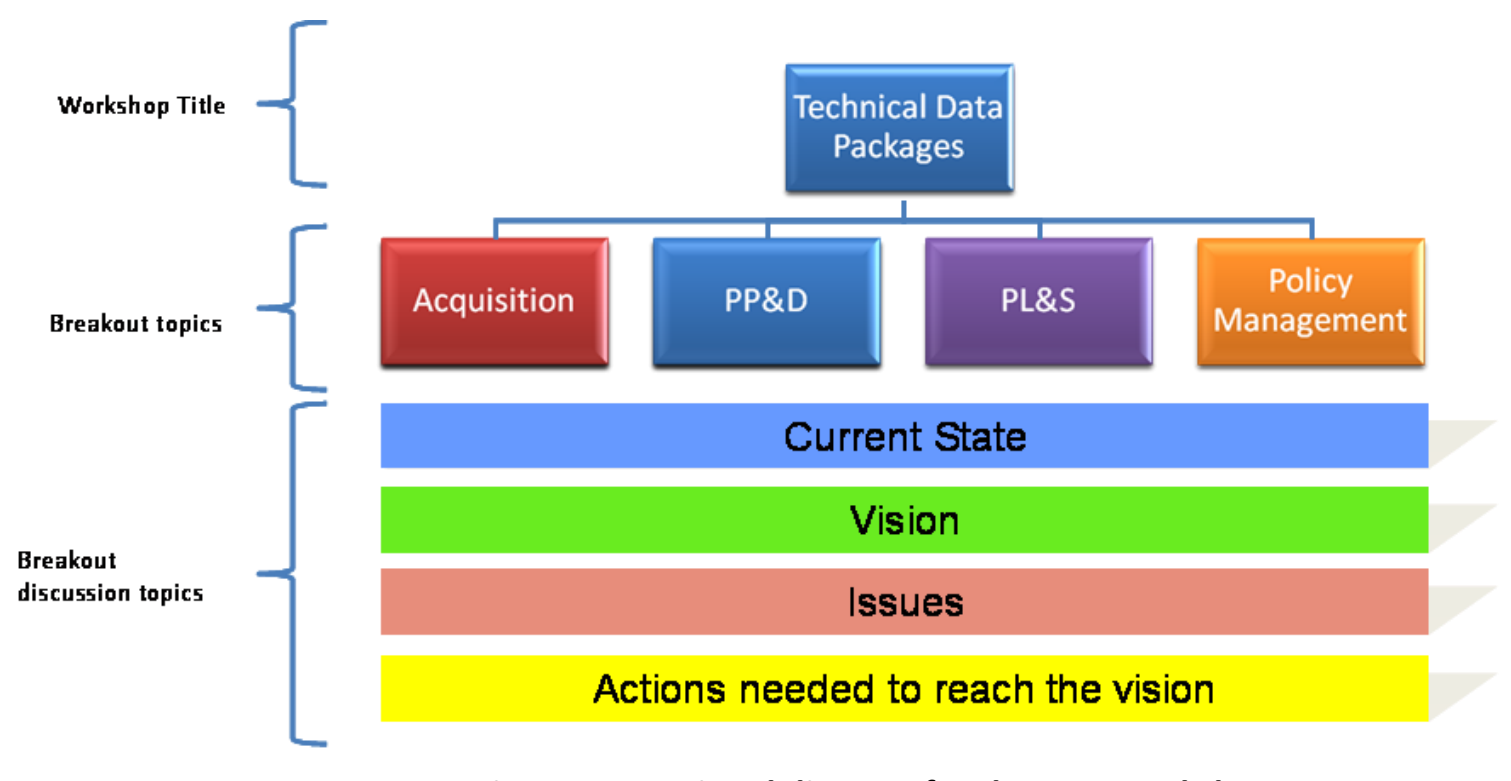

Figure 3 Functional diagram for the TDP Workshop

Following a brief overview of the workshop methodology and using the breakdown in Figure 3 the large group divided into four small groups. The facilitator in each topic group guided the discussion and assured that all had an opportunity to contribute. A scribe in each group captured the thoughts in a predeveloped template that IMTI used to keep the groups focused.

The first step in the workshop defines the Current State of Practice for each subject element in the functional model. While this included identification of emerging best practices, the primary objective of this step was to identify deficiencies and barriers that must be overcome on the way to success.

The next step defined the Future Vision for each element. The Vision step, simply put, answers the question, "If this function were perfect, what would its attributes be?"

The process core is the articulation of current Issues, followed by the actions (Solutions) needed to realize the vision. The facilitator led the group through a structured process of information gathering. The shortness of this workshop necessitated keeping it more strategic and less tactical. 
The final step in the workshop process was the prioritization of the solutions, i.e., determination of the recurring compelling themes that require immediate attention. IMTI accomplished this by developing group consensus in selecting the "critical solutions" for priority emphasis. 


\section{TDP Workshop Results}

This section presents the developments in each of the four individual small groups. Although based upon the raw notes ${ }^{10}$ they are somewhat augmented by the IMTI team to this improved articulation of the findings.

\subsection{Group A - Acquisition}

A TDP must be based on the Government's need for technical data required to support the acquisition and life cycle support strategies for the product being documented. The Government's need for technical data varies greatly from program to program. It may also be required at various stages of the acquisition process ranging from conceptual design data for concept evaluation to a complete set of detailed design data for re-procurement of items essentially identical to the original item.

TDPs define the physical and functional characteristics of the accepted configuration of the item and its subordinate assemblies, subassemblies, and parts thereof. TDP levels, types, elements, and TDP data management products are currently identified in accordance with MIL-STD-31000 and applicable data item descriptions. These items are tailored and imposed through the TDP Option Selection Worksheet and Contract Data Requirements Lists (CDRL) in contracts, purchase orders, and Military Interdepartmental Procurement Requests (MIPRs).

MIL-STD-31000 specifies two types of TDPs: Type 2D and Type 3D. This workshop focused on Type 3D. The point of this sub-topic was to capture elements that the MIL-STD-31000 fails to address and that a 3D model should be able to provide.

To receive an adequate technical data package as part of the acquisition process, we must first specify it as a contract deliverable. Too often, due to poorly defined requirements especially for 3D product data, the TDP provided with an item proves inadequate for provisioning and sustaining an item throughout the useful portion of its life cycle.

This section of the workshop will enable people who need to specify or deliver a TDP to express what changes they feel are required to specify the TDP requirements in the contract.

\subsubsection{Deficiencies or Barriers}

A variety of acquisition activities are required to support defense systems programs from their inception to retirement of the program. Inclusion of Technical Data Packages (TDPs) with procured systems and products is critical to success at each stage. During initial development of a system, the technical data will help define and evaluate the conceptual design while developing the ultimate system. During system use (which may be decades later in many cases), detailed specification data must be used in acquisition of suitable spares and replacement parts, and the acquired parts and systems must be fully documented to assure successful performance and maintenance/support capability. TDPs are especially critical when technology changes or system modifications occur, to enable configuration management of deployed systems. Coding various components and commodities into catalogs that enable acquisition of standard components for replacement parts or to create new products and systems, an often overlooked set of activities, lends further dependability and efficiency to DoD's acquisition activities. Here too, the presence of accurate TDPs for every system is of critical importance.

${ }^{10}$ Each group raw notes are available at http://www.mel.nist.gov/div826/msid/sima/mbe/2009.html. 
Increasing attention is being placed on the TDP because lack of adequate technical information on operational systems not only impacts the cost, manufacture, and delivery of defense systems, but also has an ongoing impact on the Warfighter and the ability to adequately repair and operate the equipment. However, there are a number of barriers or deficiencies that limit realization of the TDP's benefits.

The general lack of up-to-date, complete guidance and standards for acquisitions is one widespread problem with the delivery of TDPs with acquisitions. When there is no guidance or only out-of-date or ambiguous guidance that doesn't address digital data or 3D requirements, then it is not practical to expect compliance with the existing guidance or consistent data with which to operate. Furthermore, the sets of guidance and related practices are inconsistent across the services and across locations within some services. There are some good examples of TDP requirements and guidance for preparing and delivering good TDP data, including 3D data and models if and when used by the vendor (e.g. the Navy and Warner Robins Air Force examples of best practice in the Current State table below). These examples can serve as initial models for widespread use across the services.

A serious problem underlying DoD contracting and program management is the low priority given to TDP acquisition at the time the contract is being developed and thus it becomes a convenient item to negotiate away. The problem is not just with contract officers. Program managers often fail to see the value of the technical data defining the system, consider it optional, and need strong justification to insist on the delivery of the TDP along with the procured system. Program managers seem to have an erroneously high conception of the actual costs to acquire TDP. Indeed, the negative impact of acquisition decisions concerning the TDP is often not felt for some years, long after the PM has gone on to another assignment, so there are currently few consequences for bad TDP-related decisions.

A large part of the acquisition activity for any program is re-procurement of spares and replacement parts throughout the system's life cycle. Failure to have accurate and complete technical data to generate specs limits the program manager's options for re-procurement and impairs the support of the system. Contracted data rights are also an issue, particularly if vendors use technology already developed for the commercial market. Even if a TDP was specified and delivered, the vendor may still claim intellectual property and limit the right to use that delivered data for subsequent procurements, effectively limiting follow-on procurements to sole source. These issues must be resolved and contracted at the beginning of system acquisition. Another limitation that must be addressed is that vendors can claim an initial list of limited rights to TDP data, but they sometimes come back later and add to the limited rights list. The government must adjudicate such OEM assertions of proprietary data, especially since the burden of proof is on the vendors (since NDAA 07).

TDP delivery is needed not just at the end of development, but should be at regular intervals during high development phases, with changes and updates reflected more quickly after deviations from the initial baseline product.

There has been much discussion of the cost of complete and effective TDP data and it is not clear whether separate pricing of the TDP is wise. Perhaps the requirement should be simply to deliver all data, models, and process definitions used to create the system, particularly if they were developed as government-paid activities. Procurements will typically require delivery of technical manuals for a system, but providing high quality and up-to-date information during years of system use requires ongoing access to a complete and regularly updated TDP.

The ability to adequately specify the TDP requirements for a defense system can be quite challenging, and a key deficiency is limited perspective on the needs for the TDP. The Data Call for the system should all stakeholders and included all lifecycle perspectives. Designers and acquisition staff are not 
sufficient; manufacturing partners, IP lawyers, maintenance and logistics staff, support/training staff, and user representatives must all be included.

Data needs to be consistently validated. We are losing expertise needed to validate data, especially 3D and model-based data. There is a risk in waiting to get the data and in waiting (perhaps for years) to use the data and only then seeing whether it is valid data for the system. Some services are using a variety of validation reviews, mostly paper-based, but a complete solutions requires a DoD-wide systematic approach and automated means of validation.

A final, related challenge is the declining resource base. DoD has lost its ability to do a good job at defining and procuring TDPs. There is insufficient training and few recruits due to lack of recognition of the area as a valued profession. The few remaining experts cannot cover the current acquisition workload and there is concern that there may not be enough remaining expertise to train a new, replacement workforce knowledgeable in TDP issues.

Table 1 contains the complete set of points made by the Acquisitions group concerning the Current State of TDP acquisition

Table 1. Current state table for Acquisition.

\begin{tabular}{|c|c|}
\hline \multicolumn{2}{|c|}{ Current State of TDP Acquisition } \\
\hline Deficiencies or Barriers & Emerging Best Practice \\
\hline \multicolumn{2}{|c|}{ Guidance and Standards } \\
\hline $\begin{array}{l}\text { - Lack of technical data impacts Warfighter daily; } \\
\text { even as a safety issue. Data lacking to adequately } \\
\text { repair/operate equipment, etc. } \\
\text { - Key TDP acquisition guidance/standards- Out of } \\
\text { date; not complete; non-compliance; doesn't deal } \\
\text { with 3D } \\
\circ \text { Mil Std } 31000 \text { just released } \\
\circ 5000.02 \text { - guidance under which operate } \\
\text { DoD 5010.12-M (Manual)- out of date; not } \\
\text { being complied with; doesn't deal with 3D; } \\
\text { acquisition of any type of data; wasn't } \\
\text { intended for digital data } \\
\text { Verbiage of guidance is ambiguous and too } \\
\text { general; }\end{array}$ & $\begin{array}{l}\text { - Operations and Procedure Manual for } \\
\text { Contractor Prepared Data - TMIS } \\
\text { Technical Manual Information System } \\
\text { SL150-AA-PRO-010/DMP Rev } 2 \text { 01Jun09 } \\
\text { has latest guidance for developing } \\
\text { contractor prepared data; Navy } \\
\text { ownership; joint document - all services } \\
\text { have access; } \\
\text { - Army TARDEC requiring 3D data } \\
\text { - When successful getting requirements in } \\
\text { contract, will get good data. }\end{array}$ \\
\hline \multicolumn{2}{|c|}{ Contracting and Program Management } \\
\hline $\begin{array}{l}\text { - Acquisition of adequate TDP lacking; negotiated } \\
\text { away in Contract/Program office. PM office allows } \\
\text { deletions of requirements; OEMs not incentivized } \\
\text { to sell DoD the data and the loss in contracting is } \\
\text { due to their 'war of attrition' w/KOs. } \\
\text { - Policy lacks emphasis on TDPs; Program manager } \\
\text { should define; services do differently; } \\
\text { programming officer has many ways to evade } \\
\text { acquiring TDP; }\end{array}$ & $\begin{array}{l}\text { - Warner Robins AF has stringent data } \\
\text { requirements; submit a sample of digital } \\
\text { data in native, neutral, viewable formats. } \\
\text { Engineers review; if don't meet } \\
\text { requirements then vendor will do over. } \\
\text { - } \text { AF has full tech data validation review, } \\
\text { but without first article manufacturing } \\
\text { - Expeditionary Combat Support System - } \\
\text { ECSS; AF currently in process; other }\end{array}$ \\
\hline
\end{tabular}




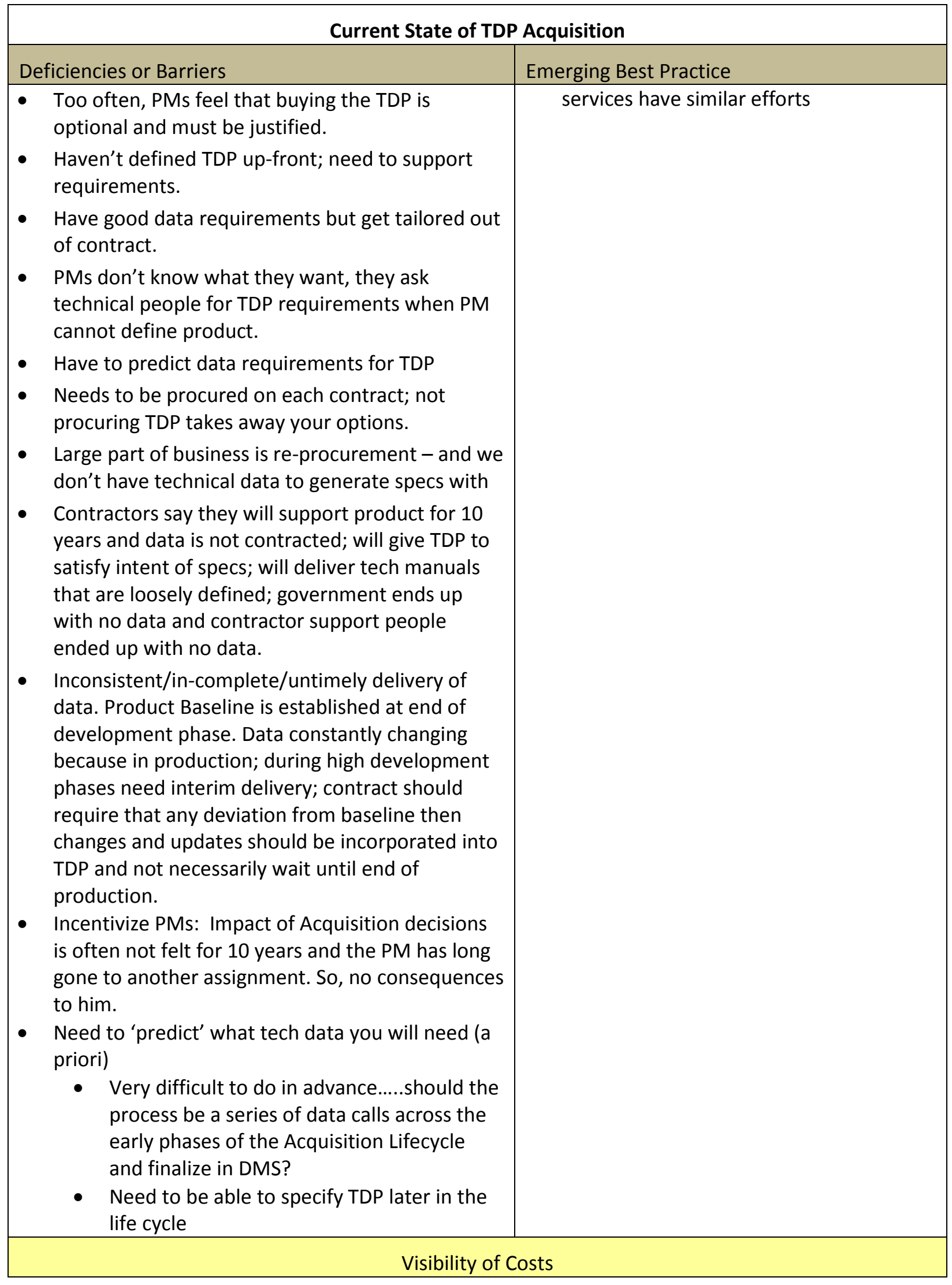




\begin{tabular}{|c|c|}
\hline \multicolumn{2}{|c|}{ Current State of TDP Acquisition } \\
\hline Deficiencies or Barriers & Emerging Best Practice \\
\hline $\begin{array}{l}\text { Engineering data is no longer separately priced } \\
\text { the price of the TDP and the tech manuals is } \\
\text { included in the hardware cost; don't know what } \\
\text { drawings cost or models cost. } \\
\text { - Section in DOD-5010.12 }{ }^{11} \text { clearly defines that we } \\
\text { need the vendor to generate to do our work. } \\
\text { Vendor generates TDP data to meet contract } \\
\text { specifications. If government paid to generate } \\
\text { that TDP data, then government should have } \\
\text { rights to data. }\end{array}$ & \\
\hline \multicolumn{2}{|c|}{ Impact of Non-Compliance } \\
\hline $\begin{array}{l}\text { - Impact of lack of TDP realized too late; no } \\
\text { consequences for non-compliance } \\
\text { - Emphasis is on procurement of tech manuals; but } \\
\text { tech manuals depend on a completeness of TDP. } \\
\text { - PMs and Acquisitions don't put emphasis on } \\
\text { engineering data; }\end{array}$ & \\
\hline \multicolumn{2}{|c|}{ Data Call } \\
\hline $\begin{array}{l}\text { - Data Call must include all stake holders, including } \\
\text { Acquisitions; to hold accountable for TDP } \\
\text { requirement. }\end{array}$ & \\
\hline \multicolumn{2}{|c|}{ Resources \& Support } \\
\hline 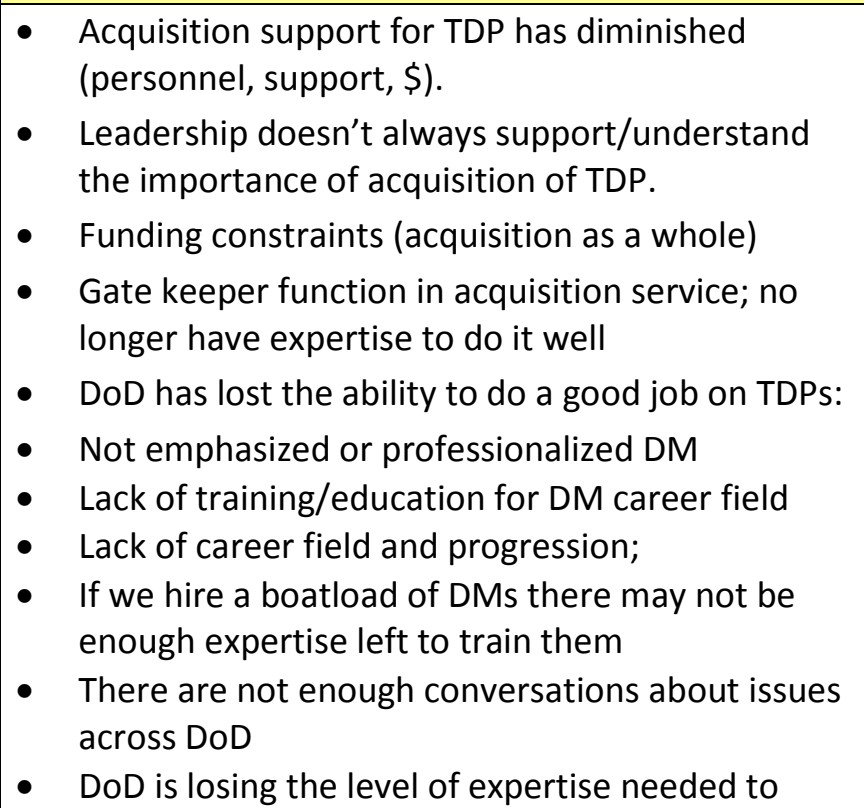 & \\
\hline
\end{tabular}

${ }^{11}$ DOD-5010.12L Acquisition Management Systems and Data Requirements Control. List (AMSDL) 


\begin{tabular}{|c|c|}
\hline \multicolumn{2}{|c|}{ Current State of TDP Acquisition } \\
\hline Deficiencies or Barriers & Emerging Best Practice \\
\hline train new resources in TDP acquisition & \\
\hline \multicolumn{2}{|c|}{ Data Rights } \\
\hline $\begin{array}{l}\text { - Data Rights - you can get everything you specified } \\
\text { but still not have entitled rights to use it; can buy } \\
\text { data but can't use it for procurement purposes; } \\
\text { restricted to sole source procurement. (IP issues) } \\
\text { - } \quad \text { At beginning of acquisition it is the best time to } \\
\text { procure data and rights to data. } \\
\text { - Vendors may have commercial equivalent and } \\
\text { therefore allow only limited rights; have clear cut } \\
\text { rights only if government paid for development. } \\
\text { Government should have unlimited rights to any } \\
\text { modifications to the commercial equivalent } \\
\text { funded by the government; typically government } \\
\text { doesn't pursue data rights for modifications. } \\
\text { Misinterpretations of DFARS clauses cause loop- } \\
\text { holes - need IP enforcements to close loop-hole. } \\
\text { DFARS requirement for offerors to state their } \\
\text { data rights claims (claim limited rights early on) } \\
\text { but they can come back later and add to the } \\
\text { limited rights list; and government typically } \\
\text { doesn't challenge. } \\
\text { - Legal issues: } \\
\text { We don't adjudicate OEM assertions of proprietary or } \\
\text { other restrictions even though the burden of proof is } \\
\text { on them (since NDAA 07 } \\
\text { Contract Officers (KO's) don't negotiate hard } \\
\text { w/contractors - may need a 'game plan' or other } \\
\text { tools }\end{array}$ & \\
\hline \multicolumn{2}{|c|}{ Validation } \\
\hline $\begin{array}{l}\text { - We do not consistently validate data and we are } \\
\text { losing expertise to validate 3Ds; don't know how } \\
\text { good the 2D data is until try to use it so how can } \\
\text { we validate/know MBE data (e.g. to build a test } \\
\text { article); there is a risk in waiting to get the data } \\
\text { and waiting to use the data } \\
\text { In Process Review (IPR) not being accomplished; } \\
\text { IPR for tech manuals and separate IPR for tech } \\
\text { data. }\end{array}$ & \\
\hline
\end{tabular}

${ }^{12}$ National Defense Authorization Act (NDAA) for Fiscal Year 2007 


\begin{tabular}{|l|l|}
\hline \multicolumn{2}{|c|}{ Current State of TDP Acquisition } \\
\hline Deficiencies or Barriers & Emerging Best Practice \\
\hline $\begin{array}{l}\text { Delivery and Acceptance of data 'deliveries' } \\
\text { (whether by access or otherwise) how do we } \\
\text { validate? Do we have the expertise to validate it? }\end{array}$ & \\
- & Long lag time in applying the data delivered, so \\
true validation may be long after we can fix it. & \\
- How to know if TDP is actual representation of & \\
vendor's existing data. & \\
If can't solve issues for 2D data then how can we & \\
solve for 3D MBE data? & \\
\hline & No systematic processes or validation tools for 2D \\
&
\end{tabular}

\subsubsection{Vision Statement}

In the future, a well-established and enforced DoD Acquisition Process will require delivery of the Technical Data package (TDP, as defined by an updated and complete MIL-STD-31000) along with the physical product. The model-based data will be received in both native and neutral format and will be easily viewable. There will be a systematic process to validate TDPs ensuring that what has been delivered to government customers and within government entities is a complete and accurate reflection of the vendor's underlying models and data. This implies that all product data and data exchange systems are interoperable and communicate without error.

All stakeholders will be involved early in the acquisition process (Data Call); with requirements easily defined and inserted into Contracts, CDRLs, DIDs, and SOWs; and tailored tools that aid the call-out of relevant requirement clauses of lengthy standards documents. As a result, the TDPs delivered with initial procurements will be sufficient to support economical re-procurement.

In a paradigm shift from earlier days, the Program Manager and Contract Officers will have to justify (or get a waiver for) not purchasing a full or complete TDP/PDD (Product Definition Data) instead of considering the TDP to be an optional item that may be yielded in negotiations.

Other elements of the Vision:

- The government will have unlimited data rights to portions of systems developed under government contract, restricted rights to contractor-developed portions, and adjudicating rights in data claims assertions.

- Incentive programs will be in place to reward or recognize Contractors who consistently provide full TDPs. Significant penalties will result if PM and Contractor fail to acquire/deliver TDP.

- The TDP and other engineering data are consistently funded and delivered, whether separately priced or automatically included in DoD procurements. This data includes drawings, models, and source data for technical manuals. 
- No item shall be stock listed without adequate engineering data (the TDP including form, fit, function, and interface).

- Data Management personnel in Acquisitions will enjoy professional status, with enhanced career options including training and certifications.

- All TDP data will reside in a common, federated DoD data repository with appropriate access and security provisions.

\subsubsection{Issues and Solutions}

The Acquisition Team identified eleven major Issues or challenges for acquisitions dealing with TDPs. The complete table of Issues and all solutions generated is shown in Appendix A-1. The Issues and their high-priority solutions are discussed in this section, followed by the team's Consolidated Top Ten solutions that were presented at the end of the workshop.

- There is limited enforcement of existing DFARS, e.g. the requirement for data to be shown as separately priced from hardware (e.g. TDP/TM). The problem is not so much that new regulations are needed; it is that compliance to existing regulations should be enforced, and perhaps some updating where needed.

- There is limited enforcement of existing DFARS, e.g. the requirement for data to be shown as separately priced from hardware (e.g. TDP/TM). The problem is not so much that new regulations are needed; it is that compliance to existing regulations should be enforced, and perhaps some updating where needed.

- There is a diminishing supply of TDP knowledge/expertise for Technical Data Management and other stakeholders. This relates to the diminishing supply of staff discussed in the previous issue, but here the focus is on the actual knowledge required for successful acquisition and use of technical data packages. Some Acquisition Data Managers feel that DoD no longer has the expertise to do a good job on TDPs.

- There is a lack of accountability and enforcement by Contracting Officers (KOs) and Program Managers (PMs) for TDPs. The length of acquisition cycle exceeds the length of PM involvement. The typical term in office for a PM is two years; this tends to encourage short-term decisions. Even if the acquisition is completed, the impact of a lack of TDP data is often realized only years later, and there are no consequences for those who failed to ensure TDP delivery as part of the acquisition.

- There is a failure to include all stakeholders involved in a defense system when establishing requirements for TDPs. All the groups that produce, use and maintain the systems should be involved, including an IP attorney experienced in data acquisition issues. The group must assure that the TDP delivered contains all the data and information needed for support, maintenance, reprocurement, etc. throughout the program.

- Decisions related to Contracted Logistic Support (CLS) or PBL; this argument is too often used to remove the TDP requirement in early procurements. Then later modifications result in custom versions. There are often no defined exit strategies in contract when previous decisions are alteredin these cases, the TDP decisions must also be altered.

- Standards are not concise and complete. There is a lack of clear guidance for obtaining/navigating standards. MIL-STD-31000 has too many options/disconnects and opportunities for special procurement items (e.g., DIDs - special, commercial, developmental, tooling, etc). As an example, when completing form DD-1423, we need to know where to find appropriate requirements. 
- Current TDP practices and decisions result in increased vendor dependence and ever increasing costs. Without the TDP, the government is unable to adequately support its systems or re-procure replacement parts. The result is inability to use open procurements and get cost competition.

- Lack of standard delivered TDP formats and interfaces causes excess cost and complexity. The government should receive all information on delivered systems in a neutral technical format and an easily viewable format accessible to all parties, whatever tools they are using. The vendor should also deliver all data and models in the format native to their tools, thus assuring in case of translation data loss that all possible data is retrievable. High priority solution called for:

- We don't adjudicate OEM assertions of proprietary or other data rights restrictions even though the burden of proof is on the OEM (since NDAA 07). Sometimes vendors come back later and put additional information to the limited right list and the government doesn't challenge them.

- We have no systematic processes or validation tools for 2D or 3D Model-Based Data (MBD). We don't know have good the provided data is until we try to use it (perhaps much later) to build a test article or re-procure replacement systems or parts. We don't have sufficient expertise to validate whether the vendor is providing the actual data and models that they were using to develop the procured systems.

These 11 issues were then modified for clarity, prioritized, and their titles shortened somewhat to identify eleven major issues that need attention in producing and managing the TDP. The issues and their solutions are documented below. The complete table of issues and all solutions generated is provided in Appendix A-1. The issues and their high-priority solutions are discussed in this section, followed by the team's consolidated Top Solutions that were presented at the end of the workshop.

\section{Section Format}

\section{A.x Issue}

\section{A.x.y Solution}

A.1 Limited enforcement of DFARS, e.g. requirement for separately priced data from hardware (e.g. TDP/TM).

A.1.1 Establish a check-list at project start-up itemizing established contract requirements for data and data rights, and have it signed by contractor that they agree.

A.1.2 Periodic mandatory compliance and verification through out the life-cycle.

A.1.3 Add performance against project check-list to CPARS check-list. Allow OEM to correct non-compliance.

A.1.4 Report to GAO/IG for enforcement of DFARS clause (rights of data, separate price of data).

A.1.5 Require a General Officer signature when out of compliance.

A.1.6 System that assists navigation to specific DFARS clauses, not just title and number.

A.1.7 Include as a stakeholder an IP Attorney experienced in data acquisition contractual issues.

A.2 Lack of career path and training for Acquisition Data Management personnel (includes Engineering Data Management officers) and other stakeholders for the understanding and establishment of TDP requirements. 
A.2.1 Establish a cross-functional DoD/Engineering Data Management working group to offer training, identify training resources, bring awareness, brainstorm, and encourage standardization across DoD; group should meet at least semi-annually.

A.2.2 Promote awareness and communicate via DAU DM Community of Practice. https://acc.dau.mil/dm

A.2.3 Publicize "horror stories" and exemplars showing the cost of ineffective TDP acquisitions practices, to increase awareness of the values and benefits of increased capability and redirection of cost. Raise awareness/make visible GAO reports concerning TDP impact.

A.2.4 Establish a career field and multi-level certification criteria in DAU for Acquisition Data Management professionals.

A.2.5 Establish and maintain capability inventory showing current and projected levels of expertise in Acquisition Data Management.

A.2.6 Perform a Desktop Study to assess job requirements and staffing needed to effectively perform Acquisition Data Management. Use results to both classify and determine staffing requirements.

A.3 Diminishing supply of TDP knowledge/expertise for Technical Data Management and other stakeholders.

A.3.1 Establish a searchable knowledge base repository with links to standards, regulations, policies, directives, instructions, and guidance, and with an intuitive interface customizable to the user's needs. This may be an extension of existing tools.

A.3.2 Establish funding and identify expertise between services to develop and implement an automated tool to assist the acquisition of TDPs.

A.3.3 Reconvene an OSD advisory group to identify and promote critical needs and to create a uniform standard for conducting business for TDPs requirements.

A.3.4 Establish a system to capture and disseminate the knowledge and expertise of existing Acquisition Data Management professionals.

A.4 Lack of accountability and enforcement by Contracting Officers (KO) and PMs for TDPs. The length of acquisition cycle exceeds the length of PM involvement (PM in office for 2 years; makes short-term decisions).

A.4.1 Establish a governance structure to clearly define decisions needed and authorities to make them and verify/document that they have been made.

A.4.2 Accountability for acquisition decisions made by PM that extends beyond his/her tenure (investigate U.K. example).

A.5 Lack of all stakeholder involvement in establishing requirements for TDPs

A.5.1 Mandated participation of all stakeholders/SMEs at Data Call and throughout program.

A.5.2 Engineering Management Data plan identifies all stakeholders.

A.5.3 Include as a stakeholder an IP Attorney experienced in data acquisition contractual issues.

A.6 Decisions related to Contracted Logistic Support (CLS) or PBL; argument too often used to remove TDP requirement in early procurements. Later modifications result in custom versions. 
No defined exit strategies in contract when previous decisions are altered - must also alter TDP decisions.

A.6.1 At Data Call, establish requirement for the exit strategy in contract, i.e. data access at scheduled intervals with clearly defined physical delivery requirements.

A.6.2 Establish requirements for data in specified formats in SOW/CDRL regardless of ACAT category.

A.7 Standards are not concise and complete; lack of guidance for obtaining/navigating standards. MIL-STD-31000 has too many options/disconnects opportunities for special procurement items (e.g. DIDs - special, commercial, developmental, tooling, etc). For example, completion of DD1423; need to know where to go to get appropriate requirements.

A.7.1 Revise MIL-STD-31000 to consolidate requirements for the three TDP levels currently defined as separate (conceptual, developmental, and production)

A.7.2 Expand SYSPARS to incorporate an automated tool to assist developing TDP requirements (CDRL, SOWs, worksheets)

A.7.3 Create a standards knowledge base for navigating and linking standards and other relevant guidance.

A.8 Current TDP practices and decisions result in increased vendor dependence and ever increasing costs.

A.8.1 Apply TDP requirements and evaluate all related decisions to make sure contractor dependence is not increased. Do this early and maintain throughout contract.

A.8.2 Establish metrics to represent the level of contractor dependency in an acquisition, including the ability to track changes to TDP requirements.

A.9 Lack of standard delivered TDP formats and interfaces causes excess cost and complexity.

A.9.1 Require native, neutral, and viewable formats for the entire supply chain. Ensure that transportable, shareable, usable, clearly identifiable formats are established at Data Call.

A.9.2 Standardize metadata requirements within the TDP across DoD.

A.10 We don't adjudicate OEM assertions of proprietary or other data rights restrictions even though the burden of proof is on the OEM (since NDAA 07).

A.10.1 Require all programs to adjudicate and validate all of contractor data rights assertions. It is a DFARS requirement today, but seen as an option.

A.11 No systematic processes/validation tools for 2D or 3D/MBD.

A.11.1 Update 20-year old guidance data.

A.11.2 Use DAU DMCoP group to identify and share Best Practices within DoD.

A.11.3 Develop a formal verification/validation process used by all DoD entities.

\section{Acquisition team Balloted Prioritized Solutions:}

The acquisition team felt that a merging of a number of these solutions listed above was appropriate for the final balloting. This lead to the following list of the Acquisition Team's consolidated top ten solutions as they were presented on the ballot for voting at the end of the workshop. 
A.1.1: Establish a check-list of data requirements at Data Call, itemizing established contract requirements for data in specified formats and including data rights and the exit strategy, with clearly defined physical delivery requirements [also includes A.6.1 \& A.6.2].

A.5.1: Mandated participation of all stakeholders/SMEs at Data Call and throughout program, including an IP Attorney experienced in data acquisition contractual issues [also includes A.1.7 \& A.5.3].

A.7.1: Revise MIL-STD-31000 to consolidate requirements for the three TDP levels currently defined as separate (conceptual, developmental, and production).

A.3.2: Establish funding and identify expertise between services to develop an automated tool (e.g. by expanding SYSPARS) to assist developing TDP requirements (CDRL, SOWs, worksheets) [also includes A.7.2].

A.8.1: Apply TDP requirements and evaluate all related decisions to make sure contractor dependence is not increased. Do this early and maintain throughout contract.

A.9.1: Require native, neutral, and viewable formats for the entire supply chain. Ensure that transportable, shareable, usable, clearly identifiable formats are established at Data Call.

A.4.2: Require accountability for acquisition decisions made by PMs and other stakeholders that extend beyond their tenure (investigate U.K. example) [also includes A.4.1 \& A.1.5].

A.10.1: Require all programs to adjudicate and validate all of contractor data rights assertions. It is a DFARS requirement today, but seen as an option.

A.2.4: Establish training, certification, and knowledge capture to address declining workforce issues for Acquisition Data Management professionals [also includes A.2.1, A.2.6, A.3.4, A.3.1,\& A.7.3].

A.3.3: Reconvene an OSD advisory group to identify and promote critical needs, showing the value of TDP and the high cost of ineffective TDP acquisition practices [also includes A.2.3 \& A.11.3]. 


\subsection{Group B - Production, Planning, and Design}

The naming of this group was accidental in a way. We are trained to think of the design and manufacturing process as sequential - design, manufacturing planning, and production. The fact that this group was named exactly backwards from the norm may mean that we are making progress in thinking of design and manufacturing as a system. The name was left as originally defined to make the point of unity of the design and manufacturing processes. However, we will revert to the sequential view because, in the interest of concurrency, design must precede production.

It is reasonable to define the scope of the group's assignment before the work is reported. There is some legitimate debate about the starting point because, as our group continually reminded itself in the workshop, our focus is on the technical data package, and the linkage to requirements in the technical data package may not be well established. However, the provision of the TDP of the future must address requirements and their traceability into design and production. Therefore, our starting point is the clear definition of product performance, process limitations, materials specifications, and compliance issues. These are all requirements that must be met in delivering a successful product. Hence, the group's scope starts with the requirements and is defined as all activities and functions associated with creating and managing a TDP in a model-based environment, from requirements through production. It is emphasized that, although sustainability and lifecycle issues are addressed in the workshop by Group C - Provisioning, Logistics, and Sustainability, there must not be any breaks in the "digital tread" or any disconnects in the seamless information flow in the model-based enterprise.

For the purposes of our mission a TDP transfers information from the people whose job includes creation of the information to the people who need it to do their job further downstream. People who supply the needed information to the TDP for the item they produce need to know how to package their information so that it will meet the TDP requirements. They also need to help develop the content and format of that information to make the process as efficient as is possible.

Historically, 2D drawings with notes and associated lists were, by default, the only standard way to document the product definition. There are many reasons for this default including both technology and cultural aspects. Recently, however, the computational capabilities required to capture the full product definition in 3D models has become more widely available leaving culture as the major obstacle. Many discrete part manufacturers use 3D product models to communicate requirements and drive the manufacturing process, especially those of large complex assemblies. It is time to rethink the cultural and business practice norms and commit to a 3-D environment.

In the small group discussions, the focus was on how best to take advantage of the 3D model ability to present a virtual view of the product is integrated with notes and lists as a replacement for the traditional set of noted drawings and the associated lists. The group considered the topics to be addressed and modified the functional model to include:

- $\quad$ Requirements/Concepts - the initial formulation of what goals/needs must be satisfied and the approaches to be used;

- Design - defining and creating/presenting both the functional and physical aspects of the envisioned product

- $\quad$ Planning - determining the sequencing of actions/methods to actually manufacture

- $\quad$ Production - manufacturing and includes sourcing whether made internally or made in a supply chain 


\subsubsection{Deficiencies or Barriers}

The following narrative is based upon the group modified functional model and provides insight to the major deficiencies, barriers, and/or needs along with emerging best practices identified by the group. A 'bullet' view of key points is also provided in Table 2.

Overall, the current state of TDP development is one of good progress in the technical capability with clear directives and mandates to move toward complete 3-D TDP provision. But, much work remains to be done to achieve the ultimate objective of consistent, rich TDPs for every product produced. This section deals with the technical and business practice requirements and, although we acknowledge the needs, seeks to leave the policy and legal issues to other groups.

From the technology standpoint, the ability to produce and support a fully functional 3-D TDP is readily available. It is certainly possible to produce a rich package for almost any envisioned system. The limitations exist in the fact that these packages would not be the result of an integrated product and process development methodology. It would not adhere to standards (or would achieve only limited adherence) because there are voids in the standards sets, there are duplicative standards that are not harmonized, and there does not exist a complete and integrated, standard method for developing TDPs.

In addition to the voids in standards there are process and methodology voids. While instructions, directives, and mandates are in place, a common methodology for applying a systems approach to creating a uniform and consistent TDP does not exist. It is important to note that, as is the case in all current state discussion, the fact that there is work to be done does not in any way seek to provide a disservice to the excellent progress that is being made.

There are emerging best practices that point in the direction of the ultimate solution. The DLA has conducted studies and performed pilots that seek to define common structures for complete 3-D TDPs. These prototypical TDPs are being reviewed and updated. Rich TDP packages have, indeed, been produced and delivered, especially at the component level. At the systems level, there are programs that have committed to the provision of a complete 3-D TDP package. One example from outside the DoD community is the NASA Aries program wherein there is a contractual commitment to the delivery and maintenance of both 2-D and 3-D TDPs for all components, subsystems, and systems. While there is much to do, much has been accomplished.

\section{Requirements/ Concepts}

The TDP has its beginning in requirements definition - often as early as the Request for Information (RFI) phase of product development. The intent to "grow" or mature the TDP from these early phases, and to provide traceability of design to requirements dictates that technical data be developed and maintained during conceptual development, which feeds the detailed design process.

In the current state the model-based tools that enable evaluation of requirements and development of concepts are spotty or immature in the best cases. In many applications, there is very limited systematic processing of requirements to concepts. There are several reasons for this. So often new concepts are developed almost exclusively from existing designs which stifles innovative solutions. While there are many advantages to such an approach - like assured maturity of both technologies and manufacturing readiness - the practice limits capability improvements to only incremental potential. The second reason for limited processing of requirements to concepts is that the MBE tools to support such development are very immature or are not available. Requirements management tools are part of the Product Lifecycle Management (PLM) packages, but are not yet as well integrated with the 3-D designs as they must and will be. As the integration of requirements modeling tools with CAD matures the ability to produce 3-D conceptual designs traceable to requirements including tradeoff support, will also mature. 
The model-based enterprise dictates the rich evaluation of concepts for the ability to satisfy requirements. Cost, producibility, schedule, performance, and risk assessment, based on requirements, that enables best decisions very early in the design process is essential for mission success. This document is focused on the TDP, and the TDP can and should capture the decision process as concepts are evaluated, down selected, optimized, and the knowledge gathered from that process, for future application.

The TDP in the requirements/conceptual stage is immature - still undergoing evolution. TDP requirements are not usually collected into a database that collaborators can access and that restricts availability of the information needed to develop a TDP during the conceptual phase. The information is dispersed and currently resides with other parties. Moreover, there are no current tools to accomplish the exchange and collaboration tasks. Therefore, data cannot be effectively exchanged with other parties thus creating an environment that impedes the ability to apply MBE tools in the initial conceptual requirements and design activities.

Although the MBE toolset has dramatically and rapidly matured, there are still many voids to fill. One is the systematic traceability or linkage of specific design artifacts to the requirements. Interoperability of systems management tools and a methodology for mapping the progress of product realization would be a great improvement. An MBE initial capabilities document would help clarify this situation and supply much needed direction. Systems engineering methodologies and vendor specific toolsets are needed to move toward this capability.

To further complicate the situation, during the conceptual design phase of a project, the requirements for TDP packages change too many times. These changes create significant configuration management and closure issues. One of the problems is that design package requirements are allowed to change when fixing or locking them in place would be more appropriate. Change propagation is often a manual function, and prone to errors and disconnects.

One of the biggest deficiencies is a lack of clear definition for TDP management. Presently, the TDP package deliverable items and the mechanisms for delivery are not clearly defined. Resolution of this lack of clarity is critical to the overall use of model based TDPs.

The PPD team identified several Emerging Best Practices that are applicable to the Requirements/ Concepts area. Model based systems engineering initiatives are beginning to integrate the systems model from which designs are driven. The use of Systems Modeling Language (SML) and the Unified Profile for DoDAF/MoDAF (UPDM) as a standard way of systems modeling is evolving. Automated settings within CAD tools are being used to force users to comply with process requirements.

There is an emerging use of a knowledge based tool set for requirements capture and decision support during conceptualization. These tools often work in a web enabled environment to support collaboration with stakeholders. An increasingly strong emphasis on affordability is driving a strong push in requirements management to support design optimization.

Increased use of tools and standards for requirements support is evidenced by the U.S. Army Automotive Research, Development, and Engineering Center (TARDEC) utilizing standards with Pro-E START files and TDP developing processes to satisfy design requirements. Likewise, the NAS 3500 (National Aerospace Standard) provides scorecard mechanisms which assure completeness of requirements and information flow mechanisms. The STEP AP233 systems engineering information model also provides an emerging capability to represent requirements and other systems engineering information. 
Lastly, there is an emerging strong link between funded programs and Warfighter needs. The DoD has implemented many programs to assure that its expenditures are directly aligned with the needs of the missions and the Warfighters. Whatever systems may be put in place, response to Warfighter needs will always require response to the voice of the customer and excellent communications of the requirements from that voice - a key purpose of the TDP.

\section{Design}

One qualifier, right up front - the consensus of the group was that "design is design." While we understand that there may be a difference in fidelity and completeness in conceptual designs and that the TDP might not be taken to the same level of detail, a conceptual design should be considered as an integrated part of the design process, including the full use of all data generated. Data entered and captured in the TDP in the conceptualization process should flow directly to the detailed design.

There are several limitations in today's environment. The cost of procuring and maintaining the Product Life-cycle Management (PLM) toolsets is seen as too high. This problem may be very manageable at large companies, even when multiple PLM platforms are maintained, but it creates real problems for the supply network. STEP has come a long way in mitigating the need for multiple systems, but STEP does not yet provide all of the information that is necessary to fully convey design intent. Some emerging tools like Adobe reader are entering this market and providing some exciting options.

Annotations to capture specific requirements and processing instructions must be added to the design, and must persist throughout the design and manufacturing environment. Special tools have been required to manage annotations, but recent additions to PLM systems have greatly increased the functionality. In today's CAD environment, it is reasonable to expect that all needed annotations can be provided. However, they may only persist in native model and there are no (or limited) standards for the integration of annotations in the TDP.

Change propagation is a critical element of a design environment and for the provision of the needed TDP. This deficiency has multiple areas of impact. On the grand scale, a design change should be propagated forward to the downstream applications and upstream to the requirements/conceptual design environment. This means that the TDP would automatically be updated. Tools are not available to support this functionality. On a more specific scale, when changes are made in a single component, subsystem, or system, in either the product or process, in today's environment, significant manual modification is required. The achievement of a seamlessly integrated - as conceived, as designed, as planned, as produced, as used and as supported environment is still to be achieved.

There is a distinct shortfall in the overall set of integrated tools and tool capabilities. Integration is lacking between conceptualization tools and detail design tools. The ability to make early producibility assessments does not generally exist in either the tools or the current practices. As mentioned before, adding to the shortfall is the high cost of design tools (product lifecycle management (PLM) and computer aided design (CAD) tools plus the lack of fully implemented Product Manufacturing Information (PMI) standards.

Models need proper annotation to match MBE standards but there is a lack of proper annotation to extract the true meaning from of a model. There are inconsistencies in the methods with which CAD vendors implement standards and a hesitancy or unwillingness of CAD vendors to respond to the definitions of the content and structure of data that is defined in the STEP application protocol. This inconsistency creates huge problems when software vendors update their systems without supporting legacy needs. 
Another severe shortfall is found in the current 3D environment which does not support mechanisms for change. The lack of OEM buy-in to MBE and 3D TDPs compounds this problem. STEP 232 TDP $^{13}$ is a move in the right direction but modularization is needed to interact with other modular applications. STEP 232 TDP does not identify what is needed in the TDP but only arranges items in the correct locations.

Because STEP requires data conversion to make use of the data, it must be validated. Unfortunately, the government has not made the necessary conversion to their system. Finally, there is a lack of insight into the design requirements for commercial off-the -shelf (COTS) and source controlled components.

Confidence in the design information at every level in the supply network is critical, but short falls undermine the needed confidence. There is difficulty in exchanging data with design partners and suppliers. Product libraries possess models that are unique to companies and organizations, but such libraries may have the same part number for different parts leading various systems to reject the parts because the model is different. This issue affects the completeness and accuracy of the models which may effect and not support the necessity of spawning designs for related components (tooling, fixtures, and molds).

At this time, the government requires the delivery of a fully annotated $2 \mathrm{D}$ drawing. In the current 2D TDP arena there is a clear definition of what is required in the TDP, such as, drawings, tech data, specifications, quality assurance processes, and packaging. The 3D TDP needs a similar definition. Standardization of quality requirements is also needed to assure that they are captured into the design and in a format acceptable to the government. There is currently no standard method for defining or delivering a complete TDP to the government that includes all narrative documents that must be delivered (digital product definition packages). The government does not clearly define the content and structure of the data it requests resulting in inconsistencies in the deliverable of the TDP to the government.

Currently, there is no scorecard available for tracking items through the product realization cycle to ensure that the TDP requirements are being met. A design maturity index is needed that is accepted and useful for all members of the supply chain. There are multiple scales for this task but there is no unifying scale to build a scorecard.

From the DoD perspective, the lack of integrating MBE and TDP strategies with the DoD acquisition process is a major barrier. One approach to overcoming many deficiencies for the DoD is leveraging the well defined acquisition strategy complete with stages called the "Acquisition Technology Development Process." The capabilities document is created as these phases are addressed. Mapping of MBE and TDP strategies with the acquisition process would be helpful. The Joint Capabilities Integration System (JCIDS) could provide the initial requirements.

While there is much to overcome, many emerging best practices are in place and evolving such as the increasing use of Design Structure Matrix (DSM) - a simple tool to perform both the analysis and the management of complex systems. The DSM enables the user to model, visualize, and analyze the dependencies among the entities of any system and derive suggestions for the improvement or synthesis of the system. There is emerging availability of free 3D viewers is assisting in making 3D imaging more widely received and used. The use of standard models of components for collaborative design model libraries of components is becoming common. Development and sharing of domain specific modeling procedures, based on an information model, are being developed. Automated tools

13 AP 232: Application Protocol for Technical Data Packaging Core Information and Exchange. The standard published in 2002 as ISO 10303-232:2002(E). 
for generating, translating, converting, validating, and distributing models as files are being applied. Rather dramatic productivity improvements are being realized from these implementations.

Several government and industry initiatives are enhancing the MBE and TDP environment. There is emerging use of knowledge based automated design in the aerospace and marine industries. In November 2008, the aerospace industry published National Aerospace Standard NAS 3500--Technical Data Package--Composition, Communication, and Application. Its purpose is to "facilitate better composition, communication, and application of technical data at every level of the supply chain. For aerospace industry primes, this means less expensive deliverables, for suppliers it means enhanced efficiency and responsiveness to their customers' requirements." ${ }^{14}$ European Aeronautic Defense and Space Company (EADS), the parent company of Airbus, has developed a TDP messaging standard. ${ }^{15}$ The automotive industry has developed recommendations addressing the implementation of STEP for engineering change management and requirements management per Automotive Industry Action Group (AIAG) D26 $6^{16}$ The Organization for the Advancement of Structured Information Standards (OASIS), a standards consortium, is developing data exchange sets and specifications to implement the ISO 10303 Standard for Exchange of Product Model Data (STEP) Product Life Cycle Support System (PLCS). Likewise, the convergence of STEP 203 and 214 to create a super set for mechanical product CAD standards is a major improvement. Additional improvements include tools to validate Product Manufacturing Information (PMI) results; improved CAD Data Exchange via the SME Productivity Through Interoperability (PTI) initiative, ${ }^{17}$ and tools from ITI TransenData ${ }^{18}$ and the overall dramatic improvements in design tools.

Lastly, a much needed and welcome major foundational element is found in the growing 3D focused workforce that is emerging across the manufacturing and design community.

\section{Planning}

Many companies experience a disconnect between product design and process design. This disconnect comes into play in the manufacturing planning and manufacturing execution functions. Companies, like Boeing, have aggressively embraced "as planned" as an important and visible part of the product development cycle. However, they openly admit that to achieve "as planned" they have been forced to develop a home grown toolset that interfaces with the CAD/PLM environment, but must be maintained in house.

It is fair to say that manufacturing planning suffers from a lack of good 3D simulation tools, which evidences itself in difficulties producing and supporting the process needs of the TDP. The majority of the models are textual based and not 3D based highlighting a need for consistent text in model annotation and notes. The lack of manufacturing process and facility models (e.g. machine tools, crane capacities, and etc.) and difficulty in creating and supporting tooling models across the supply chain also

\footnotetext{
${ }^{14}$ http://www.qualitydigest.com/magazine/2009/apr/article/reducing-errors-manufacturing.html

${ }^{15}$ http://www.eads.com/1024/en/eads/eads.html

${ }^{16}$ AIAG D-26 Engineering Change Management (ECM) Reference Process; A reference document which supports AIAG's D-29 (Engineering Change Management - ECM Recommendation) \& D-30 (ECM Recommendation Engineering Change Request - ECR) Engineering Change Management Documents. https://www.aiag.org/source/Orders/index.cfm?section=orders\&ETask=1\&Task=1\&SEARCH_TYPE=FIND\&FindI $\underline{\mathrm{n}=0 \& \text { FindSpec }=\mathrm{D}-26 \& \mathrm{x}=13 \& \mathrm{y}=5}$

${ }^{17}$ http://www.sme.org/cgi-bin/get-event.pl?--001642-000007-019944--SME-

${ }^{18}$ http://www.transcendata.com/
} 
impact the planning and the ability to capture that process to the needed level of fidelity. The lack of information integration from product to process limits the flow of information and inhibits effective change management. In fact, process changes must be manually captured, recorded, and should initiate a change in process planning and shop work instructions. The management of those changes is costly and takes too long!

There is a lack of visibility into enterprise wide assets, including characterization of equipment, processes, and the models that support their characterization. This inhibits efficient production of the complete set of data needed to support downstream applications such as first article inspection and the consumption of characteristics during production planning, and etc.

There are other deficiencies that make the execution and capture of the planning function inefficient. The lack of value stream mapping standards hinders the use of this important methodology in optimizing process flow. There is a lack of adequate tools to translate electronic bills of material (EBOM) to manufacturing bills of material (MBOM). There are interoperability issues between product life-cycle management (PLM), material requirements planning (MRP) and manufacturing execution systems (MES). All of these issues inhibit the process of creating and managing an adequate TDP that includes process information.

Problems are exacerbated due to frequent changes in design requirements during TDP development and resulting conformity issues. These challenges are magnified by the lack of integration among production planning, design data, and design requirements across the supply chain. The inability to adequately plan for surge, design changes, and lack of materials availability impacts production and product support. Incompatible business practices and lack of tool interoperability limits the engagement of suppliers in the process planning and leads to voids in the documentation.

The lack of interoperability and limitations in translators that support neutral presentation impacts the ability to create and share needed plans. There is a strong need to understand the limitations of the translation toolset to assure that the functionality needs are met and to systematically provide better solutions. Incomplete or ambiguous product information is often delivered to the supply chain due to a lack of interoperability and incomplete translation of product data needed to define key characteristics. Process modeling systems may also not integrate with a PLM tool set within a company or across multiple companies.

A lack of availability of automated tools for annotating the TDP model and the difficulty in effectively using the available tools multiplies the necessity for manual labor and cost of providing a complete TDP. The TDP requirements do not include process plans because they are often derived from Intellectual Property (IP). It certainly would be in the best interest of the government to review this policy.

The maturity of the process technologies and manufacturing readiness are not now included in the TDP. In the TDP of a mature, fielded product, it is fair to assume that the readiness levels would be high, and that they might be irrelevant. However, in product development the integration of readiness into the Level I or Level II TDP process would add value. Also, MBE activities are not presently included in the MRL documentation (the MRL desk book). But new acquisition policies state that a new TDP must be both Technology Readiness level (TRL) and Manufacturing Readiness Level (MRL) compliant.

Much work is needed to resolve problems in the planning arena, but emerging best practices are indicative of rapid progress. Some companies are beginning to design to the maximum capability of interoperability within a tool-set. There are now tools available to identify and document characteristic level data. Improved process simulations that incorporate actual equipment performance and behavior into the model are available. This results in higher fidelity models and allows for better planning. Some companies are seeing the advantages of leveraging a TDP and pieces of the TDP set for reuse with other 
designs. Likewise, the ability to validate the process plan in a 3D simulation is a very valuable asset. Other advancing capabilities include leveling the loading of production resources by comingling product and product lines to save time and material e.g., optimizing the use of steel plates by laying out components for multiple ships on the same plate. The ability to line balance the TAKT time ${ }^{19}$ by using multiple products on the same line can make a huge difference and improvement in production line scheduling and productivity. The ability to capture an approved vendor list (AVL) and an approved material list (AML) into the metadata is being used to help assure TDP compliance.

One huge emerging advantage digital model capture is the ability to store manufacturing process recipes instead of stockpiling parts. For example, Defense Micro Electronics is using recipes for supporting obsolete parts. Parts can be more easily manufactured on demand instead of having to be stockpiled.

Improved tools that enable 3D work instructions by directly using the product and process models - part of the TDP - are becoming commonplace. Some of these tools are COTS, but, in the main, they are custom applications developed and locally supported by the companies themselves. Many tools are available and in use to enable consumption of characteristic level data directly from the TDP. One interesting development in 3D model use is that NASA-Michoud has placed responsibility for management for the facility model with the facilities contractor. Elsewhere, government in-house capabilities are storing details of their process plans in the TDP and managing them in the product lifecycle management (PLM) system. This system is used by vendors and other government depots but is not yet used by private industry.

Production (includes sourcing whether made internally or made in a supply chain)

Note: many of the deficiencies and best practices described in the design sub-section also apply here, particularly those related to interoperability and data exchange across supply chain.

In an MBE enterprise, the information and data should be continually enriched until, at the point of production, all needed information is available and in the form needed. The TDP should have matured through that process. Today, this is not the norm, especially associated with providing needed data to the supply base. Similarly, the needed understanding may not be provided. For example, in a design to requirements contract, the language of the TDP may not be understood by the members of the supply chain that must receive and respond to that data. Because the language may not be clear the flow and interpretation of technical requirements through the supply chain are often not understood properly. If a supplier does not understand and cannot receive timely clarification the production of defective parts may result and time and cost is the price that is paid. One example is that in some processes, e.g. stamping a flat plate, or composite parts, the TDP may not adequately represent the details necessary to make a required $2 \mathrm{D}$ representation. In other cases there may be poor application of general dimensions and tolerances within models. It is noted that CAD tools are very expensive (particularly from the perspective of small businesses), which may impact broad based adoption by smaller lower tier members of the supply chain.

\footnotetext{
${ }^{19}$ Takt time isdefined as the maximum time per unit allowed to produce a product in order to meet demand. It is derived from the German word Taktzeit which translates to cycle time. http://en.wikipedia.org/wiki/Takt time

Alternative: "Lean manufacturing systems work on a rhythm. Whole organization works on the rhythm provided by the customer. This rhythm is known as the TAKT time of the system."

http://www.leanmanufacturingconcepts.com/LeanTool_TAKT.htm
} 
The TDP typically does not include production data but it is acknowledged that it is important to do so if we are committed to TDP's that fully support the product through its lifecycle, e.g. G-code or CNC code is not incorporated in the package.

There is a need to extract key characteristic data from the model to support statistical process control (SPC) and process control. This functionally may not be supported. The TDP usually does not contain a schedule for components for the timely completion of assembly and also may not contain the hierarchy of components and assembly.

Change propagation is a major issue in an MBE environment. Changes that are made to the product model during manufacturing may not be reflected in the TDP and the information that production needs may not be available in the TDP. The changes made in the manufacturing cycle may include substitute parts, alternative parts, substitute materials, and process changes. Sometimes changes made in the design TDP are not given to production in a timely and useful way. One reason for this disconnect may be that the current shop floor delivery systems are 2D based and cannot take advantage of 3D TDP. Mechanisms for managing non-conformances that are identified on the shop floor as part of a digital environment may not be adequate. Also, at present, there is no definition of the data required for an "as built TDP" in an MBE environment.

Lastly, regardless of whether prime vendor or supply chain member, the skill sets for using 3D data and TDP data on the shop floor must be learned skills and that learning curve must be incorporated into production schedules.

Several emerging best practices were identified by the PPD team in the Production phase. Use of the National Aerospace Standard NAS 3500--Technical Data Package--Composition, Communication, and Application enables the understanding of technical requirements in production across the supply chain. There are increasing deliveries of 3D models to supply chain management portals, i.e. MEP Columbia. Paperless communication of configuration managed condition of supply with partners and vendors is being used for the production of the Boeing 787. Integrating suppliers and vendors and other stakeholders into internal PLM system is becoming more common. Based on characteristics in the TDP, ongoing application of tools to acquire characteristic level SPC data from the supply chain is being accomplished.

3D interactive work instructions on the shop floor are becoming more commonplace and greatly assist the skilled crafts persons in performing their tasks. CNC processes are being embedded in the 3D model. This reduces time necessary to independently generate those instructions. Animated assembly tools used in production, e.g. Red River transmission, are being used during the actual assembly process to assist in accurate and timely production. The tremendous improvement in CAD and CAM systems has allowed the ability to machine freeform surfaces on multi-axis machines. The Open Applications Group Integration Specification (OAGIS) format is being used for process routes which will aid in data exchange and interoperability.

Table 2 Current state table for Production, Planning, and Design

\begin{tabular}{|l|l|}
\hline \multicolumn{2}{|c|}{ Current State of Production Planning, and Design } \\
\hline Deficiencies or Barriers & Emerging Best Practice \\
\hline \multicolumn{2}{|c|}{ Requirements/ Concepts } \\
\hline $\begin{array}{l}\text { TDP requirements are not collected into a } \\
\text { database that collaborators can access. }\end{array}$ & $\begin{array}{l}\text { Model based systems engineering initiatives } \\
\text { are beginning to integrate the systems } \\
\text { model from which designs are driven. }\end{array}$ \\
\hline
\end{tabular}




\begin{tabular}{|c|c|}
\hline \multicolumn{2}{|c|}{ Current State of Production Planning, and Design } \\
\hline Deficiencies or Barriers & Emerging Best Practice \\
\hline 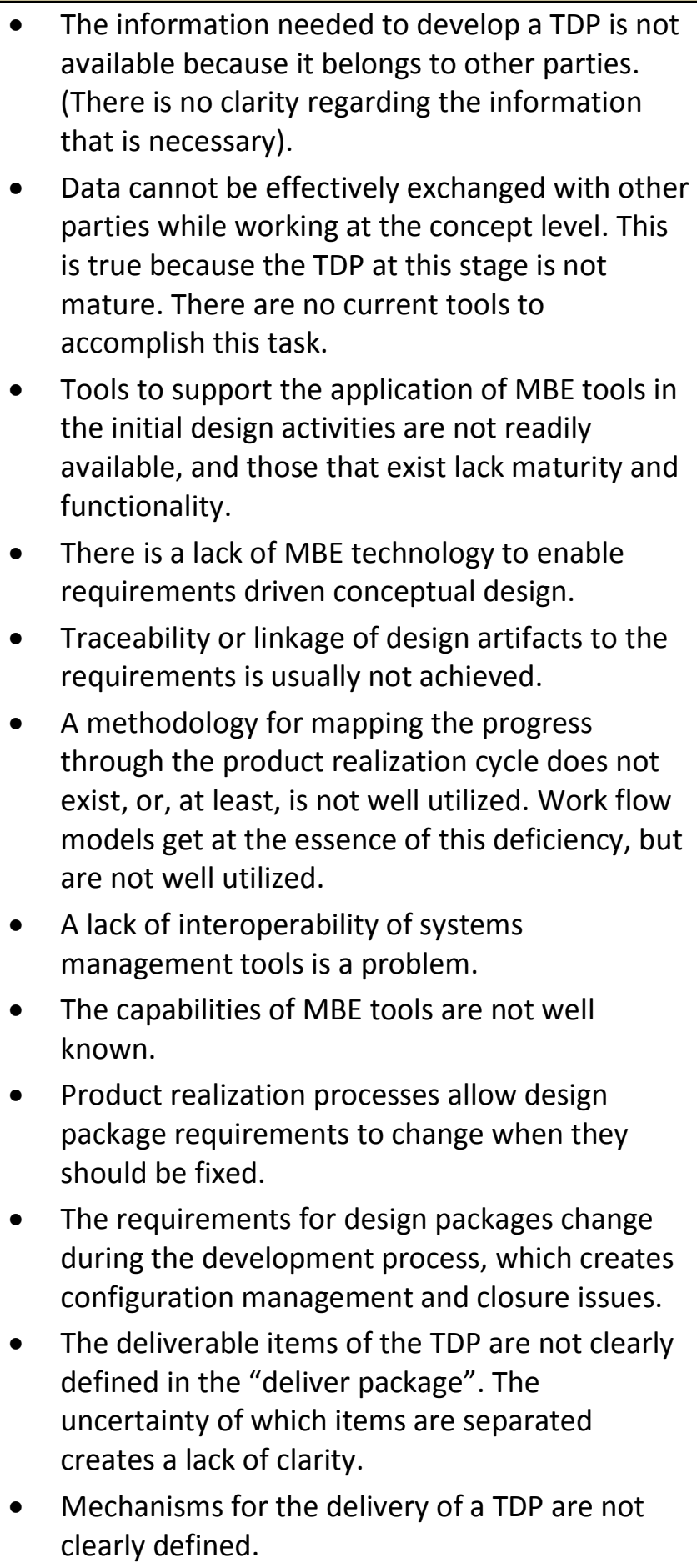 & $\begin{array}{l}\text { - Systems Modeling Language (SML), and the } \\
\text { Unified Profile for DoDAF/MoDAF (UPDM ) } \\
\text { are emerging as a standard mechanism for } \\
\text { systems modeling. } \\
\text { - Automated settings within the CAD tool are } \\
\text { being implemented to force the users to } \\
\text { comply with process requirements. } \\
\text { - Web enabled tools are in limited use to } \\
\text { collaborate with stakeholders and manage } \\
\text { various data and documents. } \\
\text { Early adopters are making use ofof a } \\
\text { knowledge based tool set for requirements } \\
\text { capture and for decision support in } \\
\text { conceptualization. } \\
\text { A strong affordability emphasis is driving a } \\
\text { major emphasis on requirements } \\
\text { management for design optimization. The } \\
\text { emphasis is being places on strong } \\
\text { functionality with minimal extras. } \\
\text { TARDEC utilizes a standard with a Pro-E } \\
\text { START file and TDP developing process to } \\
\text { satisfy design requirements. } \\
\text { The NAS (National Aerospace Standard) } 3500 \\
\text { provides scorecard mechanisms to } \\
\text { determine completeness of requirements, } \\
\text { connect, flow mechanisms. } \\
\text { information model represents requirements } \\
\text { and other systems engineering information. } \\
\text { programs and the Warfighter needs - } \\
\text { however improved customer and user voices } \\
\text { are needed via TDP. }\end{array}$ \\
\hline \multicolumn{2}{|c|}{ Design - (Functional and Physical) } \\
\hline $\begin{array}{l}\text { - There is a lack of integration between } \\
\text { conceptualization tools and the tools needed for } \\
\text { detail design. We enter and reenter data. }\end{array}$ & $\begin{array}{l}\text { - Design structure matrix - a design of } \\
\text { experiments approach to the design } \\
\text { problems. }\end{array}$ \\
\hline
\end{tabular}




\begin{tabular}{|c|c|}
\hline \multicolumn{2}{|c|}{ Current State of Production Planning, and Design } \\
\hline Deficiencies or Barriers & Emerging Best Practice \\
\hline 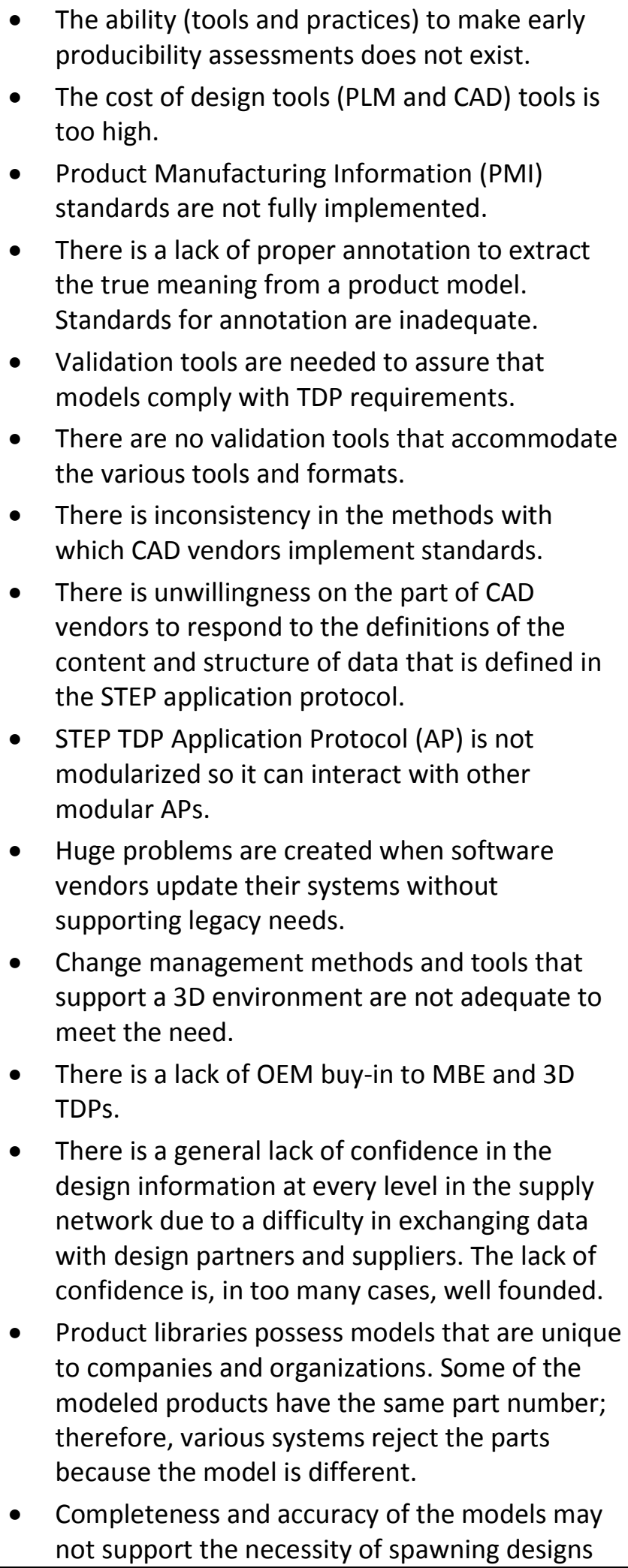 & 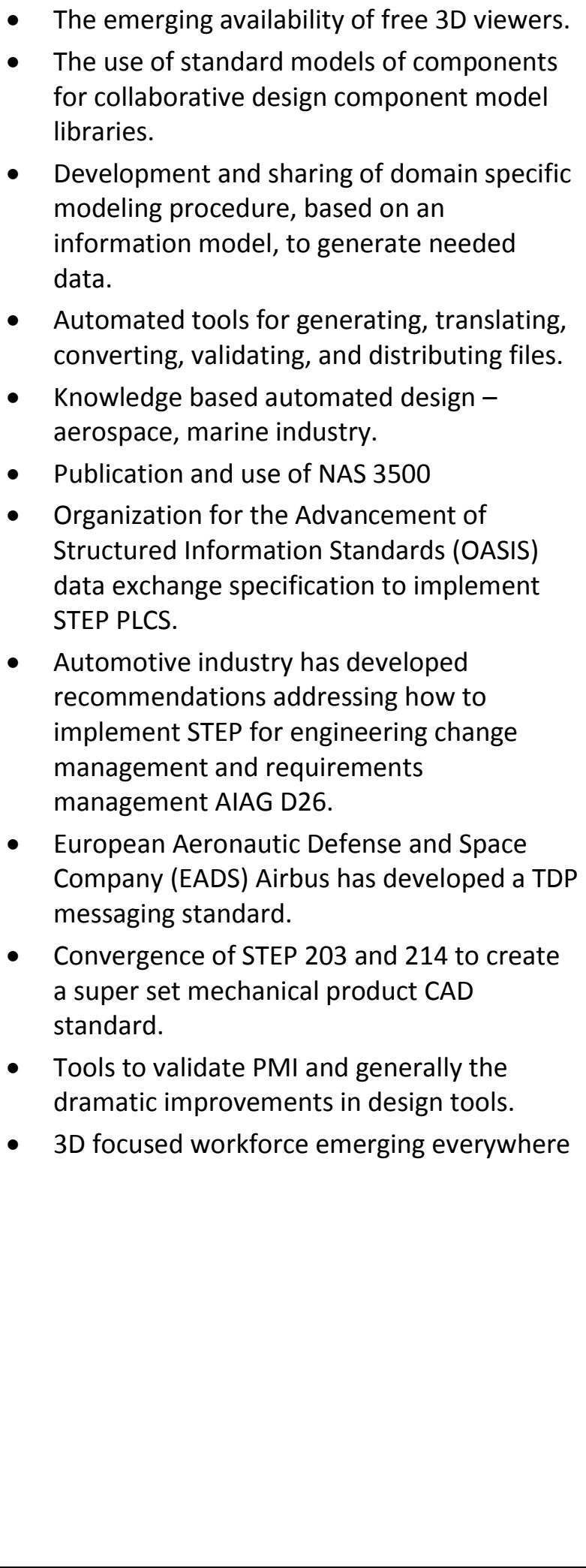 \\
\hline
\end{tabular}




\begin{tabular}{|c|c|}
\hline \multicolumn{2}{|c|}{ Current State of Production Planning, and Design } \\
\hline Deficiencies or Barriers & Emerging Best Practice \\
\hline 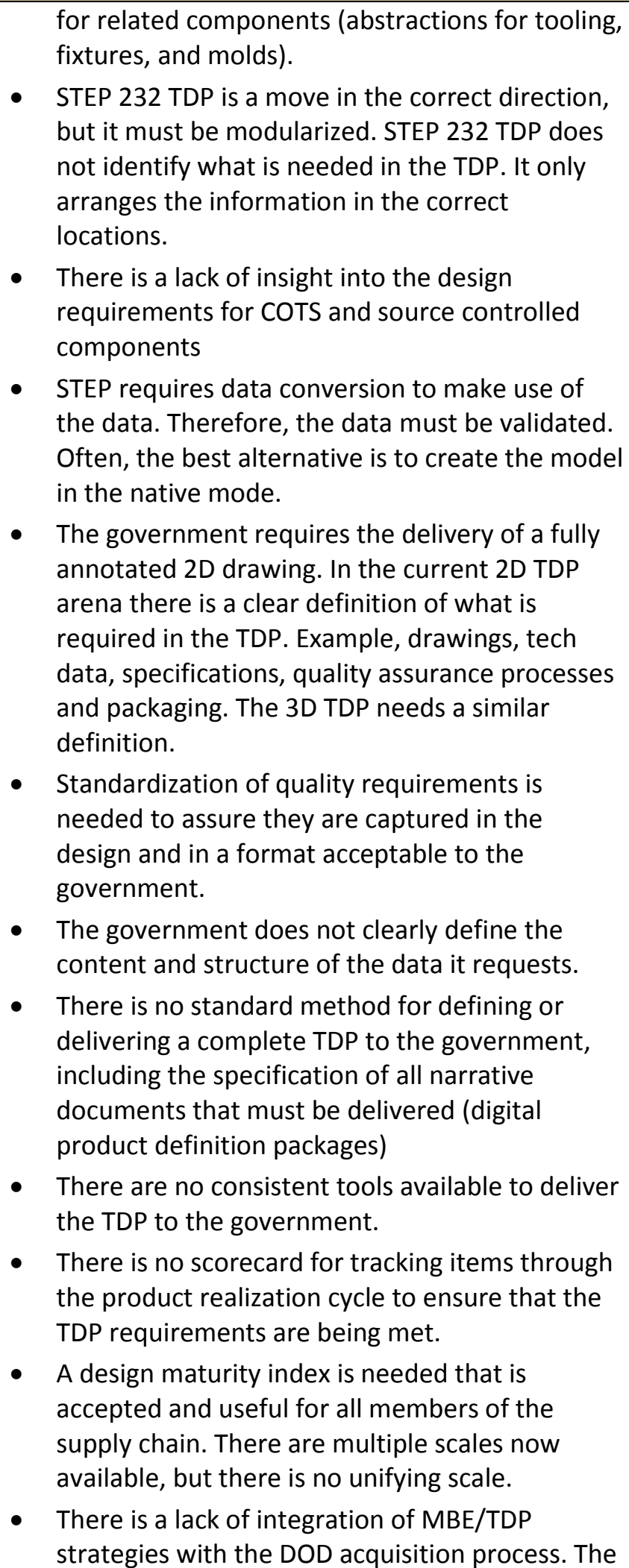 & \\
\hline
\end{tabular}




\begin{tabular}{|c|c|}
\hline \multicolumn{2}{|c|}{ Current State of Production Planning, and Design } \\
\hline Deficiencies or Barriers & Emerging Best Practice \\
\hline $\begin{array}{l}\text { DoD has a well defined acquisition strategy } \\
\text { complete with stages called the "Acquisition } \\
\text { Technology Development Process". The } \\
\text { capabilities document is created as the phases } \\
\text { are addressed. The Joint capabilities integration } \\
\text { system (JCIDS). JCIDS could provide the initial } \\
\text { requirements. A mapping of the MBE } \\
\text { capabilities and TDP requirements to the } \\
\text { acquisition process is needed. }\end{array}$ & \\
\hline \multicolumn{2}{|c|}{ Planning } \\
\hline 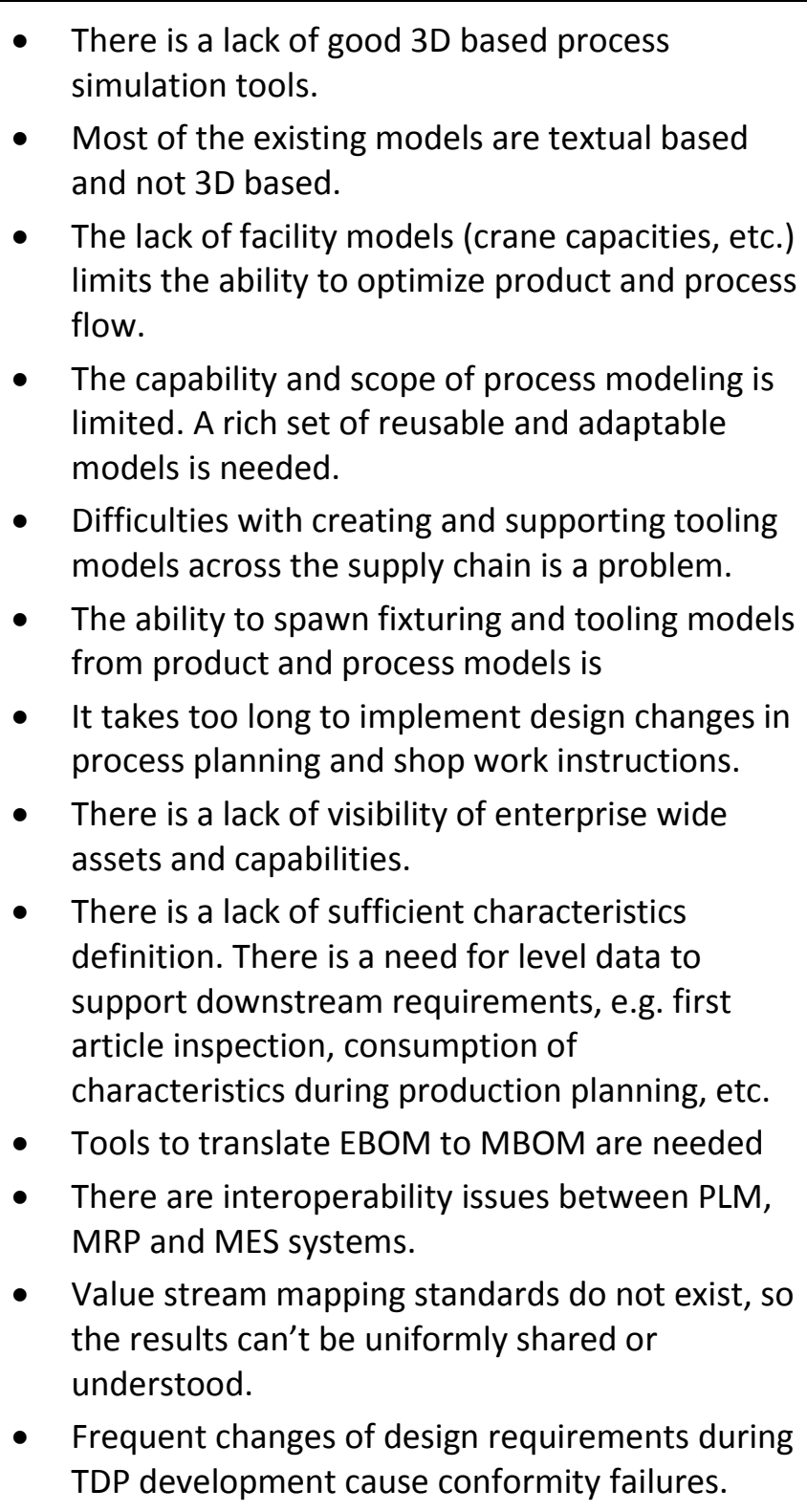 & $\begin{array}{l}\text { - Design to the maximum capability of } \\
\text { interoperability within a tool/toolset. } \\
\text { - Tools are available to identify and document } \\
\text { characteristic level data. } \\
\text { - Improved process simulations that } \\
\text { incorporate actual equipment performance } \\
\text { and behavior into the model, resulting in } \\
\text { higher fidelity models for better planning. } \\
\text { - The ability to reuse the TDP set and pieces of } \\
\text { that TDP set and send that information to } \\
\text { the floor. } \\
\text { - Ability to validate the process plan in a 3D } \\
\text { simulation environment } \\
\text { - Level loading of production resources by } \\
\text { "comingling" product and product lines. } \\
\text { (e.g., optimizing the use of steel plates by } \\
\text { laying out components for multiple ships on } \\
\text { the same plate.) } \\
\text { - The ability to line balance the TAKT time by } \\
\text { using multiple products on the same line. } \\
\text { - The ability to capture AVL (approved vendor } \\
\text { list) and AML (approved material list) into } \\
\text { the metadata for assuring compliance. } \\
\text { Stockpiling manufacturing process recipes } \\
\text { instead of parts. (Defense Micro Electronics } \\
\text { is utilizing recipes for supporting obsolete } \\
\text { parts.) } \\
\text { chabling } 3 D \text { work instructions by directly } \\
\text { TDP }\end{array}$ \\
\hline
\end{tabular}




\begin{tabular}{|c|c|}
\hline \multicolumn{2}{|c|}{ Current State of Production Planning, and Design } \\
\hline Deficiencies or Barriers & Emerging Best Practice \\
\hline $\begin{array}{l}\text { - Limited integration of production planning } \\
\text { based on design data and design requirements } \\
\text { across the supply chain. } \\
\text { - At times design changes are forced due to a lack } \\
\text { of availability of materials. } \\
\text { - } \text { Availability of materials sometimes forces design } \\
\text { changes. These design changes often are not } \\
\text { incorporated in the documentation of the TDP. } \\
\text { - Models are needed to support planning for } \\
\text { surge. There is a need to understand the limits } \\
\text { of the translation tools and design for the } \\
\text { maximum possible functionality and the } \\
\text { maximum capability of the interoperability } \\
\text { toolset. } \\
\text { - Suppliers are often not adequately engaged in } \\
\text { the process planning process. } \\
\text { Incomplete or ambiguous product information } \\
\text { (to define key characteristics) delivered to the } \\
\text { supply chain is a problem. Sometimes this } \\
\text { inadequacy results in product errors, and } \\
\text { - Tometimes in less than optimum production } \\
\text { planning. } \\
\text { Process modeling systems may not integrate } \\
\text { with a PLM tool sets within a company or across } \\
\text { multiple companies. } \\
\text { there is a lack of availability of automated tools } \\
\text { books annotating the TDP model. } \\
\text { MRLs are not part of the TDP. }\end{array}$ & $\begin{array}{l}\text { - NASA-Michoud (New Orleans) has placed } \\
\text { responsibility for management for the facility } \\
\text { model with the facilities contractor. } \\
\text { - Government in house capabilities are storing } \\
\text { details of their process plans in the TDP and } \\
\text { managing in the PLM system. This is used by } \\
\text { vendors and other depots but not to private } \\
\text { industry. } \\
\text { - STEP NC for machine and controller } \\
\text { independent process plans. } \\
\text { - New acquisition policy states that TDPs must } \\
\text { be both TRL and MRL compliant. } \\
\text { MANTECH has developed a 3-D CAD } \\
\text { capability assessment scale. }\end{array}$ \\
\hline \multicolumn{2}{|c|}{ Production- (includes sourcing whether made internally or made in a supply chain). } \\
\hline $\begin{array}{l}\text { There is a lack of direct access to the data } \\
\text { models by members of the supply base (we } \\
\text { email, ship...) } \\
\text { - In design to requirements contracts the } \\
\text { language of the TDP may not be understood by }\end{array}$ & $\begin{array}{l}\text { - NAS } 3500 \text { enables the understanding of } \\
\text { technical requirements in production across } \\
\text { the supply chain } \\
\text { - Delivery of 3D models to supply chain } \\
\text { management portals., i.e. MEP Columbia }\end{array}$ \\
\hline
\end{tabular}




\begin{tabular}{|c|c|}
\hline \multicolumn{2}{|c|}{ Current State of Production Planning, and Design } \\
\hline Deficiencies or Barriers & Emerging Best Practice \\
\hline 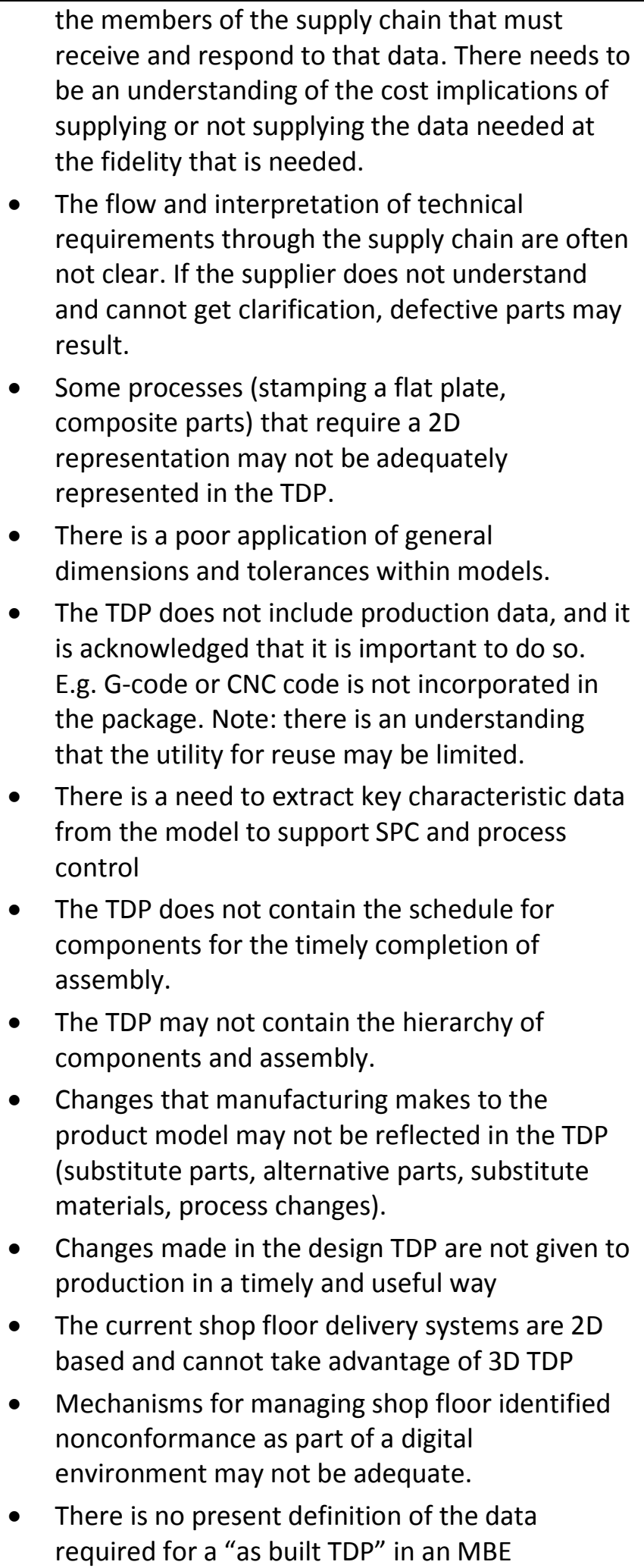 & $\begin{array}{l}\text { Paperless communication of configuration } \\
\text { managed condition of supply with partners } \\
\text { and vendors e.g. } 787 \text {. } \\
\text { - Integrating suppliers and vendors and other } \\
\text { stakeholders into internal PLM system. } \\
\text { - Ongoing application of tools to acquire } \\
\text { characteristic levels SPC data from the } \\
\text { supply chain, based on characteristics in the } \\
\text { TDP } \\
\text { - } 3 D \text { interactive work instructions on the shop } \\
\text { floor. } \\
\text { CNC processes are being embedded into the } \\
\text { 3D model. } \\
\text { Animated assembly tools used in production. } \\
\text { e.g. Red River transmission. } \\
\text { Ability to machine freeform surfaces on } \\
\text { multi-axis machines due to the tremendous } \\
\text { improvement in CAD and CAM systems. } \\
\text { Open Applications Group Integration } \\
\text { Specification (OAGIS) format for process } \\
\text { routes }\end{array}$ \\
\hline
\end{tabular}




\begin{tabular}{|l|l|}
\hline \multicolumn{2}{|c|}{ Current State of Production Planning, and Design } \\
\hline Deficiencies or Barriers & Emerging Best Practice \\
\hline $\begin{array}{l}\text { environment } \\
\text { There are not enough employees that possess } \\
\text { the skills needed to utilize 3-D data and TDPs. } \\
\text { The skill sets for using the 3D data and TRP data } \\
\text { on the shop floor must be learned skills. }\end{array}$ & \\
\end{tabular}

\title{
3.2.2 Vision Statement
}

\author{
The Technical Data Package for the MBE will drive all applications and \\ will support the product throughout its lifecycle - from requirements \\ through demilitarization.
}

In the future, the TDP will be an accurate, complete portrayal of the process of product realization and will be the natural result of that process. A requirements driven design and manufacturing environment will produce optimized products and processes in a structured and systematic environment. The environment will be an integrated system that supports the continuous flow of information as the models mature. The design and realization of the physical product will be mirrored and guided by a rich model set that will represent that physical product and enable its total value, total lifecycle optimization. The TDP will be a readily available, extractable and abstractable, presentation of the product realization model set.

This vision is built upon the following elements:

- A complete product definition capability will be capable of driving all downstream applications and supporting the product throughout its lifecycle.

- $3 \mathrm{D}$ will be the authoritative source for all programs based upon contractual requirements.

- The tools and methods for producing and managing a 3D TDP will mature to make 3-D models clearly the most cost effective method for product realization - clearly less expensive than using 2D drawings.

- TDP that incorporates all elements of producibility and sustainability will be a reality.

- The TDP shall include electronic and software information.

- The TDP shall be completely CAD and PLM agnostic.

- There will be a sufficiently annotated model to support all the elements of producibility and desired sustainability.

- The TDP will be accessible at all levels of the supply chain based on a need to know (ITAR).

- There will be a clear mechanism for communication and collaboration throughout the supply chain and with the customer. (and a clearly defined mechanism for delivering to the government, with the capability to handle a delta transaction)

- There will be a cataloging and archiving information mechanism included in the TDP (resolution of LOTAR issues) 
- A TDP that is used and useful for all CAD systems will be freely accessible for system agnostic viewing and utilization.

- The requirements are fully documented and traceable to their satisfaction in the design and product realization cycle.

- Automated change propagation is a reality

- As-built TDPs will be delivered to the government at the end of every contract.

\subsubsection{Issues and Solutions}

The Production, Planning, and Design Team evaluated the deficiencies, reviewed the directions pointed to by the emerging practices, and considered the issues that needed to be addressed to achieve the envisioned state. From this evaluation the major issues associated with producing and managing modelbased TDPs were listed within the context of production, planning, and design. These issues include:

- The requirements and the data to develop a TDP are not available

- There is a lack of MBE technology to meet requirement.

- Tools do not interoperate limiting the ability to exchange information for effective collaboration.

- A lack of standard methods for use (conditions) limits the ability to effectively communicate. (addressed in global interoperable topic)

- The acquisition professionals, PMs, and PEOs do not properly perceive the value of MBE over the lifecycle. The value of the TDP is understood in some areas and not understood in others but is not usually a priority.

- Mechanisms for the delivery, (or provision of access) storage and management of the TDP throughout the product lifecycle are not adequately in place. Subset of No. 2

- The inability to provide adequately annotated models. There is no clear guidance to define what a fully annotated model should be at each level of TDP maturity and for each purpose.

- The lack of a fully integrated supply chain negates the ability to propagate the TDP throughout the enterprise - education, standards and interoperability.

- The inability to assure through validation and verification the accuracy and completeness of the model. There is no enforcement of the provision of validated TDPs.

- Characteristic level accountability - traceability of requirements through produce design and manufacturing at the level at which they make sense and can be measured/consumed.

○ There is no definition of what manufacturing planning data is required in the TDP.

$0 \quad$ The need to include narrative documents along with the geometric data in the TDP is not well served.

- There is no definition of requirements or methodologies for inspection or QA of minimally dimensioned MBE models. 
- The cost of MBE tools and their implementation is perceived to be too high. The industry and government wide business case (ROI) is not established.

- Some organizations lack the infrastructure, IT resources, and tool sets to institutionalize and manage an MBE environment.

- Multitude of IT certification requirements across DoD is a barrier for adopting MBE tools.

- The DoD enterprise IT strategy does not enable with MBE tools well.

- The migration of legacy models into new systems is lacking

- Legacy business practices, tool sets, etc., are barriers to MBE implementation. The multiplicity of business processes and their diversity makes it virtually impossible to implement new tools sets and practices.

- Information model standards are incomplete and difficult to implement.

- There is no requirement to deliver an as-built TDP, including 3D geometry, to the government appropriate for the contract.

- Emerging tools support a portion of the need set, but they support pieces of the solution and are not working toward a comprehensive solution to the TDP vision.

These 19 issues were prioritized to identify eleven major issues or challenges that need attention in producing and managing the TDP. The major issues and their solutions are documented below. The complete table of issues and all solutions generated is provided in Appendix B-1. The issues and their high-priority solutions are discussed in this section, followed by the team's consolidated Top Solutions that were presented at the end of the workshop.

\section{Section Format}

B.x Issue

\section{B.x.y Solution}

B.1 The requirements and the data to develop a TDP are not available.

B.1.1 Evaluate existing standards to define the degree to which they address the need.

B.1.2 Evaluate and evolve coordinated contractual language to incorporate a model-based response for the TDP (it must include all stakeholders in the procurement process).

B.1.3 Create government regulations supporting MBE that mandate the delivery and enforcement of the provision of a complete and adequate TDP.

B.1.4 Create a comprehensive description of the data required for the TDP.

B.1.5 Establish responsibility and accountability including a plan of action to implement the TDP requirements.

B.1.6 Conduct pilots to evaluate the effectiveness and utility of the TDP structure and process.

B.2 There is a lack of MBE technology to meet the necessary requirements

B.2.1 Develop a comprehensive plan for MBE.

B.2.2 Conduct benchmarking studies, develop a desired architecture and identify the gaps. 
B.2.3 Define best practices and standards for MBE and mechanisms for enforcing them.

B.2.4 Create a roadmap to fill the gaps.

B.2.5 Create champions, secure funding and implement the plan (include incentives for industry implementation).

B.2.6 Create contractual language that enforces TDP requirements.

B.2.7 Create a continual process of management of the plan and its implementation.

B.3 The acquisition professionals, project managers (PMs), and Program Executive Offices (PEOs) do not properly perceive the value of MBE over the lifecycle of the TDP. The value of the function of the TDP is understood in some areas and not understood in others. Overall the value of a model based environment is not usually a priority.

B.3.1 Provide separate funding for the PM to embrace and implement MBE and the provision of complete, 3-D TDPs.

B.3.2 Embed MBOs (management by objectives) that include total cost of ownership in the PM fitness report (annual review).

B.3.3 Contract based on total lifecycle costs instead of focus on short term cost minimization to enable the upfront investment needed for MBE implementation. Make these requirements visible in the RFP.

B.3.4 Conduct an ROI analysis substantiating MBE value and communicate the results to PMs and PEOs.

B.3.5 Conduct single digital master file demonstration that validates the short term low cost implementation of cost saving MBE processes.

B.3.6 Require Defense Acquisition University (DAU) training for all acquisition professionals, $\mathrm{PMs}$ and PEOs on the value of MBE.

B.3.7 Provide pervasive enterprise level training across the supply chain for MBE implementation.

B.4 The inability to provide adequately annotated models. There is no clear guidance to define what a fully annotated model should be at each level of TDP maturity and for each purpose.

B4.1 Achieve a clear definition of and standards to support a fully annotated model across government and industry including long term archiving (LOTAR).

B.4.2 Develop and provide clear guidance on the implementation of the applicable standards.

B.4.3 Identify TDP content - and specifically annotation requirements at each level of maturity in the product realization process.

B.4.4 Develop a standard for annotation for different product types based on part classification.

B.4.5 Define the annotation standards to the lowest common interoperability standards. Complete AP203 and AP233 and MBE compatibility index levels and mandate compatibility in the contract.

B.5 Tools do not interoperate, limiting the ability to exchange information with other users for effective collaboration. 
B.5.1 Evaluate the current interoperability capabilities and identify the gaps.

B.5.2 Provide incentives for MBE tool providers to incorporate interoperability standards specifically addressing gaps.

B.5.3 Develop a validated translation process for delivering TDP information to the government. Establish an independent validation authority (could be design check software).

B.5.4 Extend the STEP standards to fully address interoperability requirements.

B.5.5 Accelerate standards development to the point that standards parallel technical capability.

B.5.6 Create international partnerships to leverage and assure consistency of interoperability standards.

B.5.7 Develop a system similar to SPC mandating the sampling of TDP packages for interoperability of information for contractual compliance.

B.5.8 Provide a government system with a validated neutral format to manage access to and distribute the TDP data.

B.6 The inability to assure through validation and verification the accuracy and completeness of the model. There is no enforcement of the provision of validated TDPs.

B.6.1 Apply existing standards and tools to achieve mutual understanding of TDP content between design sources and production sources. (NAS 3500)

B.6.2 Extend existing standards and tools to assure that they adequately address all information like provisioning data, acquisition needs, and quality (metadata).

B.6.3 Develop a practice and process for the complete configuration management of MBE TD. (Practices exist for TDP but not for MBE TDP).

B.6.4 Develop tools to validate the accuracy of the model and provide needed training to the acquisition community.

B.7 Characteristic level accountability - traceability of requirements through product design and manufacturing at the level at which they make sense and can be measured/consumed.

- There is no definition of what manufacturing planning data is required in the TDP.

- The need to include narrative documents along with the geometric data in the TDP is not well served.

- There is no definition of requirements or methodologies for inspection or QA of minimally dimensioned MBE models.

B.7.1 Evaluate the tools and methods that exist and define gaps. Perform benchmark studies to identify and establish best practices.

B.7.2 Establish TDP manufacturing (including the extended enterprise) use cases that communicate exactly what the government needs. Include narrative documents with geometric data. 
B.7.3 Develop a compliance matrix that maps the manufacturing planning requirements to the TDP.

B.8 The multitude of IT certification requirements across DoD is a barrier for adopting MBE tools. The DoD enterprise IT strategy does not support MBE tools well.

B.8.1 Determine the appropriate chain of command for IT certification in order to harmonize requirements with MBE implementation

B.8.2 Establish a process to assure that certification of net worthiness is built into the plan for every program.

B.8.3 Highlight the cost of failures in not providing a timely solution to program needs (IT installation requirements, risk analysis, net worthiness certification)

B.8.4 Understand the approval process at the installation level

B.8.5 Achieve an MBE presence and voice in IT strategy. This will be accomplished by participation in forums and meetings.

B.8.6 Obtain proper authority from OSD mandating MBE implementation and mandating processes to support that implementation.

B.8.7 Incorporate MBE enablement into gold standard processes within the government to expedite the ability to conduct MBE

B.9 The migration of legacy models into new systems

B.9.1 Develop business rules that define the amount of legacy information that must be provided to support each contract. (reasonable requirements defined by category of procurement)

B.9.2 Establish decision support systems based on business rules that guide the acquisition decisions regarding legacy data.

B.9.3 Provide line items for procurement of legacy data that is required by new systems contracts

B.9.4 Provide a robust tool set that supports the migration of 2D models to 3D models including the capture of relevant information and the migration of non-annotated 3D models to be compliant with new requirements.

B.10 There is no requirement to deliver an as-built TDP, including 3D geometry, to the government appropriate for the contract.

B.10.1 Provide clear definition including use cases that guide decisions about when as-built TDPs are required and the content that is required.

B.10.2 Define a framework that communicates the data content and the form of that data.

B.10.3 Provide tools that support the automated capture of needed as-built information and provide mechanisms to assure compatibility of the available data with the requirements of the contract.

B.10.4 Clarify data right issues associated with the as-built TDP and document general findings. (Understanding the specifics will be negotiated with each contract) 
B.10.5 Provide tools that support the capture of configured product structure and the ability to maintain the as-built TDP.

B.10.6 Provide the capability to automatically reconcile as-built with the as-designed and as planned

B.11 Emerging tools support a portion of the need set, but they support pieces of the solution and are not working toward a comprehensive solution to the TDP vision.

B.11.1 Identify population of supporting tools in context of those issues above that have cited tools as part of their solution.

B.11.2 Raise the visibility of the DEDMWG activity to the level required to achieve the critical support, and enrich that activity to address all encompassing solutions.

B.11.3 Develop and distribute the DEDMWG strategic plan as a guidance document to industry.

B.11.4 Provide incentives to the technology vendor communities to work together toward the vision to provide comprehensive interoperable solutions.

PPD Team Balloted Prioritized Solutions:

The following is a listing of the PPD team consolidated top fifteen solutions as they were presented on the ballot for voting at the end of the workshop.

B.1.4 Create a comprehensive description of the data required for the TDP.

B.4.0 Provide adequately annotated models.

B.4.3 Identify TDP content - and specifically annotation requirements at each level of maturity in the product realization process.

B.4.1 Achieve a clear definition of and standards to support a fully annotated model across government and industry including LOTAR.

B.4.4 Develop a standard for annotation for different product types based on part classification.

B.5.4 Extend the STEP standards to fully address interoperability requirements.

B.5.6 Create international partnerships to leverage and assure consistency of interoperability standards.

B.7.2 Establish manufacturing (including the extended enterprise) use cases that communicate exactly what the government needs in a TDP. Include narrative documents with geometric data.

B.7.1 Evaluate tools and methods that exist and define gaps. Benchmark to identify and establish best practices.

B.9.4 Provide a robust tool set that supports the migration of 2D models to 3D models including the capture of relevant information and the migration of non-annotated 3D models to be compliant with new requirements

B.2.3 Define best practices and standards for MBE and mechanisms for enforcing them

B.5.3 Develop a validated translation process for delivering TDP information to the government. Establish an independent validation authority (could be design check software)

B.11.3 Develop and distribute the DEDMWG strategic plan as a guidance document to industry. 
B.8.5 Achieve an MBE presence and voice in IT strategy. This will be accomplished by participation in forums and meetings.

B.3.4 Conduct an ROI analysis substantiation MBE value and communicate to PMs and PEOs. (consensus) 


\subsection{Group C - Provisioning, Logistics, and Sustainment}

People who need the TDP to contain the information required to sustain their acquisition though out its life time participated in this breakout group. This is the area of use that first comes to mind when thinking of TDP users. If the TDP contains inadequate descriptions of form, fit, and function then users and supporters of the equipment during the use cycle have a difficult and expensive time ahead of them.

For the purposes of scope and "framing," the PL\&S team aligned with the current Defense Acquisition Management System ${ }^{20}$ overlaid with the PL\&S Scope focus highlighted in Figure 4

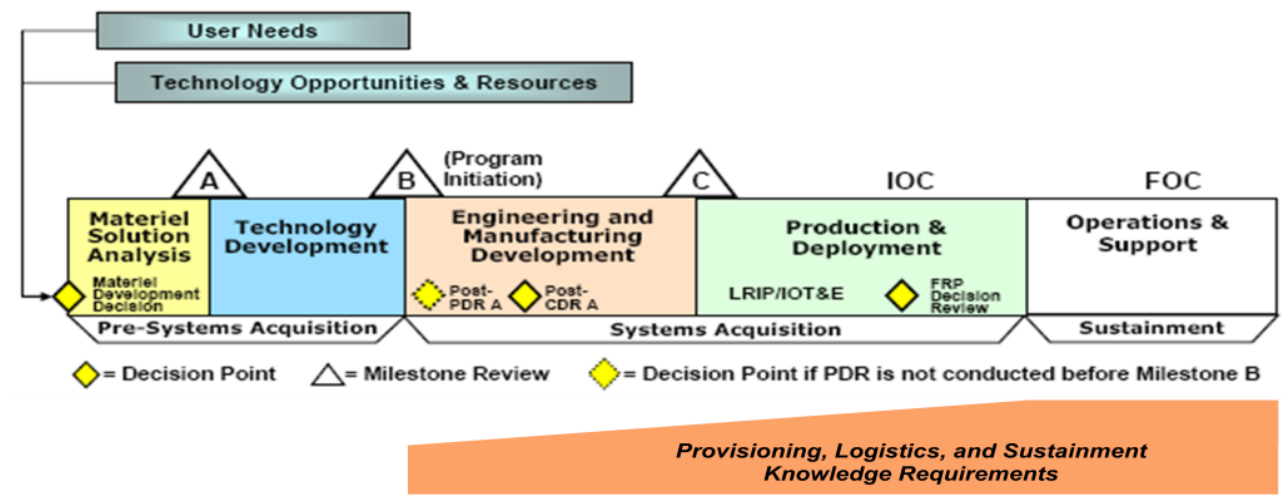

Figure 4 Figure 5.3.2 PL\&S Team Scope of Coverage versus Acquisition Life Cycle Phases

As an acquisition program is initiated, key PL\&S needs are identified, developed in conjunction with the overall phased development of a program and are fully defined and in-place by the Operations \& Support phase. A key to successful PL\&S - fully prepared, efficient, and cost effective - is its early involvement (at the beginning) in a program.

Additionally, the Acquisition life cycle phases are not to scale with respect to overall program cost. As shown in Figure 4, depending upon the source/system, Operations \& Support may be between 65 to $80 \%$ of the life cycle cost and are largely determined in the early phases. ${ }^{21}$ PL\&S actions and needs are intimately linked to the early phases of design and are also driven by early considerations of the eventual full life cycle of the system. Figure 5 graphically makes the point that the Operations and Support portions of the live-cycle contribute $65 \%$ to $85 \%$ of the total life cycle costs. Obviously anything that can be done earlier in the life-cycle that impacts the efficiency this portion will have a large leverage factor.

\footnotetext{
${ }^{20}$ Department of Defense Instruction 5000.02, December 8, 2008; from http://www.dtic.mil/whs/directives/corres/pdf/500002p.pdf

${ }^{21}$ http://www.acq.osd.mil/sse/briefs/GEIA ETM 07 DesigningforSustainmentwith SE Hardy.pdf
} 
The PL\&S team was well versed in routine nomenclature and proceeded into assessing the PL\&S current state. However, the following nomenclature was added post workshop to enhance the readers understanding of the terms and perspectives used by the PL\&S team.

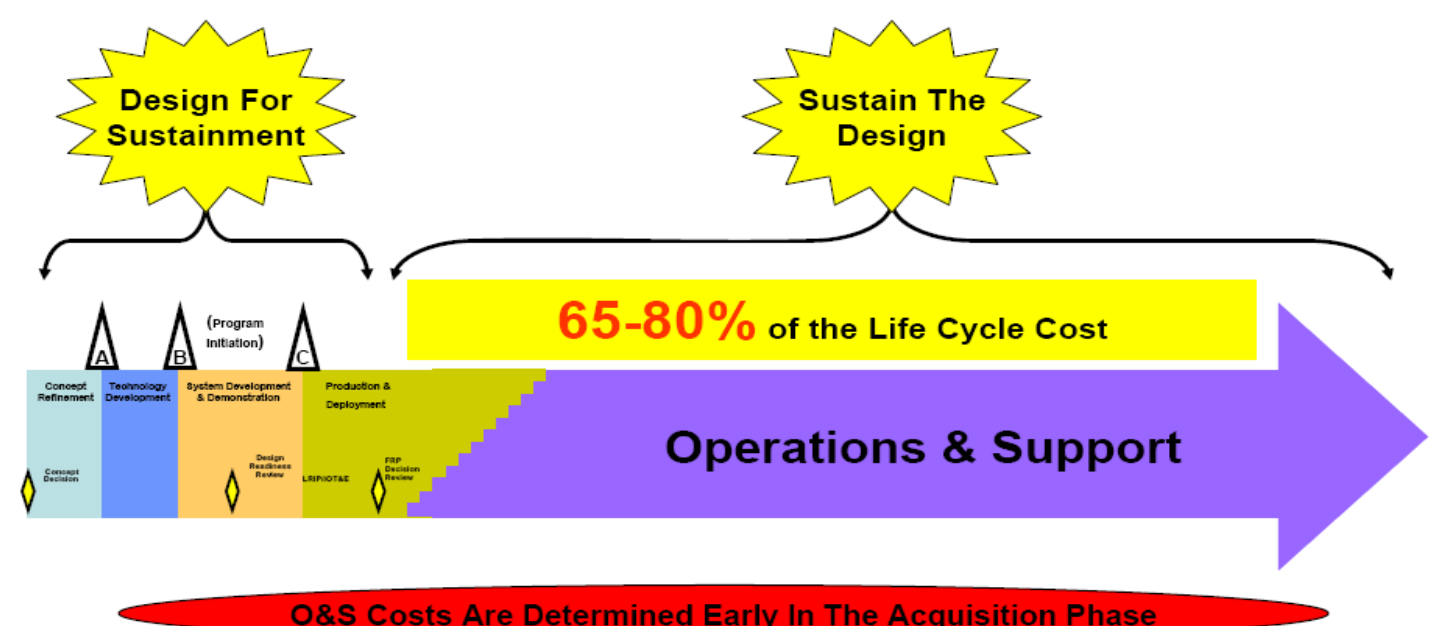

(Note: (although depicted with the prior 5000.01 life cycle phases the notional \% 'split' is the same for the O\&S phas

Figure 5 Relative Cost of a Program to Life Cycle Phases

\section{Working Definitions: ${ }^{22}$}

Logistics - (DoD) Planning and executing the movement and support of forces. It includes those aspects of military operations that deal with: a. design and development, acquisition, storage, movement, distribution, maintenance, evacuation, and disposition of materiel; b. movement, evacuation, and hospitalization of personnel; c. acquisition or construction, maintenance, operation, and disposition of facilities; and d. acquisition or furnishing of services.

Production Logistics - (DoD) That part of logistics concerning research, design, development, manufacture, and acceptance of materiel. In consequence, production logistics includes: standardization and interoperability, contracting, quality assurance, initial provisioning, transportability, reliability and defect analysis, safety standards, specifications and production processes, trials and testing (including provision of necessary facilities), equipment documentation, configuration control, and modifications.

Provisioning - (Army) A management process for determining and acquiring the range and quantity of support items necessary to operate and maintain an end item of materiel for an initial period of service. Specific types of provisioning are as follows: Initial provisioning: first-time provisioning of a new end item; follow-on provisioning: subsequent provisioning of the same end item from the same contractor; re-provisioning: subsequent provisioning of the same end item from a different contractor. ${ }^{23}$

\footnotetext{
22 Unless otherwise indicated; the definition source is: Joint Publication 1-02, DoD Dictionary of Military and Associated Terms, as amended through 310ctober 2009 located at http://www.dtic.mil/doctrine/dod dictionary/

${ }^{23}$ From Army Regulation 700-18, Logistics; Provisioning of U.S. Army Equipment, Headquarters Department of the Army Washington, DC, 20 September 2009
} 
Initial Provisioning - (DoD) The process of determining the range and quantity of items (i.e., spares and repair parts, special tools, test equipment, and support equipment) required to support and maintain an item for an initial period of service. Its phases include the identification of items of supply, the establishment of data for catalog, technical manual, and allowance list preparation, and the preparation of instructions to assure delivery of necessary support items with related end articles.

Sustainment - (DoD) The provision of logistics and personnel services required to maintain and prolong operations until successful mission accomplishment.

\subsubsection{Deficiencies or Barriers}

To better focus discussion, the PL\&S team decided to address Provisioning and Logistics from a 'prefielded' perspective, i.e., the time period in the life cycle BEFORE materials/items are put into actual field use. Sustainment on the other hand was addressed from a 'post-fielded' perspective, i.e., the time period in the life cycle AFTER materials/items are put into actual field use.

The following narrative provides insight to the major Deficiencies and/or Barriers along with Emerging Best Practices found by the group. A 'bullet' view of key points is also provided in Table 3.

\section{Provisioning (pre-fielding)}

The PL\&S team perceived a lack of representation and upfront involvement of all key stakeholders in the conceptual phase for the Integrated Project team (IPT) data call as a significant deficiency. This also extended to a lack of prime contractor support people not as involved as they should be upfront. This participation is essential in addressing another area of concern: inadequate identification of requirements upfront. Although improving personnel involvement can be addressed, another frequent barrier it the lack of adequate contractual language - resulting in not getting the right requirements in the contract.

The clarity of TDP contents for provisioning needs improvement as identified by the example that in many cases the Engineering Data or Supplemental Data for Provisioning (EDFP/SDFP) was not provided or was insufficient. Better awareness is needed about how the Source Maintainability and Recoverability (SMR) code analysis drives the requirement for the TDP. Likewise, improvements to generating the Logistics Support Analysis Record (LSAR) were identified. The LSAR is essentially a Provisioning Bill of Material (PBOM) that helps generate the data that feeds the Provisioning Master Record (PMR). However, this key piece of information is manually entered - while it could and should be automatically derived from the Engineering Bill of Material (EBOM). For new future systems the desire would be to get it from the Product Life-cycle Management (PLM) system.

Several data concerns were identified as problematic. Often, there is embedded proprietary data that can't be provided in the TDP. Data received from a Prime contractor may lack all OEM data or not contain OEM data at all - due to OEM restriction concerning the information. Metadata about the product is not searchable and therefore the true contents are difficult to ascertain and use. Mislabeling of data found in TDP also contributes to data completeness and quality concerns.

Another key deficiency is the lack of resource manpower to thoroughly review a TDP coupled with a lack of training in using the data that's received and lack of knowledge in understanding the data elements and content. By example - training to know what is stock listed and what is not is important to assessing and determining provisioning requirements.

The PL\&S team also identified some emerging 'best' practices in the provisioning area. Some prime contractors are adopting automatically derived Bills Of Materials (BOMs) - thus providing a view of the same baseline BOM data and can also see the spare parts that will be needed. In another best practice, 
the DLA has incorporated updates to the provisioning processes and practices for DLA to participate as a key stakeholder from the beginning of a weapons systems program. One example of DLA inclusion is found in the Air Force's Integrated Life Cycle Management (ILCM) guidelines, policies, and procedures. ${ }^{24}$ Another example is in an ARMY regulation which now "requires provisioning personnel and materiel managers to be members of the weapons system integrated product team." ${ }^{25}$

\section{Logistics (pre-fielding)}

Upon examining the logistics area, the PL\&S team highlighted the problems of disjointed or fragmented processes: A flowchart of the processes would help to better understand what data might be available or should be available and when in the overall system lifecycle that data should be made available in a TDP. Problems are further compounded with logistics products that are not integrated (e.g., technical publications are not linked to TDP and model data), thus contribute to a disjointed data feed, use, and dissemination process.

As found in the provisioning discussion, there is a strong need for clarity on TDP contents supporting logistics within DoD Services and Prime contractors. There is lack of clarity on what constitutes the "model." At times, there is improper requirement determination as supplied by the Services. Often there are inaccurate data feeding advanced planning and scheduling - systemic inaccuracies due to nonintegrated stovepipe systems - which may contain conflicting and redundant data. Another data complication is that once model data comes from a PLM system, you lose important associations from within that PLM system. Data incompleteness may result from a shift in support philosophy. For example, the assumed maintenance philosophy in pre-fielding may differ from the actual practice in post fielding and may result in not having the data.

The number of Non-descriptive National Stock Number (NSNs) is a deficiency that could be resolved with better TDP contents. This could move all NSNs to Type 1 (fully described) and greatly enhance the efficacy of NSNs for logistics management.

The PL\&S team identified several emerging 'best' practices in the Logistics area. There are currently enough information standards in existence to define TDPs that are valuable although some are not fully matured. Three-D (3D) technical publication capabilities are emerging that will be compliant with S1000D. ${ }^{26}$ There is strong advancement and momentum on Model Based enterprise (MBE) concepts and

\footnotetext{
${ }^{24}$ AIR FORCE INSTRUCTION 63-101, ACQUISITION AND SUSTAINMENT LIFE CYCLE MANAGEMENT, 17 APRIL 2009 ; found at http://www.af.mil/shared/media/epubs/AFI63-101.pdf "3.97. Weapon System Support Program (WSSP). AF participation in this DLA managed program is key to receiving the appropriate level of support to AF weapon systems from DLA. The AF identifies all weapon systems that use DLA consumables, how important the system is to the AF mission, the National Stock Numbers (NSNs) assigned to each weapon system and how critical each NSN is to a weapon system. DLA uses this information to plan, program, and budget for support to weapon systems. This program applies to all organic and contractor supported weapon systems that utilize DLA supported items, including classified systems. The implementation guidance for this program is contained in AFMAN 23-110, Volume 1, Part 1. Each PM with systems that use DLA NSNs shall fulfill the Weapon System Support Program (WSSP) responsibilities. These responsibilities begin prior to the first provisioning conference and end when DLA parts are no longer required to support the weapon system and the weapon system is removed from the WSSP database."

${ }^{25}$ Army Regulation 700-18, Provisioning of U.S. Army Equipment, 20 September 2009 found at: http://www.army.mil/usapa/epubs/pdf/r700 18.pdf

${ }^{26}$ From http://www.s1000d.net/: S1000D is an international specification for the procurement and production of technical publications. While this definition appears to restrict its use to technical publications, it has been found through application that the principles of the specification can also be applied to non-technical publications.
} 
practical application and TDP maturity through the use of CAD neutral 3D viewing tools. Awareness is increasing across DoD at high levels as evidenced by the Quadrennial Defense Review (QDR) emphasis on requiring and acquiring technical data and a legislative proposal to better define form, fit and function.

\section{Sustainment (post fielding)}

As the PL\&S team continued discussion into the Sustainment area, data deficiencies become even more apparent. Fundamentally, all too often, there is insufficient data for re-procurement, re-competition, demilitarization, disposal, and end-of-life actions. All too often, depots and support organizations are stuck with legacy data that may not be entirely correct. The real questions is "What do we do with it?" Additional data complications arise when over the life of a system suppliers and their data disappear resulting in Diminishing Manufacturing Sources and Material Shortages (DMSMS). ${ }^{27}$ Likewise, the unexpected lengthening of product life cycle - over the original plan - introduces additional data requirements that were not anticipated during the initial systems start-up. Use of NSNs for these legacy systems may be difficult since what's required for Type 1 (fully described NSN) may be less than what's fully available (metadata-wise). And, in a dynamic information environment, how can you accommodate adding new information into a legacy TDP to support NSN Type 1 description needs?

There are problems with Warfighters' access to accurate and sufficient data. Getting the data to the Warfighter and their support organizations is problematic with both the type of data being received and ability to get to the field. Key hurdles involve lack of systems interoperability and translation problems in conveying data. There are a plethora of legacy tools, software, and equipment. Additionally, the support workforce often does not have expertise in using tools and may not have needed software. Problems with using modern software applications were amplified by authorization hurdles and delays due to inconsistent and restrictive Directorate Office Information Management (DOIM) policies for deploying network based applications.

One barrier to moving toward a more model based environment and model supported TDPs involved the increased burden on small vendors. If a part is to be bid competitively, then the model must be made available to all vendors including the small ones. But in many cases, an elegant model based technical solution may not be possible due to the inability of small vendors to process or perhaps even view the models. Currently, prime contractors provide both 2D drawings and 3D models. Since the government will not provide a 3D viewer, the burden falls on the vendor to make the upfront capital investment.

Problems with inefficient data processing and business processes were also identified. One example is the time lag between request and procurement in the QDR (Quality Deficiency Report) process and Form $339^{28}$ collaboration between the Services and DLA. Another is that the process of change notification to DLA is broken regarding Time Compliance Technical Orders /Modification Work Orders ${ }^{29}$, (TCTO/MWO).

\footnotetext{
27 Defined as: "The loss or impending loss of manufacturers of items or suppliers of items or raw materials." From Department of Defense regulation 4140.1-R, DoD Supply Chain Management Regulation

${ }^{28}$ DLA Form 339 is the vehicle used to provide technical and engineering support necessary for the procurement and manufacture of spare parts required to support equipment, due to diminished manufacturer sources or obsolescence.

${ }^{29}$ TCTO five categories: Immediate action, Urgent action, Routine action, record, interim. (e.g. a TCTO of 'Immediate' is a kit of instructions/parts to resolve a safety condition which could result in fatal/serious injury to
} 
It is difficult to keep a sustainment BOM current due to poor configuration management control - how do you keep the configuration current if you don't communicate changes? By example - prime contractors deliver "as delivered" data but the Services may modify for an "as-used" configuration. Without configuration management data is lost between the two. Another combination business process and data configuration example was the case of a common part used by multiple Services with each assigning NSNs resulting in multiple NSNs for same part.

Many of these problems were attributed to a lack of authoritative source and control resulting in multiple copies of TDPs being out-of-sync. Without a single authoritative source or at least one system that pulls it together, the result is multiple services with different manuals with fundamentally the same data. Also, since not all metadata is captured in searchable formats including rather extensive use of comment text fields and non-electronic documentation, the ability to quickly find data, assess for completeness, make consistent interpretations, and perform consistent transmissions is compromised.

While some emerging practices were identified for sustainment by the PL\&S team, in one case the lack of adoption by DoD and agreement on whether or not a practice was 'best' served to highlight there is still much opportunity for better understanding and improvements. Boeing, for its commercial customers, has a single point data access portal yet when offered to the military, the response was each Service required its own product thus highlighting the problem of stovepipe perspectives. Also, there is the case of the legacy. The highly revered and effective Browning M2 .50 caliber, machine gun has been produced for the US Military since 1933. Reverse engineering was applied to create a data model to be used to enhance/improve/replace old data for design and manufacturing. Yet while this got the job done, it was questioned as "Is this really an emerging best practice?" or rather a creative and effective way to overcome the data gaps and lack of complete and quality data practices typically seen with legacy systems. This lack of vision is seen as a deficiency.

Table 3 Current state table for provisioning, logistics, and sustainment.

\begin{tabular}{|c|c|}
\hline \multicolumn{2}{|c|}{ Current State of Provisioning, Logistics, and Sustainment } \\
\hline Deficiencies or Barriers & Emerging Best Practice \\
\hline \multicolumn{2}{|c|}{ Sub Category Provisioning (pre-fielding) } \\
\hline 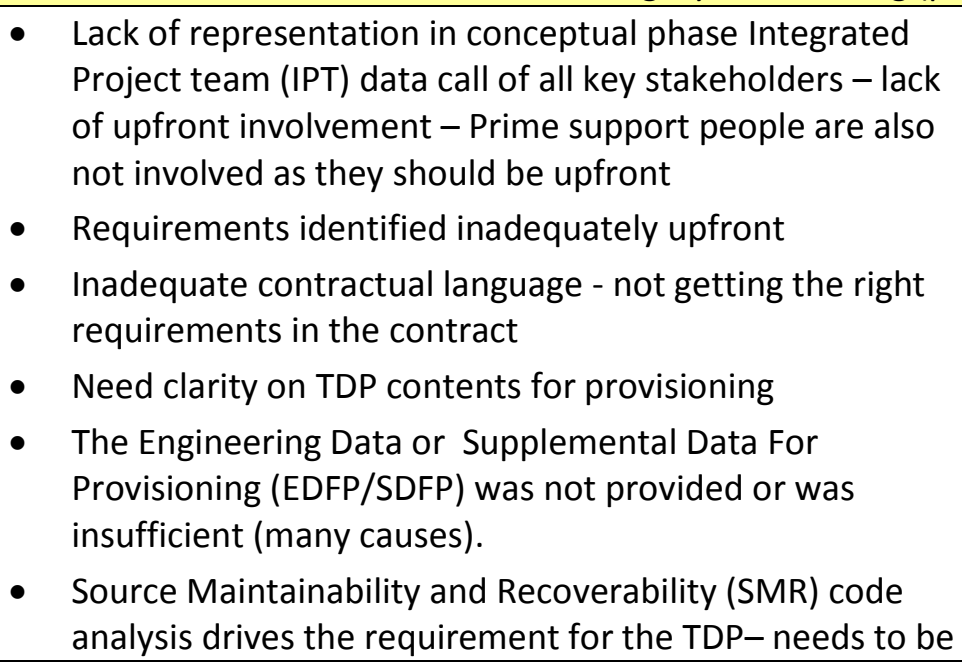 & $\begin{array}{l}\text { - DLA has incorporated updates to } \\
\text { provisioning processes and } \\
\text { practices as policy/procedure for } \\
\text { DLA to participate upfront as a } \\
\text { key stakeholder 'from the } \\
\text { beginning' of a weapons systems } \\
\text { program: } \\
\text { Air Force - As part of the } \\
\text { Integrated Life Cycle } \\
\text { Management (ILCM) } \\
\text { guidelines, policies and } \\
\text { procedures for the Air Force } \\
\text { (AF). }\end{array}$ \\
\hline
\end{tabular}

people or valuable prop; 'Urgent' is to resolve a potentially hazardous condition that could result in injury to personnel or damage to property); MWO is used to record details of work done and the certificates of tradesmen. 


\begin{tabular}{|c|c|}
\hline \multicolumn{2}{|c|}{ Current State of Provisioning, Logistics, and Sustainment } \\
\hline Deficiencies or Barriers & Emerging Best Practice \\
\hline $\begin{array}{l}\text { better awareness of this driver. } \\
\text { - Logistics Support Analysis Record (LSAR) - Provisioning Bill } \\
\text { of Material (PBOM) - is a key piece of information that is } \\
\text { manually entered - it should be derived from the } \\
\text { Engineering Bill of Material (EBOM (master design BOM). } \\
\text { It generates the data that feeds the Provisioning Master } \\
\text { Record (PMR). For new future systems the desire would } \\
\text { be to get from the Product Life-cycle Management (PLM) } \\
\text { system. } \\
\text { - Knowing what is stock listed and what is not. } \\
\text { - Embedded proprietary data that can't be accessed in the } \\
\text { - TDP. } \\
\text { - Data from Prime may lack or not contain OEM data - OEM } \\
\text { restricts information. } \\
\text { - Metadata about the product is not searchable. } \\
\text { - Lack of resource manpower to thoroughly review a TDP } \\
\text { Lack of training in using the data that's received and lack } \\
\text { of knowledge in understanding the data elements and } \\
\text { content. }\end{array}$ & $\begin{array}{l}\text { Army - "Requires provisioning } \\
\text { personnel and materiel } \\
\text { managers to be members of } \\
\text { the weapons system } \\
\text { integrated product team." } \\
\text { - Primes are adopting derived Bills } \\
\text { Of Materials (BOMs) - a view of } \\
\text { the same data and can see the } \\
\text { spares. }\end{array}$ \\
\hline \multicolumn{2}{|c|}{ Sub Category Logistics (pre-fielding) } \\
\hline $\begin{array}{l}\text { - } \quad \text { Disjointed or fragmented processes. } \\
\text { - } \text { Doed clarity on TDP contents for logistics - on both sides, } \\
\text { - Clarity on what constitutes the "model" - e.g. CAD solid } \\
\text { with an associated document. } \\
\text { - Improper requirements determination supplied by the } \\
\text { - Services. } \\
\text { - Inaccurate data to feed advanced planning and } \\
\text { scheduling - systemic inaccuracies due to non-integrated } \\
\text { stovepipe systems - may contain conflicting/redundant } \\
\text { data. } \\
\text { - Once 'model data' comes from a PLM system, you lose } \\
\text { associations from within that PLM system. } \\
\text { The assumed maintenance philosophy in pre-fielding } \\
\text { may differ than actual practice in post fielding and results } \\
\text { in not having the data. } \\
\text { - Logistics products are not integrated - technical } \\
\text { publications are not linked. } \\
\text { Non-descriptive National Stock Number (NSNs) - a better } \\
\text { TDP could move all NSNs to Type } 1 \text { (fully described). }\end{array}$ & 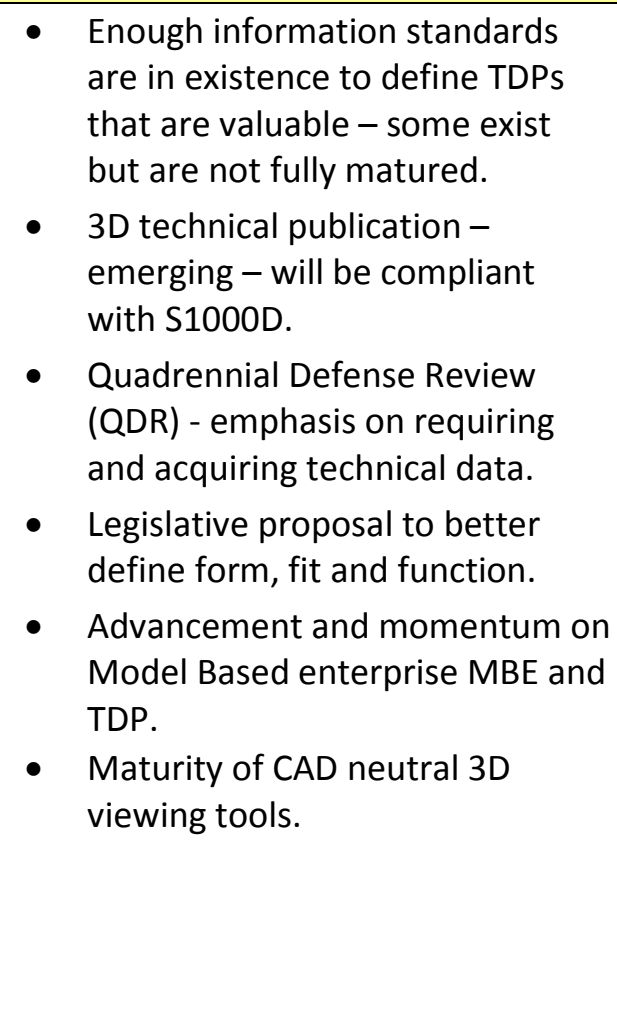 \\
\hline
\end{tabular}




\begin{tabular}{|c|c|}
\hline \multicolumn{2}{|c|}{ Current State of Provisioning, Logistics, and Sustainment } \\
\hline Deficiencies or Barriers & Emerging Best Practice \\
\hline \multicolumn{2}{|c|}{ Sub Category Sustainment (post fielding) } \\
\hline 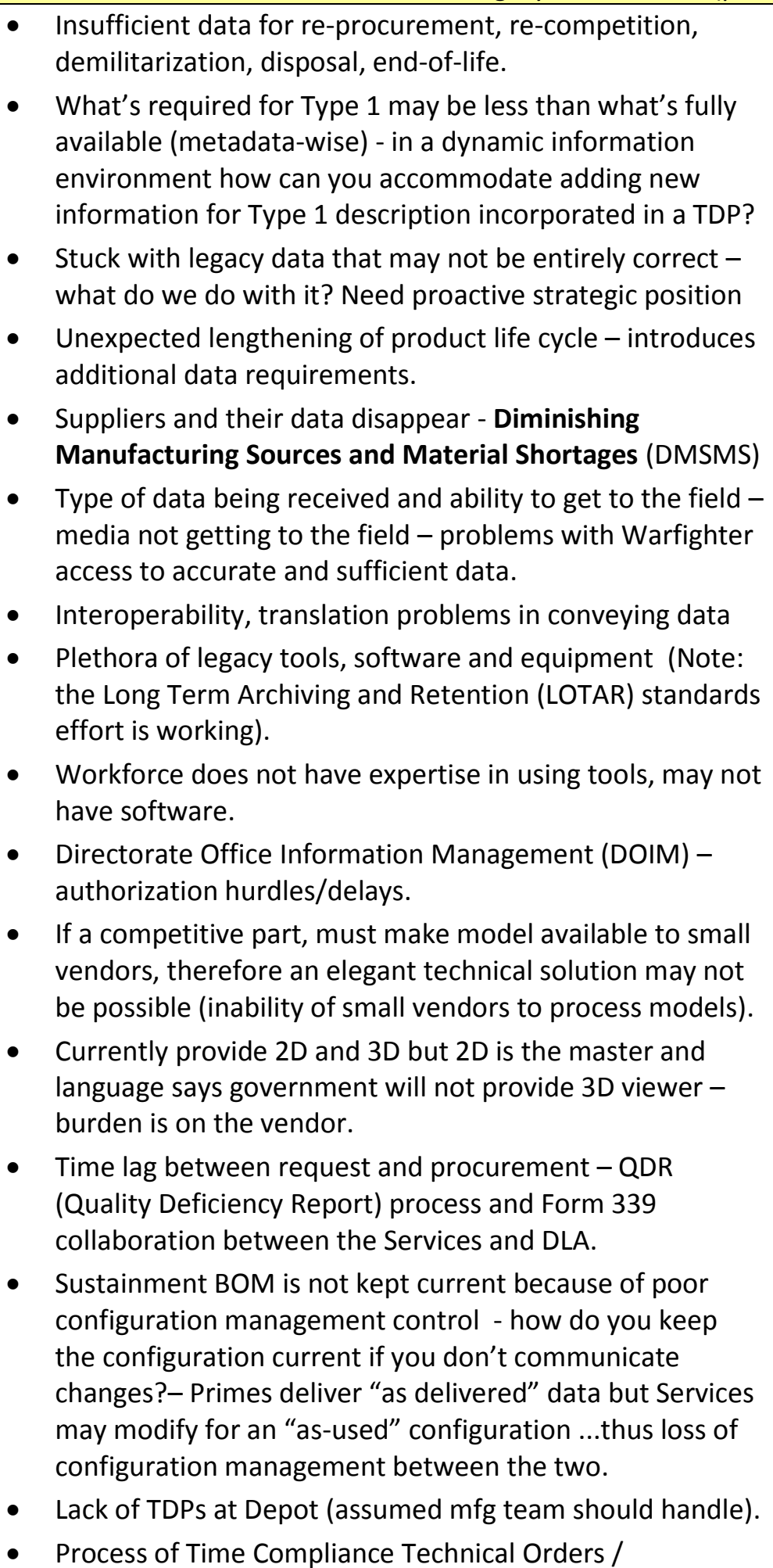 & $\begin{array}{l}\text { Boeing, for it's commercial } \\
\text { customers, has a single point } \\
\text { access portal yet when offered to } \\
\text { military the response is each } \\
\text { Service has it's own product. } \\
50 \text { caliber - reverse engineering } \\
\text { or took old data to create data } \\
\text { model - Boeing term, "convert on } \\
\text { demand" Gets the job done, but is } \\
\text { this really an emerging best } \\
\text { practice? }\end{array}$ \\
\hline
\end{tabular}




\section{Current State of Provisioning, Logistics, and Sustainment}

\section{\begin{tabular}{l|l} 
Deficiencies or Barriers & Emerging Best Practice
\end{tabular}}

Modification Work Orders, (TCTO/MWO) notification of a change to DLA is broken.

- Lack of authoritative source and control resulting in multiple copies of TDPs that are out of sync.

- Lack of a single authoritative source or at least one system that pulls it together - e.g.' same aircraft, multiple Services with different manuals, yet it's fundamentally the same data.

- Common part used by multiple Services but assign unique NSN resulting in multiple NSNs for same part.

- Not all metadata is captured in searchable formats extensive use of comment text fields and non-electronic documentation.

\subsubsection{Vision}

In the future, a universal policy will be in place and followed to assure all stakeholders are involved in conceptual upfront data calls and the TDP requirements are clearly identified for all users in the system life cycle. All contractual rights to data are fully exercised to define and assure delivery of a TDP with 'full and complete rights data' in the form of a fully annotated and certified model. The TDP configuration is managed to assure data is accessible electronically to all who need access and from an authoritative source. The user community is well trained and capable with access and tools to search all metadata. TDP data is integrated with technical manuals, derived from bills-of-materials, and seamlessly feeds into other systems and uses.

This vision is built upon the following elements developed by the PL\&S team:

- A clear and universal policy (DoD 5000 series) is followed - where all stakeholders are involved in the conceptual upfront data call, and clearly identifies the TDP requirements for all users;

- $\quad$ All rights are exercised;

- $\quad$ All TDP requirements are clearly stated as contracted deliverables, are delivered, and are maintained;

- The right/complete content is in place;

- $\quad$ All TDP needs for PL\&S are contained in and supported by a fully annotated and certified model

- $\quad$ Certified TDP - Who, How, \& When is clearly defined and understood

- $\quad$ The TDP is complete enough to sufficiently support maintenance activities - supports a full kit consisting of: automated work order, parts, tools and technical data;

- $\quad$ An authoritative source is in place; 
- Whoever needs the data can get to the authoritative source;

- $\quad$ Technical data is distributed electronically to all users; and all users have the capability to use it;

- $\quad$ Fully integrated TDPs, technical manuals, BOMs, etc.; and

- Metadata is fully searchable.

\subsubsection{Issues and Solutions}

The Provisioning, Logistics, \& Sustainment Team identified and further developed eight ${ }^{30}$ major PL\&S Issues dealing with TDPs and listed below. The complete table of Issues and all solutions generated is shown in Appendix A-3.

- $\quad$ Lack Of Complete Definition Of TDP

- Weak Contracting And TDP Requirements Definition -

- Need Attention To TDP/Model Certification And Validation

- Poor Data Content For Life Cycle Support -

- Lack Of Clear Authoritative Source -

- Inability To Reuse And Leverage Data -

- Need Improved NSN Descriptions From TDPs -

- Data Availability And Utilization

- Impacts Of Aging And Lengthening Of Life Cycle

- Workforce Readiness And Resources - (This Issue Belongs In Policy \& Management)

Eight of these ilssues and their high-priority solutions are discussed in the following section, followed by a listing of the team's consolidated top eleven solutions as they were presented on the ballot for voting at the end of the workshop.

\section{Section format}

C.x Issue

\section{C.x.y Solution}

C.1 Need for complete and detailed standard definition of TDP across all Services: Need to evolve to standard references for contracting purposes. Includes uniform and standard nomenclature with terms and their definitions. Need to clarify what constitutes model based support for TDP.

C.1.1 Develop and publish DoD TDP standards and related documents, e.g. Data Item Descriptions (DIDs)

C.1.2 Work towards an international standard - leverage existing standards work and new DoD standard

\footnotetext{
${ }^{30}$ Note: A total of 10 were identified, but one was thought to be within the purview of the Policy and Management team and the other was not developed further due to more focus on 'up-front' issues. Both issues are contained in this narrative section.
} 
C.2 Lack of upfront involvement and inadequate contract language: There is a lack of upfront involvement across the stakeholder community. All stakeholders need to define the requirements and the contract needs to reflect the requirements. Inadequate contractual language is not getting the right PL\&S requirements in the contract.

C.2.1 Expand use of Automated tools - SYSPARS/SMART-T to assist in developing program and contract documents.

C.2.2 Institutionalize involvement policies across Services - clarify and promote the need with strong business cases

\section{C.2.3 Develop appropriate contract language and clauses - tied to standard}

C.2.4 Assess execution activity- to confirm delivery of TDP

C.3 Need to address the definition, contents, and management of TDP certification and validation: Who, how and when - oversees the delivery and acceptance of a TDP

\section{C.3.1 Define who, how and when in conjunction with policy development - the "how" also driven by standard: "who" and "when" can start without a standard}

C.4 TDPs often don't contain all the information users need throughout the lifecycle: May be mislabeled, incomplete, inaccurate, conflicting, redundant and/or not searchable. Model data is disconnected from source system.

C.4.1 Develop a set of assessment rules for creating modernized data to support legacy weapons system needs

\section{C.4.2 Develop a tool kit/environment for cost effectively data modernization}

C.4.3 Identify cost effective tools and methods for developing, acquiring legacy part data2D, 3D, whatever fits the need

C.5 Lack of authoritative source and control of the TDP: Multiple copies of TDPs that are out of sync, as delivered and as used, are not configuration managed. There are multiple sources and each thinks they are THE authoritative source. Due to data manipulation to meet mission requirements, the data is modified and is not fed back to the originating/originating source. Thus, it's out of sync, redundant, multiple systems. Within some Services there is a lack of a modern repository environment. Who controls and who is the authoritative source for a common part? How do we know/assure that the most current TDP is up to date?

C.5.1 Develop requirements to utilize Global Combat Support Systems (GCSS) efforts (Enterprise Requirements Planning - ERPs) within and across the Services to facilitate Product Lifecycle Management (PLM)

C.5.2 Develop and establish a policy for an official master authoritative data source for each TDP

\section{C.5.3 Identify current potential authoritative sources}

C.6 Lack of ability to reuse and leverage product data: To derive other data products such as tech manuals, BOMs, to support all the subsequent as delivered, as used, as maintained, as designed, etc. needs across the life cycle.

C.6.1 Define modern repository requirements and architecture options, use of existing ERPs, JEDMICS, others including new commercial solutions. Note: there are multiple 
implementation options, but one with promise is primes-to-DoD mirroring. Leverage prime capability (tie into definition of data requirements)

C.6.2 Develop/discover standards based tools that take advantage of data viewing and exchange

C.6.3 Develop and prove out capability to link TDPs to tech documents and other deliverables

C.7 Need to make it easier for parts reuse and interchangeability How can the data from a model supported TDP be defined, acquired and utilized to improve NSN full descriptions?

C.7.1 Continue to push for parts management and leverage in progress Services and DLA activities

C.8 Inadequate and insufficient data access, formats, availability - poor data access, inconsistent formatting and overall lack of availability hinder broad based use across all the user domains. Users need to be able to access the authoritative source in a form that they can readily use.

C.8.1 Leverage authoritative source assessment and development work.

C.8.2 Develop and approve mechanisms that enable role based access to TDPs.

C.8.3 Drive development of data formats - PLCS (AP-239)

C.8.4 Provide low cost readers to some classes of users

\section{PL\&S Team Balloted Prioritized Solutions:}

The following list contains the PL\&S team's consolidated top eleven solutions as they were presented on the ballot for voting at the end of the workshop.

C.1.1 Develop and publish DoD TDP standard and related documents.

C.2.1 Expand use of Automated tools - SYSPARS/SMART-T.

C.2.2 Institutionalize involvement policies across Services.

C.2.3 Develop appropriate contract language and clauses - tied to standard.

C.2.4 Assess execution activity - to confirm delivery of TDP.

C.3.1 Define who, how, and when in conjunction with policy development.

C.5.1 Develop requirements to utilize Global Combat Support Systems (GCSS) efforts.

C.5.2 Develop and establish a policy for an official master authoritative data source for each TDP.

C.6.1 Define modern repository requirements and architecture options.

C.6.3 Develop and prove out capability to link TDPs to tech documents and other deliverables.

C.7.1 Continue to push for parts management and leverage in progress Services and DLA activities. 


\subsection{Group D - Policy Management}

Studies ${ }^{31}, 32$ and numerous reports indicate that DoD should strengthen policies for acquiring technical data needed to support weapons systems. They have found that even when there is a clear requirement for assessing the sustainment plans for a system the requirements lack sufficient detail to assure adequacy of the data.

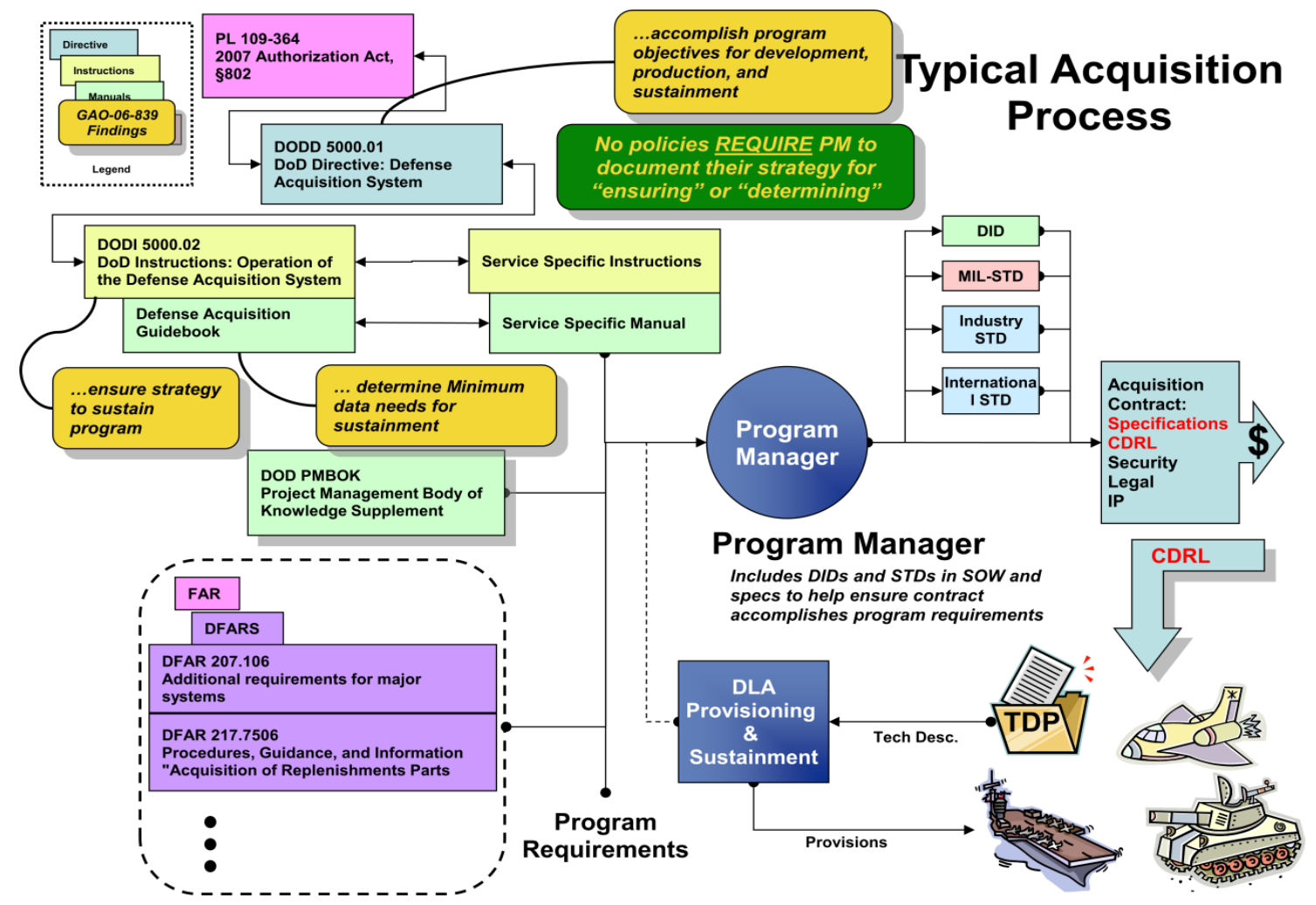

Figure 6 A summary of the document hierarchy that governs the typical DoD acquisition process.

The policies governing the acquisition process are many and varied as depicted in Figure 6.

The program manager is the key individual responsible the final choice of what defines the contract deliverables. This position is often filled by individuals for fairly short portions of their careers and thus they often focus upon benefiting the Warfighter in the near term more than acquiring sufficient data for long term sustainment of the acquire item. However, SE Hardy ${ }^{33}$ reports that $65 \%$ to $80 \%$ of the lifetime cost of a weapons system occurs during operations and sustainment and a dollar spent reducing sustainment costs is 2 to 4 times more effective in reducing overall cost than if invested to reduce cost elsewhere. To encourage the program acquisition manager to support the need to acquire adequate technical data for sustainment may require addressing the governing policies, directives, and instructions.

This group enabled people who establish the business infrastructure governing protection and compliance in the acquisition process to influence the data content and form in a TDP since their

31 GAO-06-839 DoD Should Strengthen Policies for Assessing Technical data Needs to Support Weapon Systems

32 GAO-04-715 Opportunities to Enhance the Implementation of Performance-Based Logistics

33 http://www.acq.osd.mil/sse/briefs/GEIA_ETM_07_DesigningforSustainmentwith_SE_Hardy.pdf 
business, security, commercial, and compliance rules will dictate how the model based enterprise share much of this data.

\subsubsection{Deficiencies or Barriers}

The members of the Policy Management breakout group identified twenty specific deficiencies or barriers that are perceived to prevent or hinder effective formulating, disseminating, or implementing policies that would require 3D-model based technical data packages (TDPs). The entire list of these deficiencies and barriers is shown in Table 4

The deficiencies/barriers and emerging best practices listed above can be consolidated into four moregeneral categories:

- Management, accountability, and culture;

- Data format, configuration control, obtaining the appropriate data in the appropriate format, and long-term data retention;

- Cost and funding constraints, and lack of empowerment; and

- Conflicting and inconsistent policies and regulations regarding TDPs.

\section{Management, Accountability, and Culture}

The Policy Management Group noted that short-term management cycles of active leadership make it difficult to establish a TDP consistent policy within an organization because a typical DoD program manager stays in the position on average three to five years, while the life of a program is generally much longer. Because of these frequent rotations of job function, there is a lack of accountability for ensuring the adequate and appropriate TDPs are procured and maintained.

Although MIL Standard 31000 defines what a TDP comprises, there is too much flexibility at the point of execution (across program offices), which exacerbates the lack of accountability for failure to obtain technical data. The group noted that there is a "rice bowl" (a.k.a. "stove pipe") structure in which the unwritten rule is that "it's every program manager for himself." It is difficult to overcome a culture of historical practices and processes that have existed for the past 60 years (the "we've always done it that way" syndrome).

The DFARS 252.227-7013 defines and describes DoD rights in non-commercial technical data in general terms. The group noted that enforcement of those data rights is inconsistent and sometimes does not occur. The lack of a mandatory acquisition milestone gate was cited as another reason that appropriate TDPs are not being procured.

\section{Data Format, Configuration, Control, Appropriate Data, and Data Retention}

Although MIL Standard 31000 defines the elements of a TDP, the standard does not adequately address configuration history. As modifications and in-production changes occur throughout the life of a major program, the TDP should also be modified to reflect the as-built configuration of the product. Disseminating and managing the TDPs across the product life cycle becomes a major challenge. Obsolescence of equipment during the life of a program can also affect the adequacy of a TDP. In some cases a TDP that was adequate and appropriate at the time of procurement becomes unusable because the hardware and/or software that is required to read and process the information becomes obsolete.

\section{Cost/Funding Constraints and Lack of Empowerment}

The group observed that virtually no one who is empowered to make policy decisions has a full understanding the importance of appropriate, model-centric TDP's that are available throughout the entire program life cycle. Because funding for major DoD programs is always limited and there is always 
pressure to reduce costs, the cost of TDPs frequently come under scrutiny. When called upon to make a business case for the cost of a TPD, the program manager often has no effective life cycle cost models or other tools to develop and defend a business decision. The group noted that some more-recent policies include objectives to consider life cycle costs.

\section{Conflicting and Inconsistent Policies and Regulations Regarding TDPs}

The acquisition of intellectual property and other data rights is not uniformly or adequately enforced across the DoD. The flow down of requirements (e.g. the definition of technical data) is inconsistent across the service branches. Although DoDI 5000.02 contains several references to technical data, it does not definitively define technical data requirements. There are also other policy, directive, and instruction conflicts - for example, from the Director of Information Management (DOIM) - that inhibits the implementation of needed and effective tools.

Table 4 Current state table for policy management

\begin{tabular}{|c|c|}
\hline \multicolumn{2}{|c|}{ Current State Table for Policy Management } \\
\hline Deficiencies or Barriers & Emerging Best Practice \\
\hline $\begin{array}{l}\text { - Short-term cycles of active leadership leads to } \\
\text { focus on short term results. } \\
\text { Culture - The inertia of historical practices and } \\
\text { processes (the way we have been doing it for } \\
\text { the past 20-30 years) must be overcome. } \\
\text { Rice bowl (stove pipe structure) - span of } \\
\text { responsibility is too narrow for a major } \\
\text { systematic change like basing a TDP on 3D } \\
\text { models. } \\
\text { Organizational readiness - to what degree is the } \\
\text { organization prepared? Going from 2D to 3D } \\
\text { requires technical upgrades and training to all } \\
\text { impacted organizations. } \\
\text { - Lack of accountability (often because of job } \\
\text { function rotations). Once the acquisition } \\
\text { manager has rotated to his next assignment he } \\
\text { is no longer accountable for the success of his } \\
\text { acquisition, i.e. during its' operation and } \\
\text { sustainability phase. } \\
\text { Too much flexibility at the point of execution } \\
\text { (across the program offices), therefore leaving } \\
\text { no accountability for failure to obtain tech data } \\
\text { Lack of an acquisition milestone gate } \\
\text { requirement has allowed failure in procuring } \\
\text { adequate technical data } \\
\text { Life cycle cost models fail to adequately include } \\
\text { the operations and sustainment phase during } \\
\text { initial design, development, and production. } \\
\text { Other policies/regulations conflict and inhibit } \\
\text { the procurement of needed and effective tools, } \\
\text { e.g. Directory of Information Management }\end{array}$ & $\begin{array}{l}\text { - Objectives to consider lifecycle costs being } \\
\text { included in policies. } \\
\text { - LOTAR (Long-term archival and retrieval of } \\
\text { data - Develops technology and NAS } \\
\text { standards (owned by AIA) ASD (European } \\
\text { equivalent). } \\
\text { - SYSPAR (Army) and SMART-T (Navy) are } \\
\text { examples of expert assistance tools. } \\
\text { - PLM systems, with an interoperable layer, } \\
\text { are an emerging solution that allows us to } \\
\text { gather the data that feeds in. }\end{array}$ \\
\hline
\end{tabular}




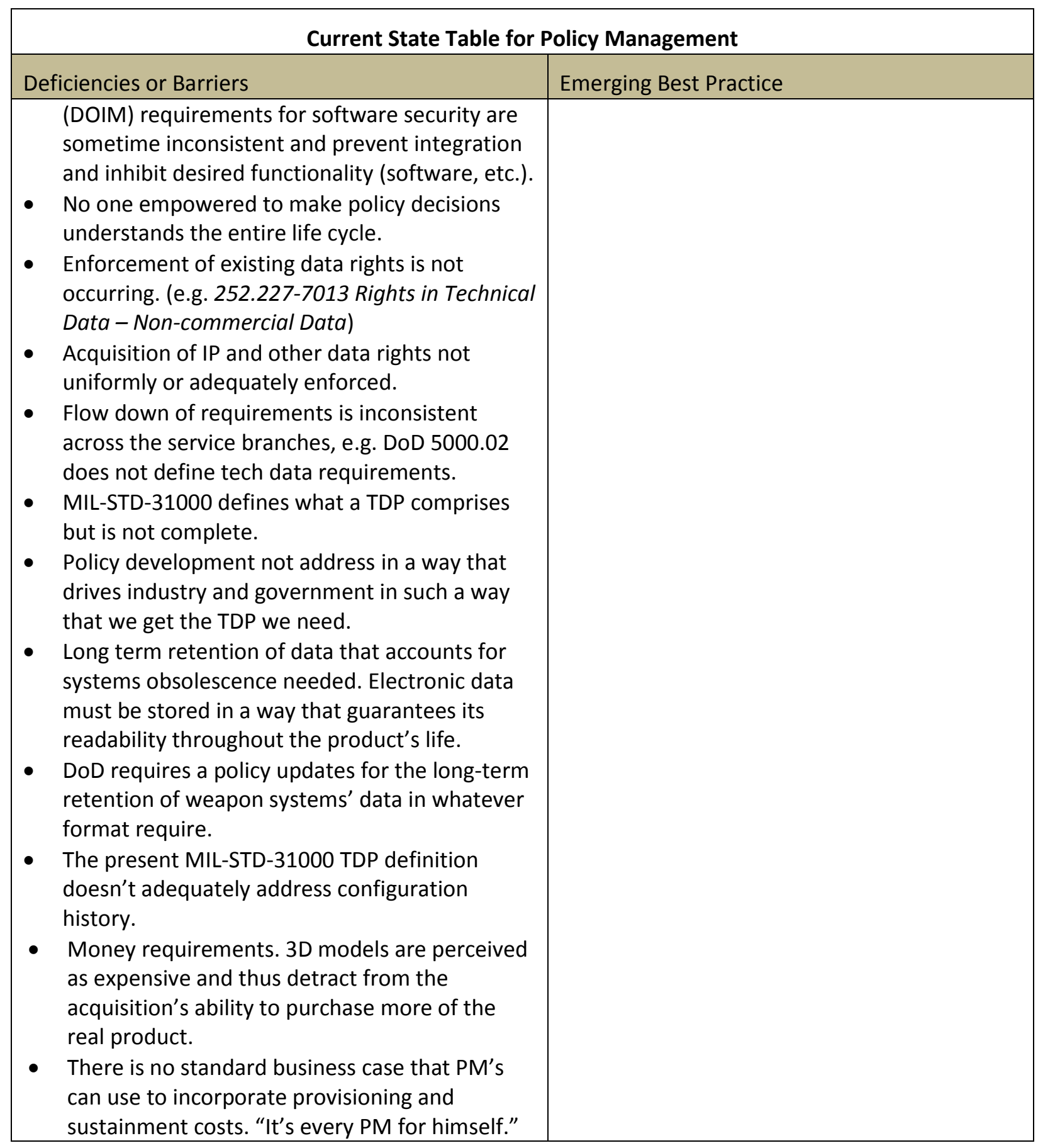

\subsubsection{Vision}

Policies are in place to drive the DoD ownership of the technical data package containing all the critical data necessary to maintain an operating weapons system in a war theater environment.

The Policy Management breakout group enumerated the visionary elements of a policy that would support the goal of obtaining and maintaining model-centric 3D technical data packages. There was 
general agreement that procurement policy should be more definitive in requiring model-centric, 3D technical data packages. This is needed in order to minimize the flexibility of individual program managers to exclude such packages, and to ensure that the program managers are held accountable for obtaining appropriate technical data packages.

Policy should support the inclusion of gates in acquisition milestones that would require the assessment of technical data to ensure that requested/provided data packages are appropriate to support 3D model-centric data requirements. There is a need to educate acquisitions and logistics personnel so that they fully understand and control existing data rights, and understand the value of technical data packages across the product life cycle. Policy should support the need for the Defense Logistics Information Service (DLIS) to have provisioning data before systems are deployed.

Policy should also ensure consistency of flow down requirements terminology, and it should not limit innovation and competition in the marketplace. Policy should support the exchange of data among all service branches in a neutral format, and it should support the implementation and utilization of commercial standards when and where appropriate. The group observed that policy should be written in such a way that it remains timeless, so as to remain priceless.

Specific vision elements included:

- Policies are more definitive to minimize the flexibility of the PM.

- There will be gates at the acquisition milestones to assess technical data.

- Gaining the ownership of the technical data.

- There will be accountability of the PM for the responsibility of obtaining technical data.

- Full understanding of the value of the technical data across the life cycle.

- DLIS (Defense Logistics Information Service - sub-agency of DLA) will have the provisioning data at the right time (before systems are deployed).

- Doesn't limit innovation and competition in the marketplace.

- Consistency of flow down requirements terminology

- Every branch of service exchanges data in a neutral format.

- Policy is written in such a way that it remains timeless, so as to remain priceless.

- Implement and utilize commercial standards when and where appropriate.

- Agnostic viewer software is readily available and free.

- Existing data rights are understood and controlled.

\subsubsection{Issues and Solutions}

After identifying and discussing the deficiencies, barriers, and emerging best practices that relate to the implementation and management of policies that significantly impact TDPs, the Policy Management breakout group used the information to formulate fifteen significant issues for further discussion as listed below. There is no single entity accountable for technical data policy within OSD.

- Decision makers and policy makers who have the ability to mandate what should be done do not do so... fully appreciate total life cycle costs. 
- Short term goals/objectives/drivers within program offices do not optimize life cycle sustainment costs. (The PM is being rewarded for short term successes rather than long term capabilities/requirements. Furthermore, the PM is not accountable to stakeholders and not held responsible for long term shortcomings.) Short term management cycles accentuate lack of accountability.

- The de facto process does not include a timely provisioning process to include the Defense Logistics Information Service (DLIS).

- Current data rights are not uniformly or adequately understood and exercised.

- There is a lack of common terms, definitions, and industry standards within DoD policy and contractual flow-down documents with respect to technical data.

- Explicit direction on TDP content and delivery (CDRLs) is not given to the contractor.

- Fidelity and robustness of technical data contractually requested often does not provide what is really needed for sustainment.

- The process of receiving data does not include a rigorous feedback loop for validating that the requested information has been received. The tech data procurement and receiving people are not communicating effectively.

- Parts demand data is not captured and provided to the DoD on contractor logistics support / performance-based logistics (CLS/PBL) contracts. Risk mitigation plans and requirements are not included in the language.

- Software OEMs don't fully support data interoperability standards.

- Engineering Data Managers are "disappearing" and along with them the knowledge of what a TDP should include.

- Providers (program management and procurement personnel) to the data users (DLA parts providers, codifiers of the info, packaging people, depots, warfighter) are not educated in the technical data and data-rights environment.

- AS-9102 (First Article Inspection Report) is not currently required to be included as a part of the TDP.

- Industry knowledge of LOTAR (AN-9300 standards) practices is incomplete.

The complete list of fifteen issues and all of their associated solutions are tabulated in Appendix A-4. The top 10 issues and their associated solutions are discussed below. The 10 high priority solutions placed on the large group's voting ballot are highlighted in yellow.

\section{Section format}

D.x Issue

\section{D.x.y Solution}

D.1 There is no single entity accountable for technical data policy within OSD. The requirements to acquire a TDP as part of an acquisition are scattered throughout the policies, instructions, manuals, FARS and DFARS to which an acquisition manager must comply. They are not consistent and sometimes only peripherally related to the TDP.

D.1.1 Need to revisit DoD 5000.02 to better address TDP policy. 
D.1.2 Require a technical data engineering data management plan (EDMP) evaluation at each milestone review by an oversight board.

D.1.3 Develop an oversight board that contains the data stakeholders.

D.1.4 Ensure that the life cycle support plan (LCSP) includes the cost and value requirements of TDP.

D.2 Decision makers and policy makers who have the ability to mandate what should be done do not do so. Acquisition managers need to fully appreciate total life cycle costs. High level managers do not seem to fully appreciate that the largest portion of the life-cycle cost of a system is accrued during its operational phase and acquisition managers should pay to acquire information that will reduce overall cost.

D.2.1 Review the training program so that technical data is understood.

D.2.2 Implement accountability requirements associated with LCSPs.

D.3 Short term goals/objectives/drivers within program offices do not optimize life cycle sustainment costs. The PM is being rewarded for short term successes rather than long term capabilities/requirements. Furthermore, the PM is not accountable to stakeholders and not held responsible for long term shortcomings. Short term management cycles accentuate lack of accountability.

D.3.1 Create a rating associated with LCSP for the weapons system that is irrespective of the program manager.

D.4 The de facto process does not include a timely provisioning process to include the Defense Logistics Information Service (DLIS). The current stage gate process for major acquisitions does not include DLIS representatives in the early-on critical reviews and decision gates. They often aren't invited until much later in the process where changes are much more difficult to effect.

D.4.1 A stronger policy statement is needed to ensure participation. Revise DoDI 5000.02 and/or the DAG.

D.4.2 Ensure that an objective assessment of provisioning actions occurs during the acquisition milestone process.

D.4.3 Enforce the requirement for DLIS participation at milestone review " $B$ " and beyond.

D.4.4 Establish/ensure a system to address modification updates affecting provisioning groups.

D.4.5 Include DLIS partnership/participation with the MILSVC in the SOW-generation process.

D.5 Current data rights are not uniformly or adequately understood and exercised. The government has certain rights to data associated with articles it procures. The rights are not fully understood by all acquisition managers and thus not acquired during the normal acquisition process. This is especially true if the vendor "pushes" back or disagrees. This is a normal part of negotiating a contract but only experienced acquisition personnel fully understand what is required to get what the government is paying for.

D.5.1 Add more resource Engineering Data Management Officers (EDMO) to the degree required to exercise technical data rights adequately.

D.5.2 Provide/require training for all participants in the acquisition process. 


\section{D.5.3 Revise DoD 5000.02 to include Redstone Arsenal (Dayne Beam) recommended changes regarding GAO 06839 (Data Rights) report.}

D.6 There is a lack of common terms, definitions, and industry standards within DoD policy and contractual flow-down documents with respect to technical data. Each service has its' own data dictionary and technical definitions. Each is defined with the services' particular flavor and thus different between the services. In time this can lead to substantial differences in these definitions and interpretation problems especially on joint service projects.

D.6.1 Develop an authoritative glossary of terms and include it as a standard source document in an updated Defense Acquisition Guidebook.

D.6.2 Evaluate existing industry standards to be used as references for authoritative definitions.

D.7 Explicit direction on TDP content and delivery (CDRLs) is not given to the contractor. Vendors have become very good at giving the government exactly what was asked for in a contract and nothing more. Calling for a TDP is not sufficient. It must be defined explicitly and sufficiently before we can get all that we need.

\section{D.7.1 Update MIL STD 31000 to have more explicit information on TDP content and delivery requirements.}

D.7.2 Establish a team to advise policy makers regarding technical data format delivery.

D.7.3 Require that model-based TDPs specifying native-format files must also include validated neutral-format files (e.g. Pro-E and STEP-APs).

D.8 Fidelity and robustness of technical data contractually requested often does not provide what is really needed for sustainment. The current documents specifying the content and format of a TDP are insufficient and can fail to require important critical information

\section{D.8.1 Support the enhancement of ASME Y14.41 and other relevant standards.}

D.8.2 Ensure that all relevant contractual "boiler plate" references (both industry and military) are identified and included in requirements documents.

D.8.3 Review DOT FAA Order 8110.4 as an example of best practice for how to define the constituents of the TDP and engage with the AIA EMC (Engineering Management Committee) to provide guidance on TDP definitions.

D.9 The process of receiving data does not include a rigorous feedback loop for validating that the requested information has been received. The tech data procurement and receiving people are not communicating effectively. This issue has to do with evaluating the TDP received as a completion of a CDRL. The current process for validating that the TDP is sufficient does not guarantee that it really is. There is no standard method for assuring its validity

\section{D.9.1 Ensure that in-process reviews are part of contractual requirements.}

D.9.2 Ensure that Integrated Product Teams (IPTs) have procedures that define roles and responsibilities with respect to TDP life cycle support; if not, create them.

D.9.3 Enhance existing tools such as Smart-T and Sys-Par to assist in implementation of policy, and ensure that the tools are DoD wide. (Intelligent Specification Assistant) 
D.10 Parts demand data is not captured and provided to the DoD on contractor logistics support / performance-based logistics (CLS/PBL) contracts. Risk mitigation plans and requirements are not included in the language.

D.10.1 Demand data should be provided regardless of sustainment/procurement method.

D.10.2 Configuration data should always be provided regardless of sustainment/procurement method.

D.10.3 Include exit-strategy in CLS/PBL contracts to mitigate risks.

D.10.4 Review the Quadrennial Defense Review (QDR) solution for form, fit, and function definition to ensure that it is adequate, and take action as necessary.

\section{Policy Team Balloted Prioritized Solutions:}

The Policy Team's listing of its top ten solutions as presented on the voting ballot at the end of the workshop follow:

D.3.1 Create a rating associated with LCSP (life cycle support plan) for the weapons system that is independent of the program manager. Such a rating could be used in the evaluation of the program manager's performance.

D.4.2 Ensure that an objective assessment of provisioning actions occurs during the acquisition milestone process, and enforce the requirement for Defense Logistics Information Service (DLIS) participation.

D.6.1 Develop an authoritative glossary of terms and include it as a standard source document in an updated Defense Acquisition Guidebook.

D.1.1 Revise DODI 5000.02 to better address TDP policy. In addition, a stronger policy statement is needed to ensure all stakeholder participation.(also D.4.1)

D.5.3 Revise DODI 5000.02 to include Redstone Arsenal (Dayne Beam) recommended changes regarding GAO 06839 (Data Rights) report. This would enhance the acquisition of data rights that must be acquired to effectively use the data contained in the TDP.

D.7.1 Update MIL STD 31000 to have more explicit information on TDP content and delivery all requirements.

D.8.3 Review DOT FAA Order 8110.4 as an example of best practice for data definition, and engage with the AIA EMC (Engineering Management Committee) to provide guidance on TDP definitions.

D.10.1 Replacement parts history (e.g. reliability and maintainability) data should be provided regardless of sustainment and procurement method. This assumes that some sort of central repository is available to archive the information.

D.10.2 Configuration data should always be provided regardless of sustainment or procurement method.

D.10.3 Include exit-strategy (e.g. an option for acquiring logistics/technical data) in contractor logistics support/performance-based logistics (CLS/PBL) contracts to mitigate risks. 


\section{Full Group Prioritization and Resulting Nuggets}

Following the small group sessions the whole assembly returned to the large room for each group to present their top, approximately 10 solutions. They were all asked to view these presentations from a high level and judge the importance of the individual solutions from that strategic view. The results are shown below in Figure 7. The unique identifier for each of the solutions is shown in Table 5.

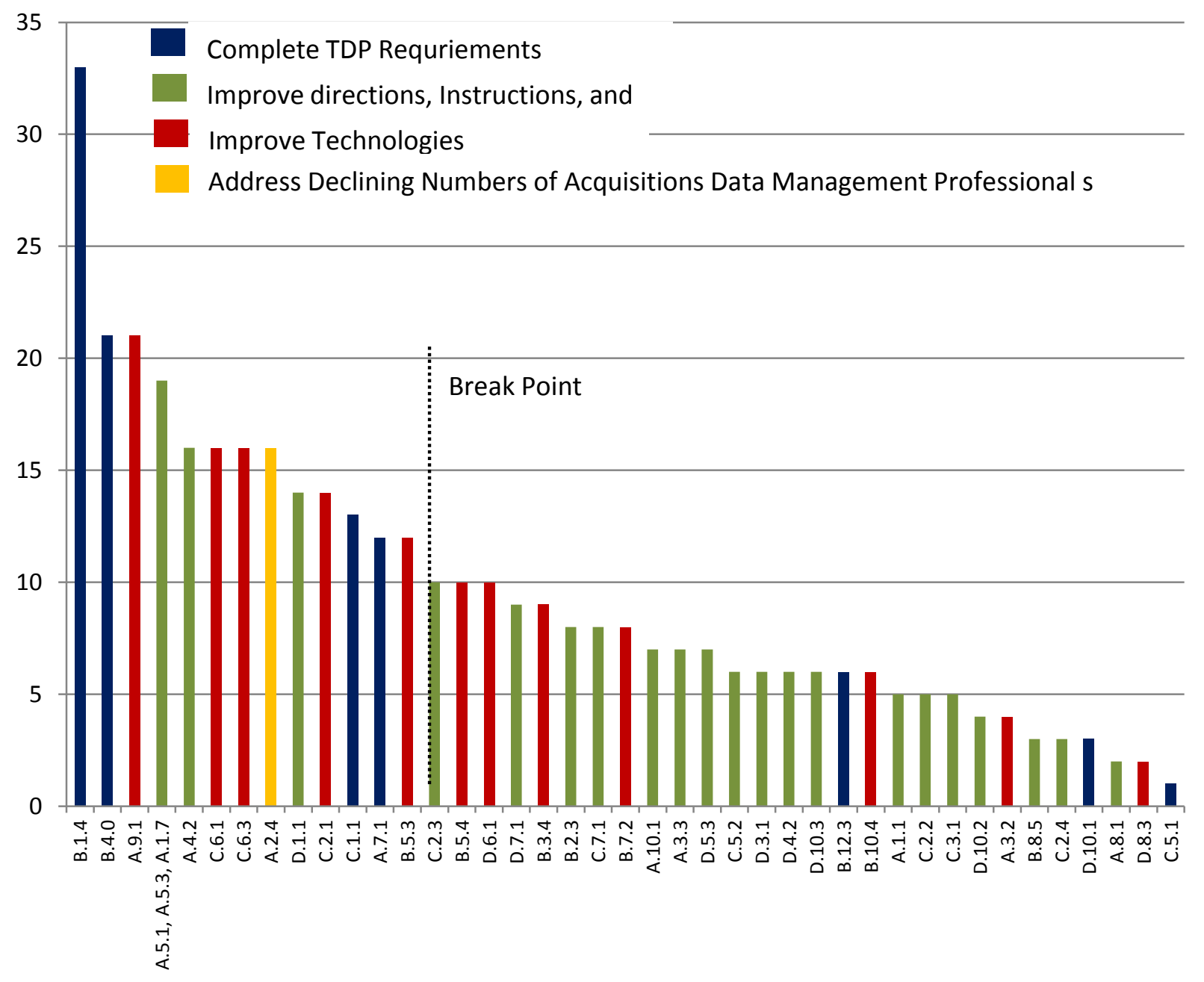

Figure 7 Large Group ranking by importance and urgency

Table 5 List of high priority solutions from each small group.

\begin{tabular}{|l|l|}
\hline $\begin{array}{l}\text { Unique } \\
\text { Identifier }\end{array}$ & Title \\
\hline A.1.1 & Establish a check-list of Data requirements at Data Call. \\
\hline A.2.4 & $\begin{array}{l}\text { Establish training, certification, and knowledge capture to address declining workforce } \\
\text { issues for Acquisition Data Management professionals. }\end{array}$ \\
\hline
\end{tabular}




\begin{tabular}{|c|c|}
\hline $\begin{array}{l}\text { Unique } \\
\text { Identifier }\end{array}$ & Title \\
\hline A.3.2 & $\begin{array}{l}\text { Establish funding and identify expertise between services to develop and implement } \\
\text { an automated tool for the acquisition of TDPs. Plus - A.7.2 Expand SYSPARS to } \\
\text { incorporate an automated tool to develop TDP requirements (CDRL, SOWs, } \\
\text { worksheets). }\end{array}$ \\
\hline A.3.3 & $\begin{array}{l}\text { Reconvene an OSD advisory group to identify and promote critical needs create a } \\
\text { uniform standard for conducting business for TDPs requirements (A.2.3). }\end{array}$ \\
\hline A.4.2 & $\begin{array}{l}\text { Accountability of decisions made by PM that extends beyond tenure for the acquisition } \\
\text { (investigate UK example). }\end{array}$ \\
\hline $\begin{array}{l}\text { A.5.1, A.5.3, } \\
\text { A.1.7 }\end{array}$ & $\begin{array}{l}\text { Mandated participation of all stakeholders/SMEs at Data Call and throughout the } \\
\text { program, including IP Attorney experienced in data acquisition contractual issues. }\end{array}$ \\
\hline A.7.1 & $\begin{array}{l}\text { Revise MIL-STD- } 31000 \text { to consolidate requirements for the three TDP levels currently } \\
\text { defined as separate (conceptual, developmental, and production) }\end{array}$ \\
\hline A.8.1 & $\begin{array}{l}\text { Apply TDP requirements and related decisions must be evaluated to make sure } \\
\text { contractor dependence is not increased. Apply early and maintain through-out } \\
\text { contract. }\end{array}$ \\
\hline A.9.1 & $\begin{array}{l}\text { Require native, neutral, and viewable formats for the entire supply chain. Ensure that } \\
\text { transportable, shareable, usable, clearly identifiable formats are established at Data } \\
\text { Call. }\end{array}$ \\
\hline A.10.1 & $\begin{array}{l}\text { Require all programs to adjudicate and validate all of contractor data rights assertions. } \\
\text { DFARS requirement today, seen as an option. }\end{array}$ \\
\hline B.1.4 & Create a comprehensive description of the data required for the TDP. \\
\hline B.2.3 & Define best practices and standards for MBE and mechanisms for enforcing them. \\
\hline B.3.4 & $\begin{array}{l}\text { Conduct an ROI analysis substantiation MBE value and communicate to PMs and PEOs. } \\
\text { (consensus). }\end{array}$ \\
\hline B.4.0 & Provide adequately annotated models. \\
\hline B.5.3 & $\begin{array}{l}\text { Develop a validated translation process for delivering TDP information to the } \\
\text { government. Establish an independent validation authority (could be design check } \\
\text { software). }\end{array}$ \\
\hline B.5.4 & Extend the STEP standards to fully address interoperability requirements. \\
\hline B.7.2 & $\begin{array}{l}\text { Establish manufacturing (including the extended enterprise) use cases that } \\
\text { communicate exactly what the government needs in a TDP and why. Include narrative } \\
\text { documents with geometric data. }\end{array}$ \\
\hline B.8.5 & $\begin{array}{l}\text { Achieve an MBE presence and voice in IT strategy. This will be accomplished by } \\
\text { participation in forums and meetings. }\end{array}$ \\
\hline B.10.4 & $\begin{array}{l}\text { Provide a robust tool set that supports the migration of } 2 \mathrm{D} \text { models to } 3 \mathrm{D} \text { models } \\
\text { including the capture of relevant information and the migration of un-annotated 3D } \\
\text { models to be compliant with new requirements. }\end{array}$ \\
\hline
\end{tabular}




\begin{tabular}{|c|c|}
\hline $\begin{array}{l}\text { Unique } \\
\text { Identifier }\end{array}$ & Title \\
\hline B.12.3 & $\begin{array}{l}\text { Develop and distribute the DEDMWG strategic plan as a guidance document to } \\
\text { industry. }\end{array}$ \\
\hline C.1.1 & Develop and publish DoD TDP standard and related documents. \\
\hline C.2.1 & Expand use of Automated tools - SYSPARS/SMART-T. \\
\hline C.2.2 & Institutionalize involvement policies across Services. \\
\hline C.2.3 & Develop appropriate contract language and clauses - tied to standard. \\
\hline C.2.4 & Assess execution activity - to confirm delivery of TDP. \\
\hline C.3.1 & Define who, how, and when in conjunction with policy development. \\
\hline C.5.1 & Develop requirements to utilize Global Combat Support Systems (GCSS) efforts. \\
\hline C.5.2 & $\begin{array}{l}\text { Develop and establish a policy for an official master authoritative data source for each } \\
\text { TDP. }\end{array}$ \\
\hline C.6.1 & Define modern repository requirements and architecture options. \\
\hline C.6.3 & $\begin{array}{l}\text { Develop and prove out capability to link TDPs to tech documents and other } \\
\text { deliverables. }\end{array}$ \\
\hline C.7.1 & $\begin{array}{l}\text { Continue to push for parts management and leverage in progress Services and DLA } \\
\text { activities. }\end{array}$ \\
\hline D.1.1 & $\begin{array}{l}\text { Need to revisit DoD } 5000.02 \text { to better address TDP policy. In addition, a stronger policy } \\
\text { statement is needed to ensure all stakeholder participation. Revise DoD I5000.02 } \\
\text { and/or the DAG (D.4.1). }\end{array}$ \\
\hline D.3.1 & $\begin{array}{l}\text { Create a rating associated with LCSP (life cycle support plan) for the weapons system } \\
\text { that is irrespective of the program manager. }\end{array}$ \\
\hline D.4.2 & $\begin{array}{l}\text { Ensure that an objective assessment of provisioning actions occurs during the } \\
\text { acquisition milestone process, and enforce the requirement for Defense Logistics } \\
\text { Information Service (DLIS) participation. }\end{array}$ \\
\hline D.5.3 & $\begin{array}{l}\text { Revise DoD } 5000.02 \text { to include Redstone Arsenal (Dayne Beam) recommended changes } \\
\text { regarding GAO } 06839 \text { (Data Rights) report. }\end{array}$ \\
\hline D.6.1 & $\begin{array}{l}\text { Develop an authoritative glossary of terms and include it as a standard source } \\
\text { document in an updated Defense Acquisition Guidebook. }\end{array}$ \\
\hline D.7.1 & $\begin{array}{l}\text { Update MIL STD } 31000 \text { to have more explicit information on TDP content and delivery } \\
\text { all requirements. }\end{array}$ \\
\hline D.8.3 & $\begin{array}{l}\text { Review DOT FAA Order } 8110.4 \text { as an example of best practice for data definition*, and } \\
\text { engage with the AIA EMC (Engineering Management Committee) to provide guidance } \\
\text { on TDP definitions. *(Defines the constituents of the TDP.) }\end{array}$ \\
\hline D.10.1 & $\begin{array}{l}\text { Replacement parts history (e.g. reliability and maintainability) data should be provided } \\
\text { regardless of sustainment/procurement method. }\end{array}$ \\
\hline
\end{tabular}




\begin{tabular}{|l|l|}
\hline $\begin{array}{l}\text { Unique } \\
\text { Identifier }\end{array}$ & Title \\
\hline D.10.2 & $\begin{array}{l}\text { Configuration data should always be provided regardless of sustainment/procurement } \\
\text { method. }\end{array}$ \\
\hline D.10.3 & $\begin{array}{l}\text { Include exit-strategy (e.g. an option for acquiring logistics/technical data) in contractor } \\
\text { logistics support/performance-based logistics (CLS/PBL) contracts to mitigate risks. }\end{array}$ \\
\hline
\end{tabular}

\subsection{Analysis}

An analysis of these top 41 solutions reveals that there are at least four types of solutions recommended. Twenty-one of these solutions dealt with a need for improvements in directives, instructions, and/or policies. Three of these were ranked in the top 13 in the final balloting. These solutions called for stronger and clearer directions regarding the acquisition of technical data packages and included somehow increasing the importance of acquiring the TDP to the acquisition manager. Seven called for better definition of technical data package's required content and the migration of that required content into the model based environment. Four of these made it into the top 13 solutions. Twelve solutions proposed improving some sort of technical capability. Five of these solutions made it into the top 13. Most of these dealt with the need for architecture, infrastructure, and other capabilities that enable model collaboration and data exchange. Finally, the single solution addressing the issue of a declining workforce of experienced acquisition data management professionals ranked $6^{\text {th }}$ overall. Grouped according to these four categories the best of the best solutions are listed below.

\section{TDP Definition}

1. Create a comprehensive description of the data required for the TDP (B.1.4).

2. Develop and publish DoD TDP standard and related documents (C.1.1).

3. Revise MIL-STD-31000 to consolidate requirements for the three TDP levels currently defined as separately (A.7.1).

4. Develop a validated translation process for delivering TDP information to the government. Establish an independent validation authority (B.5.3).

\section{Improved direction, instructions, or policies}

1. Mandate participation of all stakeholders / SMEs at Data Call and throughout the program, including IP attorney experienced in data acquisition contractual issues. (A.5.1, A.5.3, A.1.7).

2. Make accountability of decisions made by PM extend beyond tenure for acquisition, i.e. UK example (A.4.2).

3. Revisit DODI 5000.02 to better address TDP policy. In addition, a stronger policy statement is needed to ensure all stakeholder participation. Revise DoDI 5000.02 and/or the DAG (D.1.1 \& D.4.1).

\section{Technology Development}

1. Require native, neutral, and viewable formats for the entire supply chain. Ensure that transportable, shareable, usable, clearly identifiable formats are established at Data Call.

2. Define modern repository requirements and architecture options (C.6.1). 
3. Develop and prove out capability to link TDPs to tech documents and other deliverables (C.6.3).

4. Provide adequately annotated models.

5. Expand use of automated tools, i.e. SYSPARS \& SMART-T (C.2.1).

\section{Diminishing Experts}

1. Establish training, certification, and knowledge capture to address declining workforce issues for acquisition data management professionals. 
APPENDICES 


\section{A-1 Group A. Acquisition Issues and Solutions Table}

Yellow highlighted below means these items given the highest priority by the group.

\begin{tabular}{|c|c|c|c|}
\hline ID & \multicolumn{3}{|l|}{ Issue/Need Description } \\
\hline A.1 & \multicolumn{3}{|c|}{$\begin{array}{l}\text { Limited enforcement of DFARS, e.g. requirement for separately priced data from hardware (e.g. } \\
\text { TDP/TM). }\end{array}$} \\
\hline \multirow[b]{2}{*}{ ID } & \multirow[b]{2}{*}{ Solution } & \multicolumn{2}{|l|}{ Timing } \\
\hline & & $\begin{array}{l}\text { Start } \\
\text { Year } 0 \\
1,2 \ldots\end{array}$ & $\begin{array}{l}\text { Duratio } \\
\text { n Years }\end{array}$ \\
\hline A.1.1 & $\begin{array}{l}\text { Establish a check-list at project start-up itemizing established contract } \\
\text { requirements for data and data rights, and have it signed by contractor } \\
\text { that they agree. }\end{array}$ & 0 & 2 \\
\hline A.1.2 & $\begin{array}{l}\text { Periodic mandatory compliance and verification through out the life- } \\
\text { cycle. }\end{array}$ & & \\
\hline A.1.3 & $\begin{array}{l}\text { Add performance against project check-list to CPARS check-list. Allow } \\
\text { OEM to correct non-compliance. }\end{array}$ & & \\
\hline A.1.4 & $\begin{array}{l}\text { Report to GAO/IG for enforcement of DFARS clause (rights of data, } \\
\text { separate price of data). }\end{array}$ & & \\
\hline A.1.5 & Require a General Officer signature when out of compliance. & 0 & 5 \\
\hline A.1.6 & $\begin{array}{l}\text { System that assists navigation to specific DFARS clauses, not just title } \\
\text { and number. }\end{array}$ & & \\
\hline A.1.7 & $\begin{array}{l}\text { Include as a stakeholder an IP Attorney experienced in data acquisition } \\
\text { contractual issues. }\end{array}$ & 0 & 3 \\
\hline ID & \multicolumn{3}{|l|}{ Issue/Need Description } \\
\hline A.2 & \multicolumn{3}{|c|}{$\begin{array}{l}\text { Lack of career path and training for Acquisition Data Management personnel (includes } \\
\text { Engineering Data Management officers) and other stakeholders for the understanding and } \\
\text { establishment of TDP requirements. }\end{array}$} \\
\hline \multirow[b]{2}{*}{ ID } & & \multicolumn{2}{|l|}{ Timing } \\
\hline & Solution (add Metric for Success for "Top" Solutions) & $\begin{array}{l}\text { Start } \\
\text { Year } 0 \\
1,2 \ldots\end{array}$ & $\begin{array}{l}\text { Duratio } \\
\text { n Years }\end{array}$ \\
\hline A.2.1 & $\begin{array}{l}\text { Establish a cross-functional DoD/Engineering Data Management working } \\
\text { group to offer training, identify training resources, bring awareness, } \\
\text { brainstorm, and encourage standardization across DoD; group should } \\
\text { meet at least semi-annually. }\end{array}$ & 0 & 5 \\
\hline A.2.2 & $\begin{array}{l}\text { Promote awareness and communicate via DAU DM Community of } \\
\text { Practice. https://acc.dau.mil/dm }\end{array}$ & & \\
\hline
\end{tabular}




\begin{tabular}{|c|c|c|c|}
\hline A.2.3 & $\begin{array}{l}\text { Publicize "horror stories" and exemplars showing the cost of ineffective } \\
\text { TDP acquisitions practices, to increase awareness of the values and } \\
\text { benefits of increased capability and redirection of cost. Raise } \\
\text { awareness/make visible GAO reports concerning TDP impact. }\end{array}$ & 0 & 2 \\
\hline A.2.4 & $\begin{array}{l}\text { Establish a career field and multi-level certification criteria in DAU for } \\
\text { Acquisition Data Management professionals. }\end{array}$ & 0 & 5 \\
\hline A.2.5 & $\begin{array}{l}\text { Establish and maintain capability inventory showing current and } \\
\text { projected levels of expertise in Acquisition Data Management. }\end{array}$ & & \\
\hline A.2.6 & $\begin{array}{l}\text { Perform a Desktop Study to assess job requirements and staffing needed } \\
\text { to effectively perform Acquisition Data Management. Use results to both } \\
\text { classify and determine staffing requirements. }\end{array}$ & 0 & 5 \\
\hline ID & \multicolumn{3}{|l|}{ Issue/Need Description } \\
\hline A.3 & \multicolumn{3}{|c|}{$\begin{array}{l}\text { Diminishing supply of TDP knowledge/expertise for Technical Data Management and other } \\
\text { stakeholders. }\end{array}$} \\
\hline \multirow[b]{2}{*}{ ID } & \multirow[b]{2}{*}{ Solution (add Metric for Success for "Top" Solutions) } & \multicolumn{2}{|l|}{ Timing } \\
\hline & & $\begin{array}{l}\text { Start } \\
\text { Year } 0 \\
1,2 \ldots\end{array}$ & $\begin{array}{l}\text { Duratio } \\
\mathrm{n} \text { Years }\end{array}$ \\
\hline A.3.1 & $\begin{array}{l}\text { Establish a searchable knowledge base repository with links to } \\
\text { standards, regulations, policies, directives, instructions, and guidance, } \\
\text { and with an intuitive interface customizable to the user's needs. This } \\
\text { may be an extension of existing tools. }\end{array}$ & 0 & 5 \\
\hline A.3.2 & $\begin{array}{l}\text { Establish funding and identify expertise between services to develop and } \\
\text { implement an automated tool to assist the acquisition of TDPs. }\end{array}$ & 0 & 2 \\
\hline A.3.3 & $\begin{array}{l}\text { Reconvene an OSD advisory group to identify and promote critical needs } \\
\text { and to create a uniform standard for conducting business for TDPs } \\
\text { requirements. }\end{array}$ & 0 & 2 \\
\hline A.3.4 & $\begin{array}{l}\text { Establish a system to capture and disseminate the knowledge and } \\
\text { expertise of existing Acquisition Data Management professionals. }\end{array}$ & 0 & 5 \\
\hline ID & \multicolumn{3}{|l|}{ Issue/Need Description } \\
\hline A.4 & \multicolumn{3}{|c|}{$\begin{array}{l}\text { Lack of accountability and enforcement by Contracting Officers (KO) and PMs for TDPs. The } \\
\text { length of acquisition cycle exceeds the length of PM involvement (PM in office for } 2 \text { years; } \\
\text { makes short-term decisions). }\end{array}$} \\
\hline \multirow[b]{2}{*}{ ID } & \multirow[b]{2}{*}{ Solution (add Metric for Success for "Top" Solutions) } & \multicolumn{2}{|l|}{ Timing } \\
\hline & & $\begin{array}{l}\text { Start } \\
\text { Year } 0 \\
1,2 \ldots\end{array}$ & $\begin{array}{l}\text { Duratio } \\
\mathrm{n} \text { Years }\end{array}$ \\
\hline A.4.1 & $\begin{array}{l}\text { Establish a governance structure to clearly define decisions needed and } \\
\text { authorities to make them and verify/document that they have been }\end{array}$ & 0 & 5 \\
\hline
\end{tabular}




\begin{tabular}{|c|c|c|c|}
\hline & made. & & \\
\hline A.4.2 & $\begin{array}{l}\text { Accountability for acquisition decisions made by PM that extends } \\
\text { beyond his/her tenure (investigate U.K. example). }\end{array}$ & 0 & 5 \\
\hline ID & \multicolumn{3}{|l|}{ Issue/Need Description } \\
\hline A.5 & \multicolumn{3}{|l|}{ Lack of all stakeholder involvement in establishing requirements for TDPs } \\
\hline \multirow[b]{2}{*}{ ID } & \multirow[b]{2}{*}{ Solution (add Metric for Success for "Top" Solutions) } & \multicolumn{2}{|l|}{ Timing } \\
\hline & & $\begin{array}{l}\text { Start } \\
\text { Year } 0 \\
1,2\end{array}$ & $\begin{array}{l}\text { Duratio } \\
\mathrm{n} \text { Years }\end{array}$ \\
\hline A.5.1 & $\begin{array}{l}\text { Mandated participation of all stakeholders/SMEs at Data Call and } \\
\text { throughout program. }\end{array}$ & 0 & 3 \\
\hline A.5.2 & Engineering Management Data plan identifies all stakeholders. & & \\
\hline A.5.3 & $\begin{array}{l}\text { Include as a stakeholder an IP Attorney experienced in data acquisition } \\
\text { contractual issues. }\end{array}$ & 0 & 3 \\
\hline ID & \multicolumn{3}{|l|}{ Issue/Need Description } \\
\hline A.6 & \multicolumn{3}{|c|}{$\begin{array}{l}\text { Decisions related to Contracted Logistic Support (CLS) or PBL; argument too often used to } \\
\text { remove TDP requirement in early procurements. Later modifications result in custom versions. } \\
\text { No defined exit strategies in contract when previous decisions are altered - must also alter TDP } \\
\text { decisions. }\end{array}$} \\
\hline \multirow[b]{2}{*}{ ID } & \multirow[b]{2}{*}{ Solution (add Metric for Success for "Top" Solutions) } & \multicolumn{2}{|l|}{ Timing } \\
\hline & & $\begin{array}{l}\text { Start } \\
\text { Year } 0 \\
1,2 \ldots\end{array}$ & $\begin{array}{l}\text { Duratio } \\
\mathrm{n} \text { Years }\end{array}$ \\
\hline A.6.1 & $\begin{array}{l}\text { At Data Call, establish requirement for the exit strategy in contract, i.e. } \\
\text { data access at scheduled intervals with clearly defined physical delivery } \\
\text { requirements. }\end{array}$ & 0 & 2 \\
\hline A.6.2 & $\begin{array}{l}\text { Establish requirements for data in specified formats in SOW/CDRL } \\
\text { regardless of ACAT category. }\end{array}$ & 0 & 2 \\
\hline ID & \multicolumn{3}{|l|}{ Issue/Need Description } \\
\hline A.7 & \multicolumn{3}{|c|}{$\begin{array}{l}\text { Standards are not concise and complete; lack of guidance for obtaining/navigating standards. } \\
\text { MIL-STD-31000 has too many options/disconnects opportunities for special procurement items } \\
\text { (e.g. DIDs - special, commercial, developmental, tooling, etc). For example, completion of DD- } \\
\text { 1423; need to know where to go to get appropriate requirements. }\end{array}$} \\
\hline \multirow[b]{2}{*}{ ID } & & \multicolumn{2}{|l|}{ Timing } \\
\hline & Solution (add Metric for Success for "Top" Solutions) & $\begin{array}{l}\text { Start } \\
\text { Year } 0 \\
1,2\end{array}$ & $\begin{array}{l}\text { Duratio } \\
\mathrm{n} \text { Years }\end{array}$ \\
\hline A.7.1 & Revise MIL-STD-31000 to consolidate requirements for the three TDP & 0 & 1 \\
\hline
\end{tabular}




\begin{tabular}{|c|c|c|c|}
\hline & $\begin{array}{l}\text { levels currently defined as separate (conceptual, developmental, and } \\
\text { production) }\end{array}$ & & \\
\hline A.7.2 & $\begin{array}{l}\text { Expand SYSPARS to incorporate an automated tool to assist developing } \\
\text { TDP requirements (CDRL, SOWs, worksheets) }\end{array}$ & 0 & 2 \\
\hline A.7.3 & $\begin{array}{l}\text { Create a standards knowledge base for navigating and linking standards } \\
\text { and other relevant guidance. }\end{array}$ & 0 & 5 \\
\hline ID & \multicolumn{3}{|l|}{ Issue/Need Description } \\
\hline A.8 & \multicolumn{3}{|c|}{$\begin{array}{l}\text { Current TDP practices and decisions result in increased vendor dependence and ever increasing } \\
\text { costs. }\end{array}$} \\
\hline \multirow[b]{2}{*}{ ID } & \multirow[b]{2}{*}{ Solution (add Metric for Success for "Top" Solutions) } & \multicolumn{2}{|l|}{ Timing } \\
\hline & & $\begin{array}{l}\text { Start } \\
\text { Year } 0 \\
1,2 \ldots\end{array}$ & $\begin{array}{l}\text { Duratio } \\
\mathrm{n} \text { Years }\end{array}$ \\
\hline A.8.1 & $\begin{array}{l}\text { Apply TDP requirements and evaluate all related decisions to make sure } \\
\text { contractor dependence is not increased. Do this early and maintain } \\
\text { throughout contract. }\end{array}$ & 1 & 3 \\
\hline A.8.2 & $\begin{array}{l}\text { Establish metrics to represent the level of contractor dependency in an } \\
\text { acquisition, including the ability to track changes to TDP requirements. }\end{array}$ & & \\
\hline ID & \multicolumn{3}{|l|}{ Issue/Need Description } \\
\hline A.9 & \multicolumn{3}{|c|}{ Lack of standard delivered TDP formats and interfaces causes excess cost and complexity. } \\
\hline \multirow[b]{2}{*}{ ID } & \multirow[b]{2}{*}{ Solution (add Metric for Success for "Top" Solutions) } & \multicolumn{2}{|l|}{ Timing } \\
\hline & & $\begin{array}{l}\text { Start } \\
\text { Year } 0 \\
1,2 \ldots\end{array}$ & $\begin{array}{l}\text { Duratio } \\
\text { n Years }\end{array}$ \\
\hline A.9.1 & $\begin{array}{l}\text { Require native, neutral, and viewable formats for the entire supply } \\
\text { chain. Ensure that transportable, shareable, usable, clearly identifiable } \\
\text { formats are established at Data Call. }\end{array}$ & 1 & 2 \\
\hline A.9.2 & Standardize metadata requirements within the TDP across DoD. & & \\
\hline ID & \multicolumn{3}{|l|}{ Issue/Need Description } \\
\hline A.10 & \multicolumn{3}{|c|}{$\begin{array}{l}\text { We don't adjudicate OEM assertions of proprietary or other data rights restrictions even though } \\
\text { the burden of proof is on the OEM (since NDAA 07). }\end{array}$} \\
\hline \multirow[b]{2}{*}{ ID } & \multirow[b]{2}{*}{ Solution (add Metric for Success for "Top" Solutions) } & \multicolumn{2}{|l|}{ Timing } \\
\hline & & $\begin{array}{l}\text { Start } \\
\text { Year } 0 \\
1,2 \ldots\end{array}$ & $\begin{array}{l}\text { Duratio } \\
\mathrm{n} \text { Years }\end{array}$ \\
\hline A.10.1 & $\begin{array}{l}\text { Require all programs to adjudicate and validate all of contractor data } \\
\text { rights assertions. It is a DFARS requirement today, but seen as an option. }\end{array}$ & 0 & 3 \\
\hline ID & \multicolumn{3}{|l|}{ Issue/Need Description } \\
\hline
\end{tabular}




\begin{tabular}{|l|l|l|l|}
\hline A.11 & No systematic processes/validation tools for 2D or 3D/MBD. & \multicolumn{3}{|l|}{ Timing } \\
\cline { 3 - 4 } ID & & $\begin{array}{l}\text { Start } \\
\text { Year } 0, \\
1,2 \ldots\end{array}$ & $\begin{array}{l}\text { Duratio } \\
n \text { Years }\end{array}$ \\
\hline A.11.1 & Update 20-year old guidance data. & & \\
\hline A.11.2 & Use DAU DMCoP group to identify and share Best Practices within DoD. & & \\
\hline A.11.3 & Develop a formal verification/validation process used by all DoD entities. & 0 & 2 \\
\hline
\end{tabular}




\section{A-2 Group B. Production, Planning, and Design Table}

Yellow highlighted below means these items received the highest number of group votes.

Grey highlighted below means these items were considered by the group to be important

\begin{tabular}{|c|c|c|c|}
\hline ID & \multicolumn{3}{|l|}{ Issue/Need Description } \\
\hline B.1 & \multicolumn{3}{|l|}{ The requirements and the data to develop a TDP are not available } \\
\hline \multirow[b]{2}{*}{ ID } & \multirow[b]{2}{*}{ Solution (add Metric for Success for "Top" Solutions) } & \multicolumn{2}{|l|}{ Timing } \\
\hline & & $\begin{array}{l}\text { Start } \\
\text { Years } \\
0,1,2 \ldots\end{array}$ & $\begin{array}{l}\text { Duratio } \\
\text { n Years }\end{array}$ \\
\hline B.1.1 & $\begin{array}{l}\text { Evaluate existing standards to define the degree to which they address the } \\
\text { need }\end{array}$ & $S$ & S \\
\hline B.1.2 & $\begin{array}{l}\text { Evaluate and evolve coordinated contractual language to incorporate MBE } \\
\text { in the TDP (it must include all stakeholders in the procurement process) }\end{array}$ & $S$ & $\begin{array}{l}\text { evaluate } \\
\text { (S) } \\
\text { evolve } \\
\text { (L) }\end{array}$ \\
\hline B.1.3 & $\begin{array}{l}\text { Create government regulations mandating the enforcement of a TDP that } \\
\text { supports MBE }\end{array}$ & M & L+ \\
\hline B.1.4 & Create a comprehensive description of the data required for the TDP. & S & S \\
\hline B.1.5 & $\begin{array}{l}\text { Create responsibility and accountability including a plan of action to } \\
\text { implement the TDP requirements }\end{array}$ & M & M \\
\hline B.1.6 & $\begin{array}{l}\text { Conduct pilot to evaluate the effectiveness and utility of the TDP structure } \\
\text { and process }\end{array}$ & M & M \\
\hline ID & \multicolumn{3}{|l|}{ Issue/Need Description } \\
\hline B.2 & \multicolumn{3}{|l|}{ A lack of MBE technology to meet requirements } \\
\hline \multirow[b]{2}{*}{ ID } & \multirow[b]{2}{*}{ Solution (add Metric for Success for "Top" Solutions) } & \multicolumn{2}{|l|}{ Timing } \\
\hline & & $\begin{array}{l}\text { Start } \\
\text { Years } \\
0,1,2 \ldots\end{array}$ & $\begin{array}{l}\text { Duratio } \\
\text { n Years }\end{array}$ \\
\hline B.2.1 & Develop a comprehensive plan for MBE & $\mathrm{S}$ & M \\
\hline B.2.2 & $\begin{array}{l}\text { Conduct benchmarking studies develop a desired architecture and identify } \\
\text { the gaps }\end{array}$ & M & M \\
\hline B.2.3 & $\begin{array}{l}\text { Define best practices and standards for MBE and mechanisms for enforcing } \\
\text { them }\end{array}$ & M & M \\
\hline
\end{tabular}




\begin{tabular}{|c|c|c|c|}
\hline B.2.4 & Create a roadmap to fill the gaps & M & M \\
\hline B.2.5 & $\begin{array}{l}\text { Create champions, secure funding and implement the plan (include } \\
\text { incentives for industry implementation) }\end{array}$ & M & M \\
\hline B.2.6 & Create contractual language that enforces requirements & $\mathrm{M+}$ & $\mathrm{L}$ \\
\hline B.2.7 & $\begin{array}{l}\text { Create a continual process of management of the plan and its } \\
\text { implementation. }\end{array}$ & M & $\mathrm{S}$ \\
\hline ID & \multicolumn{3}{|l|}{ Issue/Need Description } \\
\hline B. 3 & \multicolumn{3}{|c|}{$\begin{array}{l}\text { The acquisition professionals, PMs, and PEOs do not properly perceive the value of MBE over the } \\
\text { lifecycle. The value of the TDP is understood in some areas and not understood in others but is not } \\
\text { usually a priority. }\end{array}$} \\
\hline \multirow[b]{2}{*}{ ID } & \multirow[b]{2}{*}{ Solution (add Metric for Success for "Top" Solutions) } & \multicolumn{2}{|l|}{ Timing } \\
\hline & & $\begin{array}{l}\text { Start } \\
\text { Years } \\
0,1,2 \ldots\end{array}$ & $\begin{array}{l}\text { Duratio } \\
\mathrm{n} \text { Years }\end{array}$ \\
\hline B.3.1 & Provide separate funding for the PM to embrace and implement MBE. & S & M \\
\hline B.3.2 & $\begin{array}{l}\text { Embed MBOs (management by objective) that include total cost of } \\
\text { ownership in the PM fitness report (annual review) }\end{array}$ & M & M \\
\hline B.3.3 & $\begin{array}{l}\text { Contract based on total lifecycle costs instead of focus on short term cost } \\
\text { minimization to enable the upfront investment needed for MBE } \\
\text { implementation. Requirements in RFP. }\end{array}$ & $\mathrm{L}$ & $\mathrm{L}$ \\
\hline B.3.4 & $\begin{array}{l}\text { Conduct an ROI analysis substantiation MBE value and communicate to PMs } \\
\text { and PEOs. }\end{array}$ & $\mathrm{S}$ & $\mathrm{S}$ \\
\hline B.3.5 & $\begin{array}{l}\text { Conduct single digital master file demonstration that validates the short } \\
\text { term low cost implementation of cost saving MBE processes. }\end{array}$ & $\mathrm{S}$ & M \\
\hline B.3.6 & $\begin{array}{l}\text { Require DAU training for all acquisition professionals, PMs and PEOs on the } \\
\text { value of MBE }\end{array}$ & M & M \\
\hline B.3.7 & $\begin{array}{l}\text { Provide pervasive enterprise level training across the supply chain for MBE } \\
\text { implementation }\end{array}$ & $\mathrm{S}$ & $\mathrm{L}$ \\
\hline ID & \multicolumn{3}{|l|}{ Issue/Need Description } \\
\hline B.4 & \multicolumn{3}{|c|}{$\begin{array}{l}\text { The inability to provide adequately annotated models. There is no clear guidance to define what a } \\
\text { fully annotated model should be at each level of TDP maturity and for each purpose. }\end{array}$} \\
\hline \multirow[b]{2}{*}{ ID } & \multirow[b]{2}{*}{ Solution (add Metric for Success for "Top" Solutions) } & \multicolumn{2}{|l|}{ Timing } \\
\hline & & $\begin{array}{l}\text { Start } \\
\text { Years } \\
0,1,2 \ldots\end{array}$ & $\begin{array}{l}\text { Duratio } \\
\mathrm{n} \text { Years }\end{array}$ \\
\hline B4.1 & $\begin{array}{l}\text { Achieve a clear definition of and standards to support a fully annotated } \\
\text { model across government and industry including LOTAR. }\end{array}$ & $\mathrm{S}$ & M \\
\hline
\end{tabular}




\begin{tabular}{|c|c|c|c|}
\hline B.4.2 & $\begin{array}{l}\text { Develop and provide clear guidance on the implementation of the applicable } \\
\text { standards. }\end{array}$ & M & S \\
\hline B.4.3 & $\begin{array}{l}\text { Identify TDP content - and specifically annotation requirements at each level } \\
\text { of maturity in the product realization process. }\end{array}$ & S & M \\
\hline B.4.4 & $\begin{array}{l}\text { Develop a standard for annotation for different product types based on part } \\
\text { classification. }\end{array}$ & S & M \\
\hline B.4.5 & $\begin{array}{l}\text { Define the annotation standards to the lowest common interoperability } \\
\text { standards. } \\
\text { Complete AP } 203 \text { and AP } 233 \text { and MBE compatibility index levels and } \\
\text { mandate compatibility in the contract. }\end{array}$ & S & S \\
\hline ID & \multicolumn{3}{|l|}{ Issue/Need Description } \\
\hline B.5 & \multicolumn{3}{|c|}{ Tools do not interoperate limiting the ability to exchange information for effective collaboration. } \\
\hline \multirow[b]{2}{*}{ ID } & \multirow[b]{2}{*}{ Solution (add Metric for Success for "Top" Solutions) } & \multicolumn{2}{|l|}{ Timing } \\
\hline & & $\begin{array}{l}\text { Start } \\
\text { Years } \\
0,1,2 \ldots\end{array}$ & $\begin{array}{l}\text { Duratio } \\
\mathrm{n} \text { Years }\end{array}$ \\
\hline B.5.1 & Evaluate the current interoperability capabilities and identify the gaps. & S & S \\
\hline B.5.2 & $\begin{array}{l}\text { Provide incentives for MBE tool providers to incorporate interoperability } \\
\text { standards specifically addressing gaps. }\end{array}$ & M & $\mathrm{L}$ \\
\hline B.5.3 & $\begin{array}{l}\text { Develop a validated translation process for delivering TDP information to the } \\
\text { government. Establish an independent validation authority (could be design } \\
\text { check software) }\end{array}$ & M & M \\
\hline B.5.4 & Extend the STEP standards to fully address interoperability requirements. & $\mathrm{S}$ & $\mathrm{L}$ \\
\hline B.5.5 & $\begin{array}{l}\text { Accelerate standards development to the point that standards parallel } \\
\text { technical capability. }\end{array}$ & S & S \\
\hline B.5.6 & $\begin{array}{l}\text { Create international partnerships to leverage and assure consistency of } \\
\text { interoperability standards. }\end{array}$ & S & M \\
\hline B.5.7 & $\begin{array}{l}\text { Develop a system similar to SPC mandating the sampling of TDP packages for } \\
\text { interoperability of information for contractual compliance. }\end{array}$ & M & $\mathrm{L}$ \\
\hline B.5.8 & $\begin{array}{l}\text { Provide a government system with a validated neutral format to manage } \\
\text { access to and distribute the TDP data }\end{array}$ & M & L \\
\hline ID & \multicolumn{3}{|l|}{ Issue/Need Description } \\
\hline B.6 & \multicolumn{3}{|c|}{$\begin{array}{l}\text { The inability to assure through validation and verification the accuracy and completeness of the } \\
\text { model. There is no enforcement of the provision of validated TDPs. }\end{array}$} \\
\hline ID & Solution (add Metric for Success for "Top" Solutions) & Timing & \\
\hline
\end{tabular}




\begin{tabular}{|c|c|c|c|}
\hline & & $\begin{array}{l}\text { Start } \\
\text { Years } \\
0,1,2 \ldots\end{array}$ & $\begin{array}{l}\text { Duratio } \\
\text { n Years }\end{array}$ \\
\hline B.6.1 & $\begin{array}{l}\text { Apply existing standards and tools to achieve mutual understanding of TDP } \\
\text { content between design sources and production sources. (NAS 3500) }\end{array}$ & S & $S$ \\
\hline B.6.2 & $\begin{array}{l}\text { Extend existing standards and tools to assure that they adequately address } \\
\text { all information like provisioning data, acquisition needs, and quality } \\
\text { (metadata) }\end{array}$ & S & M \\
\hline B.6.3 & $\begin{array}{l}\text { Develop a practice and process for the complete configuration management } \\
\text { of MBE TD. (practices exist for TDP but not for MBE TDP) }\end{array}$ & $\mathrm{S}$ & $\mathrm{M+}$ \\
\hline B.6.4 & $\begin{array}{l}\text { Develop tools to validate the accuracy of the model and provide needed } \\
\text { training to the acquisition community }\end{array}$ & S & M \\
\hline ID & \multicolumn{3}{|l|}{ Issue/Need Description } \\
\hline B.7 & \multicolumn{3}{|c|}{$\begin{array}{l}\text { Character Characteristic level accountability - traceability of requirements through product design } \\
\text { and manufacturing at the level at which they make sense and can be measured/consumed. } \\
\text { There is no definition of what manufacturing planning data is required in the TDP. } \\
\text { The need to include narrative documents along with the geometric data in the TDP is not well } \\
\text { served. } \\
\text { There is no definition of requirements or methodologies for inspection or QA of minimally } \\
\text { dimensioned MBE models. }\end{array}$} \\
\hline \multirow[b]{2}{*}{ ID } & \multirow[b]{2}{*}{ Solution (add Metric for Success for "Top" Solutions) } & \multicolumn{2}{|l|}{ Timing } \\
\hline & & $\begin{array}{l}\text { Start } \\
\text { Years } \\
0,1,2 \ldots\end{array}$ & $\begin{array}{l}\text { Duratio } \\
\mathrm{n} \text { Years }\end{array}$ \\
\hline B.7.1 & $\begin{array}{l}\text { Evaluate tools and methods that exist and define gaps. Benchmark to } \\
\text { identify and establish best practices. }\end{array}$ & & \\
\hline B.7.2 & $\begin{array}{l}\text { Establish manufacturing (including the extended enterprise) use cases that } \\
\text { communicate exactly what the government needs in a TDP and why. Include } \\
\text { narrative documents with geometric data. }\end{array}$ & & \\
\hline B.7.3 & $\begin{array}{l}\text { Develop a compliance matrix that maps the manufacturing planning } \\
\text { requirements to the TDP. }\end{array}$ & & \\
\hline ID & \multicolumn{3}{|l|}{ Issue/Need Description } \\
\hline B.8 & \multicolumn{3}{|c|}{$\begin{array}{l}\text { Multitude of IT certification requirements across DoD is a barrier for adopting MBE tools. } \\
\text { The DoD enterprise IT strategy does not link with MBE tools (both DoD and corporate IT strategies }\end{array}$} \\
\hline ID & Solution (add Metric for Success for "Top" Solutions) & Timing & \\
\hline
\end{tabular}




\begin{tabular}{|c|c|c|c|}
\hline & & $\begin{array}{l}\text { Start } \\
\text { Years } \\
0,1,2 \ldots\end{array}$ & $\begin{array}{l}\text { Duration } \\
\text { Years }\end{array}$ \\
\hline B.8.1 & $\begin{array}{l}\text { Determine the appropriate chain of command for IT certification in order to } \\
\text { harmonize requirements with MBE implementation }\end{array}$ & & \\
\hline B.8.2 & $\begin{array}{l}\text { Establish a process to assure that certification of net worthiness is built into } \\
\text { the plan for every program. }\end{array}$ & & \\
\hline B.8.3 & $\begin{array}{l}\text { Highlight the cost of failures in not providing a timely solution to program } \\
\text { needs (IT installation requirements, risk analysis, net worthiness } \\
\text { certification) }\end{array}$ & & \\
\hline B.8.4 & Understand the approval process at the installation level & & \\
\hline B.8.5 & $\begin{array}{l}\text { Achieve an MBE presence and voice in IT strategy. This will be } \\
\text { accomplished by participation in forums and meetings. }\end{array}$ & & \\
\hline B.8.6 & $\begin{array}{l}\text { Obtain proper authority from OSD mandating MBE implementation and } \\
\text { mandating processes to support that implementation. }\end{array}$ & & \\
\hline B.8.7 & $\begin{array}{l}\text { Incorporate MBE enablement into gold standard processes within the } \\
\text { government to expedite the ability to conduct MBE }\end{array}$ & & \\
\hline ID & \multicolumn{3}{|l|}{ Issue/Need Description } \\
\hline B.9 & \multicolumn{3}{|l|}{ The migration of legacy models into new systems } \\
\hline \multirow[b]{2}{*}{ ID } & \multirow[b]{2}{*}{ Solution (add Metric for Success for "Top" Solutions) } & \multicolumn{2}{|l|}{ Timing } \\
\hline & & $\begin{array}{l}\text { Start } \\
\text { Years } \\
0,1,2 \ldots\end{array}$ & $\begin{array}{l}\text { Duration } \\
\text { Years }\end{array}$ \\
\hline B.9.1 & $\begin{array}{l}\text { Develop business rules that define the amount of legacy information that } \\
\text { must be provided to support each contract. (reasonable requirements } \\
\text { defined by category of procurement) }\end{array}$ & & \\
\hline B.9.2 & $\begin{array}{l}\text { Establish decision support systems based on business rules that guide the } \\
\text { acquisition decisions regarding legacy data. }\end{array}$ & & \\
\hline B.9.3 & $\begin{array}{l}\text { Provide line items for procurement of legacy data that is required by new } \\
\text { systems contracts }\end{array}$ & & \\
\hline B.9.4 & $\begin{array}{l}\text { Provide a robust tool set that supports the migration of } 2 \mathrm{D} \text { models to } 3 \mathrm{D} \\
\text { models including the capture of relevant information and the migration of } \\
\text { un-annotated } 3 \mathrm{D} \text { models to be compliant with new requirements. }\end{array}$ & & \\
\hline ID & \multicolumn{3}{|l|}{ Issue/Need Description } \\
\hline B.10 & \multicolumn{3}{|c|}{$\begin{array}{l}\text { There is no requirement to deliver an as-built TDP, including 3D geometry, to the government } \\
\text { appropriate for the contract. }\end{array}$} \\
\hline ID & Solution (add Metric for Success for "Top" Solutions) & Timing & \\
\hline
\end{tabular}




\begin{tabular}{|c|c|c|c|}
\hline & & $\begin{array}{l}\text { Start } \\
\text { Years } \\
0,1,2 \ldots\end{array}$ & $\begin{array}{l}\text { Duration } \\
\text { Years }\end{array}$ \\
\hline B.10.1 & $\begin{array}{l}\text { Provide clear definition including use cases that guide decisions about when } \\
\text { as-built TDPs are required and the content that is required. }\end{array}$ & & \\
\hline B.10.2 & $\begin{array}{l}\text { Define a framework that communicates the data content and the form of } \\
\text { that data. }\end{array}$ & & \\
\hline B.10.3 & $\begin{array}{l}\text { Provide tools that support the automated capture of needed as-built } \\
\text { information and provide mechanisms to assure compatibility of the available } \\
\text { data with the requirements of the contract. }\end{array}$ & & \\
\hline B.10.4 & $\begin{array}{l}\text { Clarify data right issues associated with the as-built TDP and document } \\
\text { general findings. (Understanding the specifics will be negotiated with each } \\
\text { contract) }\end{array}$ & & \\
\hline B.10.5 & $\begin{array}{l}\text { Provide tools that support the capture of configured product structure and } \\
\text { the ability to maintain the as-built TDP. }\end{array}$ & & \\
\hline B.10.6 & $\begin{array}{l}\text { Provide the capability to automatically reconcile as-built with the as- } \\
\text { designed and as planned }\end{array}$ & & \\
\hline ID & \multicolumn{3}{|l|}{ Issue/Need Description } \\
\hline B.11 & \multicolumn{3}{|c|}{$\begin{array}{l}\text { Emerging tools support a portion of the needed set, but they support pieces of the solution and are } \\
\text { not working toward a comprehensive solution to the TDP vision. }\end{array}$} \\
\hline \multirow[b]{2}{*}{ ID } & \multirow[b]{2}{*}{ Solution (add Metric for Success for "Top" Solutions) } & \multicolumn{2}{|l|}{ Timing } \\
\hline & & $\begin{array}{l}\text { Start } \\
\text { Years } \\
0,1,2 \ldots\end{array}$ & $\begin{array}{l}\text { Duration } \\
\text { Years }\end{array}$ \\
\hline B.11.1 & $\begin{array}{l}\text { Identify population of supporting tools in context of those issues above } \\
\text { that have cited tools as part of their solution }\end{array}$ & & \\
\hline B.11.2 & $\begin{array}{l}\text { Raise the visibility of the DEDMWG activity to the level required to achieve } \\
\text { the critical support, and enrich that activity to address all encompassing } \\
\text { solutions }\end{array}$ & & \\
\hline B.11.3 & $\begin{array}{l}\text { Develop and distribute the DEDMWG strategic plan as a guidance } \\
\text { document to industry. }\end{array}$ & & \\
\hline B.11.4 & $\begin{array}{l}\text { Provide incentives to the technology vendor community to work together } \\
\text { against the vision to provide4 comprehensive interoperable solutions. }\end{array}$ & & \\
\hline
\end{tabular}




\section{A-3 Group C. Provisioning, Logistics, and Sustainment Table}

Of the twenty-one (21) solutions developed, eleven (11) were rated as High Priority and are shaded yellow. Additionally, each solution was further developed with start year and duration information. The High Priority Solutions were presented to the full TDP Summit/Workshop participants for voting along with High Priority Solutions from the other TDP teams.

\begin{tabular}{|c|c|c|c|}
\hline ID & \multicolumn{3}{|l|}{ Issue/Need Description } \\
\hline C.1 & \multicolumn{3}{|c|}{$\begin{array}{l}\text { Need for complete and detailed standard definition of TDP across all Services: Need to evolve to } \\
\text { standard references for contracting purposes. Includes uniform and standard nomenclature with } \\
\text { terms and their definitions. Need to clarify what constitutes model based support for TDP. }\end{array}$} \\
\hline \multirow[b]{2}{*}{ ID } & \multirow[b]{2}{*}{ Solution (add Metric for Success for "Top" Solutions) } & \multicolumn{2}{|l|}{ Timing } \\
\hline & & $\begin{array}{l}\text { Start Year } \\
0,1,2 \ldots\end{array}$ & $\begin{array}{l}\text { Duration } \\
\text { Years }\end{array}$ \\
\hline C.1.1 & $\begin{array}{l}\text { Develop and publish DoD TDP standards and related documents, e.g. } \\
\text { Data Item Descriptions (DIDs) }\end{array}$ & 0 & 2 \\
\hline C.1.2 & $\begin{array}{l}\text { Work towards an international standard - leverage existing standards } \\
\text { work and new DoD standard }\end{array}$ & 0 & 5 \\
\hline ID & \multicolumn{3}{|l|}{ Issue/Need Description } \\
\hline C. 2 & \multicolumn{3}{|c|}{$\begin{array}{l}\text { Lack of upfront involvement and inadequate contract language: There is a lack of upfront } \\
\text { involvement across the stakeholder community. All stakeholders need to define the requirements } \\
\text { and the contract needs to reflect the requirements. Inadequate contractual language is not getting } \\
\text { the right PL\&S requirements in the contract. }\end{array}$} \\
\hline \multirow[b]{2}{*}{ ID } & \multirow[b]{2}{*}{ Solution (add Metric for Success for "Top" Solutions) } & \multicolumn{2}{|l|}{ Timing } \\
\hline & & $\begin{array}{l}\text { Start Year } \\
0,1,2 \ldots\end{array}$ & $\begin{array}{l}\text { Duration } \\
\text { Years }\end{array}$ \\
\hline C.2.1 & $\begin{array}{l}\text { Expand use of Automated tools - SYSPARS/SMART-T to assist in } \\
\text { developing program and contract documents. }\end{array}$ & 0 & 2 \\
\hline C.2.2 & $\begin{array}{l}\text { Institutionalize involvement policies across Services - clarify and } \\
\text { promote the need with strong business cases }\end{array}$ & 0 & 2 \\
\hline C.2.3 & Develop appropriate contract language and clauses - tied to standard & 0 & 2 \\
\hline C.2.4 & Assess execution activity- to confirm delivery of TDP & 1 & By TDP \\
\hline
\end{tabular}

\begin{tabular}{|l|l|l|}
\hline ID & \multicolumn{1}{|l|}{ Issue/Need Description } \\
\hline C.3 & $\begin{array}{l}\text { Need to address the definition, contents, and management of TDP certification and validation: } \\
\text { Who, how and when - oversees the delivery and acceptance of a TDP }\end{array}$ \\
\hline ID & Solution (add Metric for Success for “Top" Solutions) & Timing \\
\hline
\end{tabular}




\begin{tabular}{|c|c|c|c|}
\hline & & $\begin{array}{l}\text { Start Year } \\
0,1,2 \ldots\end{array}$ & $\begin{array}{l}\text { Duration } \\
\text { Years }\end{array}$ \\
\hline C.3.1 & $\begin{array}{l}\text { Define who, how and when in conjunction with policy development - } \\
\text { the "how" also driven by standard: "who" and "when" can start without } \\
\text { a standard }\end{array}$ & 0 & 2 \\
\hline ID & \multicolumn{3}{|l|}{ Issue/Need Description } \\
\hline C. 4 & \multicolumn{3}{|c|}{$\begin{array}{l}\text { TDPs often don't contain all the information users need throughout the lifecycle: May be } \\
\text { mislabeled, incomplete, inaccurate, conflicting, redundant and/or not searchable. Model data is } \\
\text { disconnected from source system. }\end{array}$} \\
\hline & \multirow[b]{2}{*}{ Solution (add Metric for Success for "Top" Solutions) } & \multicolumn{2}{|l|}{ Timing } \\
\hline ID & & $\begin{array}{l}\text { Start Year } \\
0,1,2 \ldots\end{array}$ & $\begin{array}{l}\text { Duration } \\
\text { Years } \\
\end{array}$ \\
\hline C.4.1 & $\begin{array}{l}\text { Develop a set of assessment rules for creating modernized data to } \\
\text { support legacy weapons system needs }\end{array}$ & 0 & 1 \\
\hline C.4.2 & Develop a tool kit/environment for cost effectively data modernization & 0 & 10 phased \\
\hline C.4.3 & $\begin{array}{l}\text { Identify cost effective tools and methods for developing, acquiring legacy } \\
\text { part data-2D, 3D, whatever fits the need }\end{array}$ & 0 & $\begin{array}{l}\text { Continuous } \\
3-5 \mathrm{yr} \\
\text { cycles }\end{array}$ \\
\hline ID & \multicolumn{3}{|l|}{ Issue/Need Description } \\
\hline C.5 & \multicolumn{3}{|c|}{$\begin{array}{l}\text { Lack of authoritative source and control of the TDP: Multiple copies of TDPs that are out of sync, as } \\
\text { delivered and as used, are not configuration managed. There are multiple sources and each thinks } \\
\text { they are THE authoritative source. Due to data manipulation to meet mission requirements, the } \\
\text { data is modified and is not fed back to the originating/originating source. Thus, it's out of sync, } \\
\text { redundant, multiple systems. Within some Services there is a lack of a modern repository } \\
\text { environment. Who controls and who is the authoritative source for a common part? How do we } \\
\text { know/assure that the most current TDP is up to date? }\end{array}$} \\
\hline & \multirow[b]{2}{*}{ Solution (add Metric for Success for "Top" Solutions) } & \multicolumn{2}{|l|}{ Timing } \\
\hline ID & & $\begin{array}{l}\text { Start Year } \\
0,1,2 \ldots \\
\end{array}$ & $\begin{array}{l}\text { Duration } \\
\text { Years }\end{array}$ \\
\hline C.5.1 & $\begin{array}{l}\text { Develop requirements to utilize Global Combat Support Systems (GCSS) } \\
\text { efforts (Enterprise Requirements Planning - ERPs) within and across the } \\
\text { Services to facilitate Product Lifecycle Management (PLM) }\end{array}$ & 0 & $\begin{array}{l}\text { Ongoing } \\
5 \mathrm{yr} \min \end{array}$ \\
\hline C.5.2 & $\begin{array}{l}\text { Develop and establish a policy for an official master authoritative data } \\
\text { source for each TDP }\end{array}$ & 0 & 2 \\
\hline C.5.3 & Identify current potential authoritative sources & 0 & 1 \\
\hline ID & \multicolumn{3}{|l|}{ Issue/Need Description } \\
\hline C.6 & \multicolumn{3}{|c|}{ Lack of ability to reuse and leverage product data: To derive other data products such as tech } \\
\hline
\end{tabular}




\begin{tabular}{|c|c|c|c|}
\hline \multirow[b]{3}{*}{ ID } & \multicolumn{3}{|c|}{$\begin{array}{l}\text { manuals, BOMs, to support all the subsequent as delivered, as used, as maintained, as designed, } \\
\text { etc. needs across the life cycle. }\end{array}$} \\
\hline & \multirow[b]{2}{*}{ Solution (add Metric for Success for "Top" Solutions) } & \multicolumn{2}{|l|}{ Timing } \\
\hline & & $\begin{array}{l}\text { Start Year } \\
0,1,2 \ldots\end{array}$ & $\begin{array}{l}\text { Duration } \\
\text { Years }\end{array}$ \\
\hline C.6.1 & $\begin{array}{l}\text { Define modern repository requirements and architecture options, use } \\
\text { of existing ERPs, JEDMICS, others including new commercial solutions. } \\
\text { Note: there are multiple implementation options, but one with promise } \\
\text { is primes-to-DoD mirroring. Leverage prime capability (tie into definition } \\
\text { of data requirements) }\end{array}$ & 0 & 2 \\
\hline C.6.2 & $\begin{array}{l}\text { Develop/discover standards based tools that take advantage of data } \\
\text { viewing and exchange }\end{array}$ & $\begin{array}{l}0 \\
2\end{array}$ & $\begin{array}{l}\text { 1- Discover } \\
4 \text { - Develop }\end{array}$ \\
\hline C.6.3 & $\begin{array}{l}\text { Develop and prove out capability to link TDPs to tech documents and } \\
\text { other deliverables }\end{array}$ & 0 & $1-1 / 2$ \\
\hline ID & \multicolumn{3}{|l|}{ Issue/Need Description } \\
\hline C.7 & \multicolumn{3}{|c|}{$\begin{array}{l}\text { Need to make it easier for parts reuse and interchangeability How can the data from a model } \\
\text { supported TDP be defined, acquired and utilized to improve NSN full descriptions? }\end{array}$} \\
\hline \multirow[b]{2}{*}{ ID } & \multirow[b]{2}{*}{ Solution (add Metric for Success for "Top" Solutions) } & \multicolumn{2}{|l|}{ Timing } \\
\hline & & $\begin{array}{l}\text { Start Year } \\
0,1,2 \ldots\end{array}$ & $\begin{array}{l}\text { Duration } \\
\text { Years }\end{array}$ \\
\hline C.7.1 & $\begin{array}{l}\text { Continue to push for parts management and leverage in progress } \\
\text { Services and DLA activities }\end{array}$ & 0 & continuous \\
\hline ID & \multicolumn{3}{|l|}{ Issue/Need Description } \\
\hline C.8 & \multicolumn{3}{|c|}{$\begin{array}{l}\text { Inadequate and insufficient data access, formats, availability - poor data access, inconsistent } \\
\text { formatting and overall lack of availability hinder broad based use across all the user domains. Users } \\
\text { need to be able to access the authoritative source in a form that they can readily use. }\end{array}$} \\
\hline \multirow[b]{2}{*}{ ID } & \multirow[b]{2}{*}{ Solution (add Metric for Success for "Top" Solutions) } & \multicolumn{2}{|l|}{ Timing } \\
\hline & & $\begin{array}{l}\text { Start Year } \\
0,1,2 \ldots\end{array}$ & $\begin{array}{l}\text { Duration } \\
\text { Years }\end{array}$ \\
\hline C.8.1 & Leverage authoritative source assessment and development work. & 0 & 2 \\
\hline C.8.2 & Develop and approve mechanisms that enable role based access to TDPs. & 0 & $2-1 / 2$ \\
\hline C.8.3 & Drive development of data formats - PLCS (AP-239) & 0 & $1-1 / 2$ \\
\hline C.8.4 & Provide low cost readers to some classes of users & 0 & continuous \\
\hline
\end{tabular}




\section{A-4 Group D. Policy Management Table}

This group felt that all policies changes could be started immediately but estimating the required duration was fruitless since the process is fraught with negotiations and compromises. Thus they elected to spend no time attempting to fill out the "Timing" portions of this table.

Solutions highlighted in yellow were taken forward into the large group prioritization process.

\begin{tabular}{|c|c|c|c|}
\hline ID & \multicolumn{3}{|l|}{ Issue/Need Description } \\
\hline D.1 & \multicolumn{3}{|l|}{ There is no single entity accountable for technical data policy within OSD. } \\
\hline & \multirow[b]{2}{*}{ Solution (add Metric for Success for "Top" Solutions) } & \multicolumn{2}{|l|}{ Timing } \\
\hline ID & & $\begin{array}{l}\text { Start } \\
\text { Years } \\
0,1,2 \ldots\end{array}$ & $\begin{array}{l}\text { Duration } \\
\text { Years }\end{array}$ \\
\hline D.1.1 & Need to revisit DoD 5000.02 to better address TDP policy. & & \\
\hline D.1.2 & $\begin{array}{l}\text { Require a technical data engineering data management plan (EDMP) } \\
\text { evaluation at each milestone review by an oversight board. }\end{array}$ & & \\
\hline D.1.3 & Develop an oversight board that contains the data stakeholders. & & \\
\hline D.1.4 & $\begin{array}{l}\text { Ensure that the life cycle support plan (LCSP) includes the cost and value } \\
\text { requirements of TDP. }\end{array}$ & & \\
\hline ID & \multicolumn{3}{|l|}{ Issue/Need Description } \\
\hline D.2 & \multicolumn{3}{|c|}{$\begin{array}{l}\text { Decision makers and policy makers who have the ability to mandate what should be done do not do } \\
\text { so... fully appreciate total life cycle costs. }\end{array}$} \\
\hline & \multirow[b]{2}{*}{ Solution (add Metric for Success for "Top" Solutions) } & \multicolumn{2}{|l|}{ Timing } \\
\hline ID & & $\begin{array}{l}\text { Start } \\
\text { Years } \\
0,1,2 \ldots\end{array}$ & $\begin{array}{l}\text { Duration } \\
\text { Years }\end{array}$ \\
\hline D.2.1 & Review the training program so that technical data is understood. & & \\
\hline D.2.2 & Implement accountability requirements associated with LCSPs. & & \\
\hline ID & \multicolumn{3}{|l|}{ Issue/Need Description } \\
\hline D.3 & \multicolumn{3}{|c|}{$\begin{array}{l}\text { Short term goals/objectives/drivers within program offices do not optimize life cycle sustainment } \\
\text { costs. (The PM is being rewarded for short term successes rather than long term } \\
\text { capabilities/requirements. Furthermore, the PM is not accountable to stakeholders and not held } \\
\text { responsible for long term shortcomings.) Short term management cycles accentuate lack of } \\
\text { accountability. }\end{array}$} \\
\hline & \multirow[b]{2}{*}{ Solution (add Metric for Success for "Top" Solutions) } & \multicolumn{2}{|l|}{ Timing } \\
\hline ID & & $\begin{array}{l}\text { Start } \\
\text { Years }\end{array}$ & $\begin{array}{l}\text { Duration } \\
\text { Years }\end{array}$ \\
\hline
\end{tabular}




\begin{tabular}{|c|c|c|c|}
\hline & & $0,1,2 \ldots$ & \\
\hline D.3.1 & $\begin{array}{l}\text { Create a rating associated with LCSP for the weapons system that is } \\
\text { irrespective of the program manager. }\end{array}$ & & \\
\hline ID & \multicolumn{3}{|l|}{ Issue/Need Description } \\
\hline D.4 & \multicolumn{3}{|c|}{$\begin{array}{l}\text { The de facto process does not include a timely provisioning process to include the Defense Logistics } \\
\text { Information Service (DLIS). }\end{array}$} \\
\hline & \multirow[b]{2}{*}{ Solution (add Metric for Success for "Top" Solutions) } & \multicolumn{2}{|l|}{ Timing } \\
\hline ID & & $\begin{array}{l}\text { Start } \\
\text { Years } \\
0,1,2 \ldots\end{array}$ & $\begin{array}{l}\text { Duration } \\
\text { Years }\end{array}$ \\
\hline D.4.1 & $\begin{array}{l}\text { A stronger policy statement is needed to ensure participation. Revise DoD } \\
15000.02 \text { and/or the DAG. }\end{array}$ & & \\
\hline D.4.2 & $\begin{array}{l}\text { Ensure that an objective assessment of provisioning actions occurs during } \\
\text { the acquisition milestone process. }\end{array}$ & & \\
\hline D.4.3 & $\begin{array}{l}\text { Enforce the requirement for DLIS participation at milestone review " } \mathrm{B} \text { " and } \\
\text { beyond. }\end{array}$ & & \\
\hline D.4.4 & $\begin{array}{l}\text { Establish/ensure a system to address modification updates affecting } \\
\text { provisioning groups. }\end{array}$ & & \\
\hline D.4.5 & $\begin{array}{l}\text { Include DLIS partnership/participation with the MILSVC in the SOW- } \\
\text { generation process. }\end{array}$ & & \\
\hline ID & \multicolumn{3}{|l|}{ Issue/Need Description } \\
\hline D.5 & \multicolumn{3}{|l|}{ Current data rights are not uniformly or adequately understood and exercised. } \\
\hline & \multirow[b]{2}{*}{ Solution (add Metric for Success for "Top" Solutions) } & \multicolumn{2}{|l|}{ Timing } \\
\hline ID & & $\begin{array}{l}\text { Start } \\
\text { Years } \\
0,1,2 \ldots\end{array}$ & $\begin{array}{l}\text { Duration } \\
\text { Years }\end{array}$ \\
\hline D.5.1 & $\begin{array}{l}\text { Add more resource Engineering Data Management Officers (EDMO) to the } \\
\text { degree required to exercise technical data rights adequately. }\end{array}$ & & \\
\hline D.5.2 & Provide/require training for all participants in the acquisition process. & & \\
\hline D.5.3 & $\begin{array}{l}\text { Revise DoD } 5000.02 \text { to include Redstone Arsenal (Dayne Beam) } \\
\text { recommended changes regarding GAO } 06839 \text { (Data Rights) report. }\end{array}$ & & \\
\hline ID & \multicolumn{3}{|l|}{ Issue/Need Description } \\
\hline D.6 & \multicolumn{3}{|c|}{$\begin{array}{l}\text { There is a lack of common terms, definitions, and industry standards within DoD policy and } \\
\text { contractual flow-down documents with respect to technical data. }\end{array}$} \\
\hline & \multirow[b]{2}{*}{ Solution (add Metric for Success for "Top" Solutions) } & \multicolumn{2}{|l|}{ Timing } \\
\hline ID & & Start & Duration \\
\hline
\end{tabular}




\begin{tabular}{|c|c|c|c|}
\hline & & $\begin{array}{l}\text { Years } \\
0,1,2 \ldots\end{array}$ & Years \\
\hline D.6.1 & $\begin{array}{l}\text { Develop an authoritative glossary of terms and include it as a standard } \\
\text { source document in an updated Defense Acquisition Guidebook. }\end{array}$ & & \\
\hline D.6.2 & $\begin{array}{l}\text { Evaluate existing industry standards to be used as references for } \\
\text { authoritative definitions. }\end{array}$ & & \\
\hline ID & \multicolumn{3}{|l|}{ Issue/Need Description } \\
\hline D.7 & \multicolumn{3}{|l|}{ Explicit direction on TDP content and delivery (CDRLs) is not given to the contractor. } \\
\hline & \multirow[b]{2}{*}{ Solution (add Metric for Success for "Top" Solutions) } & \multicolumn{2}{|l|}{ Timing } \\
\hline ID & & $\begin{array}{l}\text { Start } \\
\text { Years } \\
0,1,2 \ldots\end{array}$ & $\begin{array}{l}\text { Duration } \\
\text { Years }\end{array}$ \\
\hline D.7.1 & $\begin{array}{l}\text { Update MIL STD } 31000 \text { to have more explicit information on TDP content } \\
\text { and delivery requirements. }\end{array}$ & & \\
\hline D.7.2 & $\begin{array}{l}\text { Establish a team to advise policy makers regarding technical data format } \\
\text { delivery. }\end{array}$ & & \\
\hline D.7.3 & $\begin{array}{l}\text { Require that model-based TDPs specifying native-format files must also } \\
\text { include validated neutral-format files (e.g. Pro-E and STEP-APs). }\end{array}$ & & \\
\hline ID & \multicolumn{3}{|l|}{ Issue/Need Description } \\
\hline D.8 & \multicolumn{3}{|c|}{$\begin{array}{l}\text { Fidelity and robustness of technical data contractually requested often does not provide what is } \\
\text { really needed for sustainment. }\end{array}$} \\
\hline \multirow[b]{2}{*}{ ID } & \multirow[b]{2}{*}{ Solution (add Metric for Success for "Top" Solutions) } & \multicolumn{2}{|l|}{ Timing } \\
\hline & & $\begin{array}{l}\text { Start } \\
\text { Years } \\
0,1,2 \ldots\end{array}$ & $\begin{array}{l}\text { Duration } \\
\text { Years }\end{array}$ \\
\hline D.8.1 & Support the enhancement of ASME Y14.41 and other relevant standards. & & \\
\hline D.8.2 & $\begin{array}{l}\text { Ensure that all relevant contractual "boiler plate" references (both industry } \\
\text { and military) are identified and included in requirements documents. }\end{array}$ & & \\
\hline D.8.3 & $\begin{array}{l}\text { Review DOT FAA Order } 8110.4 \text { as an example of best practice for data } \\
\text { definition*, and engage with the AIA EMC (Engineering Management } \\
\text { Committee) to provide guidance on TDP definitions. } \\
\text { *(Defines the constituents of the TDP.) }\end{array}$ & & \\
\hline ID & \multicolumn{3}{|l|}{ Issue/Need Description } \\
\hline D.9 & \multicolumn{3}{|c|}{ The process of receiving data does not include a rigorous feedback loop for validating that the } \\
\hline
\end{tabular}




\begin{tabular}{|c|c|c|c|}
\hline \multirow[b]{3}{*}{ ID } & \multicolumn{3}{|c|}{$\begin{array}{l}\text { requested information has been received. The tech data procurement and receiving people are not } \\
\text { communicating effectively. }\end{array}$} \\
\hline & \multirow[b]{2}{*}{ Solution (add Metric for Success for "Top" Solutions) } & \multicolumn{2}{|l|}{ Timing } \\
\hline & & $\begin{array}{l}\text { Start } \\
\text { Years } \\
0,1,2 \\
\ldots\end{array}$ & $\begin{array}{l}\text { Duration } \\
\text { Years }\end{array}$ \\
\hline D.9.1 & Ensure that in-process reviews are part of contractual requirements. & & \\
\hline D.9.2 & $\begin{array}{l}\text { Ensure that Integrated Product Teams (IPTs) have procedures that define } \\
\text { roles and responsibilities with respect to TDP life cycle support; if not, create } \\
\text { them. }\end{array}$ & & \\
\hline D.9.3 & $\begin{array}{l}\text { Enhance existing tools such as Smart-T and Sys-Par to assist in } \\
\text { implementation of policy, and ensure that the tools are DoD wide. (Intelligent } \\
\text { Specification Assistant) }\end{array}$ & & \\
\hline ID & \multicolumn{3}{|l|}{ Issue/Need Description } \\
\hline D.10 & \multicolumn{3}{|c|}{$\begin{array}{l}\text { Parts demand data is not captured and provided to the DoD on contractor logistics support / } \\
\text { performance-based logistics (CLS/PBL) contracts. Risk mitigation plans and requirements are not } \\
\text { included in the language. }\end{array}$} \\
\hline & \multirow[b]{2}{*}{ Solution (add Metric for Success for "Top" Solutions) } & \multicolumn{2}{|l|}{ Timing } \\
\hline ID & & $\begin{array}{l}\text { Start } \\
\text { Years } \\
0,1,2 \\
\ldots\end{array}$ & $\begin{array}{l}\text { Duration } \\
\text { Years }\end{array}$ \\
\hline D.10.1 & $\begin{array}{l}\text { Demand data should be provided regardless of sustainment/procurement } \\
\text { method. }\end{array}$ & & \\
\hline D.10.2 & $\begin{array}{l}\text { Configuration data should always be provided regardless of } \\
\text { sustainment/procurement method. }\end{array}$ & & \\
\hline D.10.3 & Include exit-strategy in CLS/PBL contracts to mitigate risks. & & \\
\hline D.10.4 & $\begin{array}{l}\text { Review the Quadrennial Defense Review (QDR) solution for form, fit, and } \\
\text { function definition to ensure that it is adequate, and take action as necessary. }\end{array}$ & & \\
\hline ID & \multicolumn{3}{|l|}{ Issue/Need Description (Use only for coping and pasting new table) } \\
\hline D.11 & \multicolumn{3}{|l|}{ Software OEMs don't fully support data interoperability standards. } \\
\hline & \multirow[b]{2}{*}{ Solution (add Metric for Success for "Top" Solutions) } & \multicolumn{2}{|l|}{ Timing } \\
\hline ID & & $\begin{array}{l}\text { Start } \\
\text { Years } \\
0,1,2 \\
\ldots\end{array}$ & $\begin{array}{l}\text { Duration } \\
\text { Years }\end{array}$ \\
\hline
\end{tabular}




\begin{tabular}{|c|c|c|c|}
\hline ID & \multicolumn{3}{|c|}{ Issue/Need Description (Use only for coping and pasting new table) } \\
\hline D.12 & \multicolumn{3}{|c|}{$\begin{array}{l}\text { Engineering Data Managers are "disappearing" and along with them the knowledge of what a TDP } \\
\text { should include. }\end{array}$} \\
\hline & \multirow[b]{2}{*}{ Solution (add Metric for Success for "Top" Solutions) } & \multicolumn{2}{|l|}{ Timing } \\
\hline ID & & \begin{tabular}{|l} 
Start \\
Years \\
$0,1,2$ \\
$\ldots$ \\
\end{tabular} & $\begin{array}{l}\text { Duration } \\
\text { Years }\end{array}$ \\
\hline ID & \multicolumn{3}{|c|}{ Issue/Need Description (Use only for coping and pasting new table) } \\
\hline D.13 & \multicolumn{3}{|c|}{$\begin{array}{l}\text { Providers (program management and procurement personnel) to the data users (DLA parts } \\
\text { providers, codifiers of the info, packaging people, depots, warfighter) are not educated in the } \\
\text { technical data and data-rights environment. }\end{array}$} \\
\hline & \multirow[b]{2}{*}{ Solution (add Metric for Success for "Top" Solutions) } & \multicolumn{2}{|l|}{ Timing } \\
\hline ID & & $\begin{array}{l}\text { Start } \\
\text { Years } \\
0,1,2 \\
\ldots\end{array}$ & $\begin{array}{l}\text { Duration } \\
\text { Years }\end{array}$ \\
\hline ID & \multicolumn{3}{|c|}{ Issue/Need Description (Use only for coping and pasting new table) } \\
\hline D.14 & \multicolumn{3}{|c|}{$\begin{array}{l}\text { AS-9102 (First Article Inspection Report) is not currently required to be included as a part of the } \\
\text { TDP. }\end{array}$} \\
\hline & \multirow[b]{2}{*}{ Solution (add Metric for Success for "Top" Solutions) } & \multicolumn{2}{|l|}{ Timing } \\
\hline ID & & $\begin{array}{l}\text { Start } \\
\text { Years } \\
0,1,2 \\
\ldots\end{array}$ & $\begin{array}{l}\text { Duration } \\
\text { Years }\end{array}$ \\
\hline ID & \multicolumn{3}{|c|}{ Issue/Need Description (Use only for coping and pasting new table) } \\
\hline D.15 & \multicolumn{3}{|c|}{ Industry knowledge of LOTAR (AN-9300 standards) practices is incomplete. } \\
\hline & & \multicolumn{2}{|l|}{ Timing } \\
\hline ID & Solution (add Metric for Success for "Top" Solutions) & $\begin{array}{l}\text { Start } \\
\text { Years } \\
0,1,2 \\
\ldots\end{array}$ & $\begin{array}{l}\text { Duratio } \\
\mathrm{n} \\
\text { Years }\end{array}$ \\
\hline
\end{tabular}




\section{A-5 Summit Agenda \\ MBE Summit Agenda}

15-Dec-09

0800 - 0810 Welcoming Remarks and Admin Issues -

Simon Frechette, NIST

0810 - 0830 NIST Overview -

Dr. Howard Harary, (NIST)

0830 - 0850 OSD Direction for MBE -

Ms. Adele Ratcliff, (OSD)

0850 - 0910 Introduce Summit Goal and Objectives -

Paul Huang, ARL

OSD ManTech Project Update:

0910 - 0940 TDP Definition -

Paul Huang, (ARL)

$0940-1015$ Certification of 3D Models -

Simon Frechette, (NIST)

1015 - 1030 Break

1030 - 1100 Contracting for TDP within MBE -

Ric Norton, (DLIS)

1100 - 1130 Intelligent Specification Assistant- SYSPAR/Smart-T -

Jim Colson (LOGSA)

Rick Wagoner (NAVSEA)

Ric Norton (DLIS)

1130 - 1200 OSD Organic Facilities (Depot/Shipyard/ALC): MBE Data Reuse Capability

Rich Eckenrode, (BAE)

1200 - 1300 Working Lunch (Open Discussion)

1300 - 1330 MBE Provisioning Demo at DLA/DLIS A-10 \& MRAP

Ric Norton \&

Tim Haidl, (DLIS/DAPS)

1330 - 1400 Single Digital Master File Connectivity Demonstration

1400 - 1430 DoD National Supply Chain Model

Steve Luckowski, (ARDEC)

Pau Villanova,(ARDEC)

\section{Army ManTech Projects:}

1400 - 1425 Supply Chain Assessment Report

Roy Whittenburg,(BAE)

1425 - 1445 S1000D Technical Pilot MRAP Publication

Julie Miller/

Roy Whittenburg

1445 - 1500 Break

1500 - 1530 Adobe Quick Print and Visualization Enhancement

Roy Whittenburg (BAE)

1530 - 1630 Digital Depot -

Rich Eckenrode (BAE) 
Jack Martin (RRAD)

Eric Burkholder (LEAD)

1630 - 1700 MBE Success Story MRAP Egress Trainer

Rich Eckenrode, (BAE)

\section{6-Dec-09}

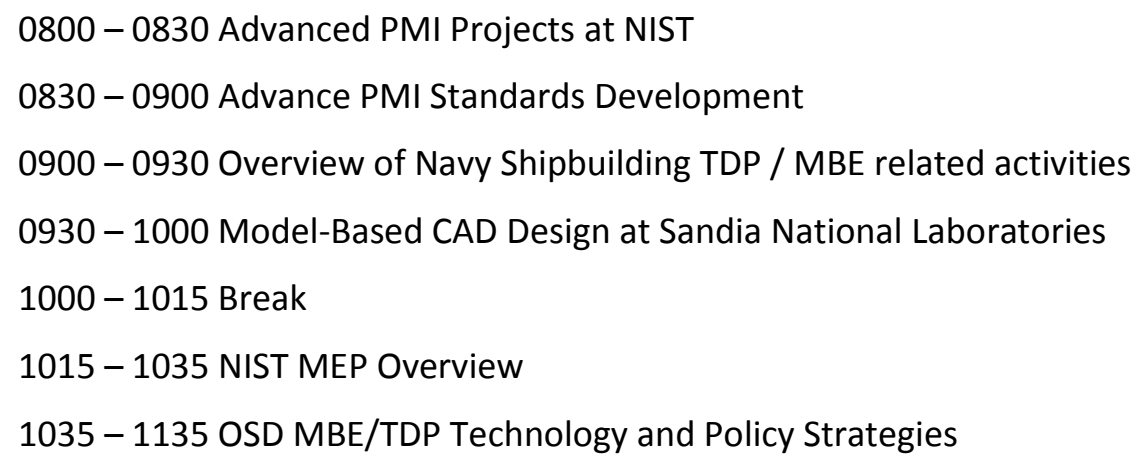

\section{TDP Summit Agenda}

\section{6-Dec-09}

$1330-1345$ Welcoming Remarks and Introductions

1345-1400 DEDMWG Website Demo

$1400-1415$ Workshop Methodology and Instructions

1415-1730 Small Groups (Current State, Vision, Issues, Solutions)
A) Acquisition
B) Production, Planning and Design (PP\&D)
C) Provisioning, Logistics and Sustainment (PL\&S)
D) Policy Management

1730 Adjourn for the day

\section{7-Dec-09}

0800 - 1130 Small Groups Meetings A-D (continuation)

$1130-1230$ Working Lunch in Breakout Groups

12301330 Small Groups Meeting A-D Review of Groups' Solutions and Prioritization

$1330-1400$ Break

$1400-1500$ All groups presents: Vision \& Top 10 Issues/Solutions (10 min/each)

$1500-1530$ Review of groups issues and prioritization 
$1500-1600$ Path forward, MBE Strategies review, and Concluding Remarks 


\section{A-6 Participants}

\begin{tabular}{|c|c|c|c|c|c|c|}
\hline & & Breakouts & 21 & 33 & 16 & 14 \\
\hline fName & IName & Activity/Company & Acq & PP\&D & PL\&S & Policy \\
\hline Eric & Adams & ARDEC Army & & & 1 & \\
\hline Kent & Alexander & Siemens PLM & & & 1 & \\
\hline Dave & Baum & Raytheon & & & & 1 \\
\hline Tina & Bigler & USCG HQ/EIS Army TARDEC & 1 & & & \\
\hline Bob & Brown & Delmia & & 1 & & \\
\hline Eric & Burkholder & LEAD & & 1 & & \\
\hline Alan $\mathrm{R}$ & Carlson & Raytheon & & 1 & & \\
\hline Otha & Carter & JMTC-RIA & & 1 & & \\
\hline Pad & Cherukuri & TARDEC/EBG & & 1 & & \\
\hline John & Christensen & contractor to OSD & & & & 1 \\
\hline Mike & Clare & Boeing Research \& Technology & & & 1 & \\
\hline James & Colson & LOGSA & & & 1 & \\
\hline T. Patrick & Coulehan & TechniGraphics, Inc. & & 1 & & \\
\hline Mike & $\begin{array}{l}\text { Cowperthwai } \\
\mathrm{t}\end{array}$ & PEO Aviation & & & 1 & \\
\hline Dave & Crouse & HQ AFMC & & 1 & & \\
\hline Nancy & Darnell & TARDEC/EBG & 1 & & & \\
\hline Ashley & Davis & DSCR-VABB & & & 1 & \\
\hline Steve & Deflitch & DSN Innovations & & 1 & & \\
\hline James & DeLaPorte & GulfStream & & & & 1 \\
\hline Denise & Duncan & LMI & 1 & & & \\
\hline Rich & Eckenrode & BAE & & 1 & & 1 \\
\hline Paul & Embry & Lockheed Martin & & 1 & & \\
\hline Simon & Frechette & NIST & & & 1 & \\
\hline Stanley P & Fuelscher & BAE Systems & & 1 & & \\
\hline Herman (Gary) & Gaines & Navy & 1 & & & \\
\hline John & Gamoa & BAE Systems & & 1 & & \\
\hline Suhair & Ghannam & TARDEC & 1 & & & \\
\hline
\end{tabular}




\begin{tabular}{|c|c|c|c|c|c|c|}
\hline Tom & Giesler & IMTI & & 1 & & \\
\hline Marilyn & Giles & IMTI & & & 1 & \\
\hline Gary & Grant & Warner Robins AFB & 1 & & & \\
\hline Gerry & Graves & SCRA & 1 & & & \\
\hline Rene & Graves & IMTI & 1 & & & \\
\hline John & Gray & ITI & & 1 & & \\
\hline Tim & Haidl & DLIS & 1 & & & \\
\hline Daniel K & Harn & Raytheon Missile Systems (RMS) & & 1 & & \\
\hline Rick & Harris & Sandia National Labs & & 1 & & \\
\hline George & Haskin & BAE systems & & 1 & & \\
\hline Tony & Hernandez & Sandia National Lab & & 1 & & \\
\hline Paul & Huang & Army Research Lab (ARL) & 1 & 1 & & \\
\hline Mark & Hubbart & DLIS & 1 & & 1 & \\
\hline Sara & Jordan & IMTI & 1 & & & \\
\hline Al & Kapinos & TARDEC/EBG & & 1 & & \\
\hline Bruce & Kaplan & LMI & & & 1 & \\
\hline Ben & Kassel & NSWCCD & & 1 & & \\
\hline Sharon & Kemmerer & NIST & & & & 1 \\
\hline John & Kreider & $\begin{array}{l}\text { RDAR-EIS-CS/Small Caliber Systems } \\
\text { Branch }\end{array}$ & & 1 & & \\
\hline Montana & Mallett & NIST - MEP & 1 & & & \\
\hline Debra Ann & Martin & Defense Logistics Agency (DLA) & & & 1 & \\
\hline Sam & McSpadden & IMTI & & & & 1 \\
\hline Bob & Morris & Renaissance Services, Inc. & & 1 & & \\
\hline Charlie & Neal & IMTI & & & 1 & \\
\hline Richard & Neal & IMTI & & 1 & & \\
\hline Doug & Neilson & ARL & 1 & & & \\
\hline Mark & Nielsen & PTC & 1 & 1 & & \\
\hline Ric & Norton & DLIS-KPD & & & 1 & 1 \\
\hline Henry (Hank) & Oakes & OASIS Systems Inc. & 1 & & & 1 \\
\hline Matthew & Payne & Naval Air Systems Command & 1 & & & 1 \\
\hline Nainesh & Rathod & Imaginestics, LLC & 1 & & & \\
\hline
\end{tabular}




\begin{tabular}{|c|c|c|c|c|c|c|}
\hline Gary & Reece & AFMC 516 & 1 & & & \\
\hline Jeff & Rembold & PTC & & 1 & & \\
\hline Walter & Roy & Army Research Lab (ARL) & & & & 1 \\
\hline Dr. Andreas & Schreiber & PROSTEP INC. & & 1 & & \\
\hline Natalie & Seiling & DLA & & & & 1 \\
\hline Carl & Sens & GDLS & & 1 & & \\
\hline Dan & Skabialka & AMRDEC Spares & & & 1 & \\
\hline Rob & Steele & IMTI & & & & 1 \\
\hline David & Stieren & NIST & & 1 & & \\
\hline Charlie & Stirk & CostVision Inc. & & 1 & & \\
\hline Liz & Sumrell & FRC-East & & & 1 & \\
\hline Gary & Sunderland & NAVAIR & 1 & & & 1 \\
\hline Jose & Tapia & ARDEC & & & 1 & \\
\hline Ken & Tashiro & Elysium Defense & & 1 & & \\
\hline Siyuan & Tu & LMI & & 1 & & \\
\hline Paul & Villanova & Picatinny Arsenal ARDEC & & 1 & & \\
\hline Rick & Wagoner & NSWC PHD Detachment Louisville & 1 & & & \\
\hline Greg & Wetsig & Northrup Grumman & 1 & & & 1 \\
\hline Roy & Whittenburg & BAE & & 1 & & \\
\hline
\end{tabular}




\section{A-7 Wiring Diagrams}

This sections contains a depictions of the hierarchy of the governing directives, instructions, guidance, and handbooks for the DoD acquisition process. These charts are rather notional and incomplete but do give a sense of how the program manager goes about satisfying the program requirements dealing with an acquisition.

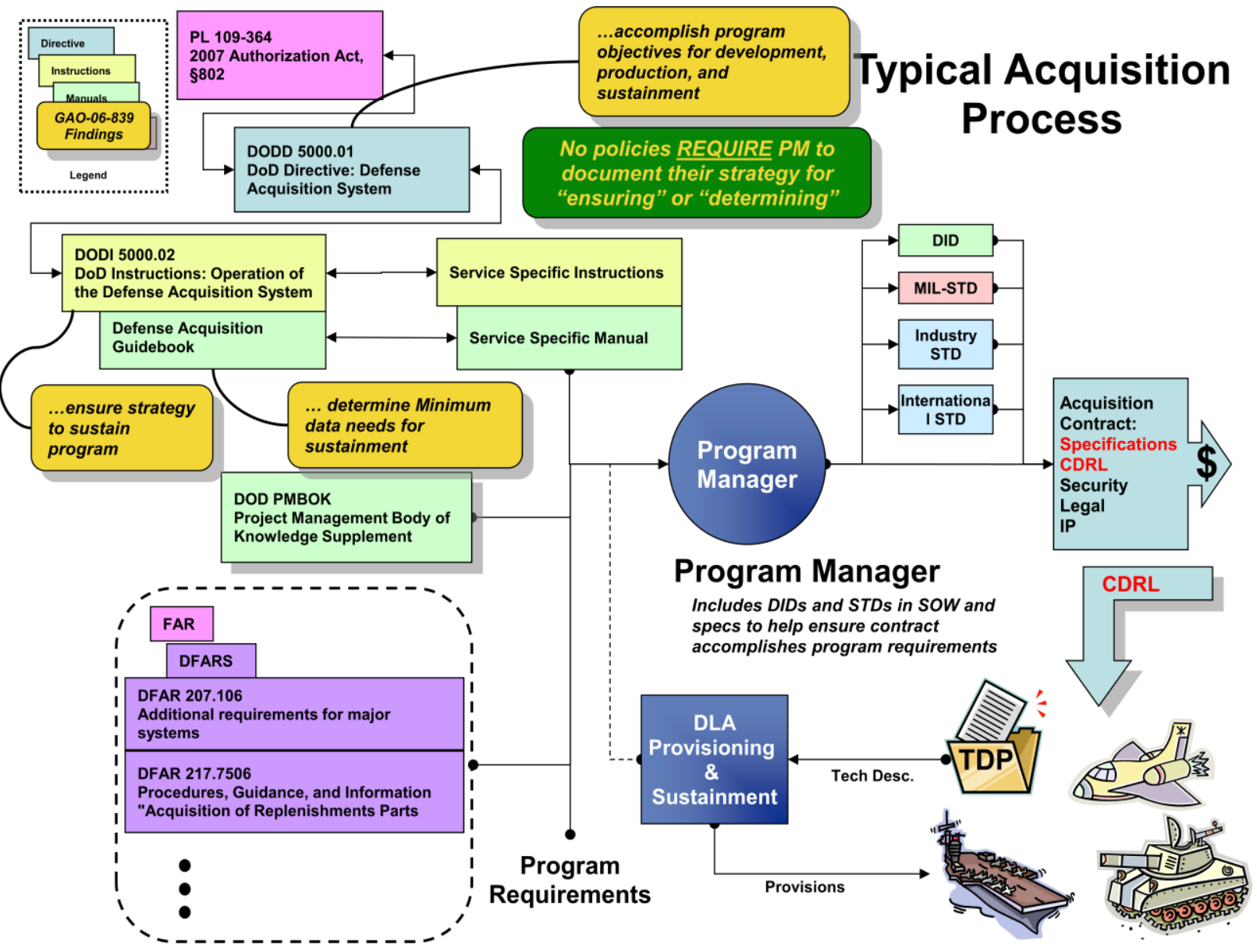

- Public Law 109-364 in ' $\$ 802$ calls for acquisitions to "(e) provide for technical data rights needed to sustain such systems and subsystems over their life cycle."

- DIRECTION and INSTRUCTIONS from DoD and Services required the program manager (or acquisition manager) to "address", "consider", or "ensure" the life-cycle of the product as he makes the purchase.

- GAO-06-839 found that very little oversight is mandated as to the sufficiency of the consideration but some of the newer DoD documents do have a requirement to review the sufficiency of the data.

- To help specify the contract deliverables the program manager is provided with many Data Item Descriptions (DID), Military, Industry, and International standards to include by reference in the contract data requirements list (CDRL). But again, there is nothing that says that they MUST use either this one or that one. 
The words "technical data package" are not used consistently. Sometimes it is Engineering Data, or Technical data. 
Each service has documentation covering directives, instructions, and manuals that generally follow the DoD level documents but with specific structure unique to that service. Each service is currently updating their individual policies.

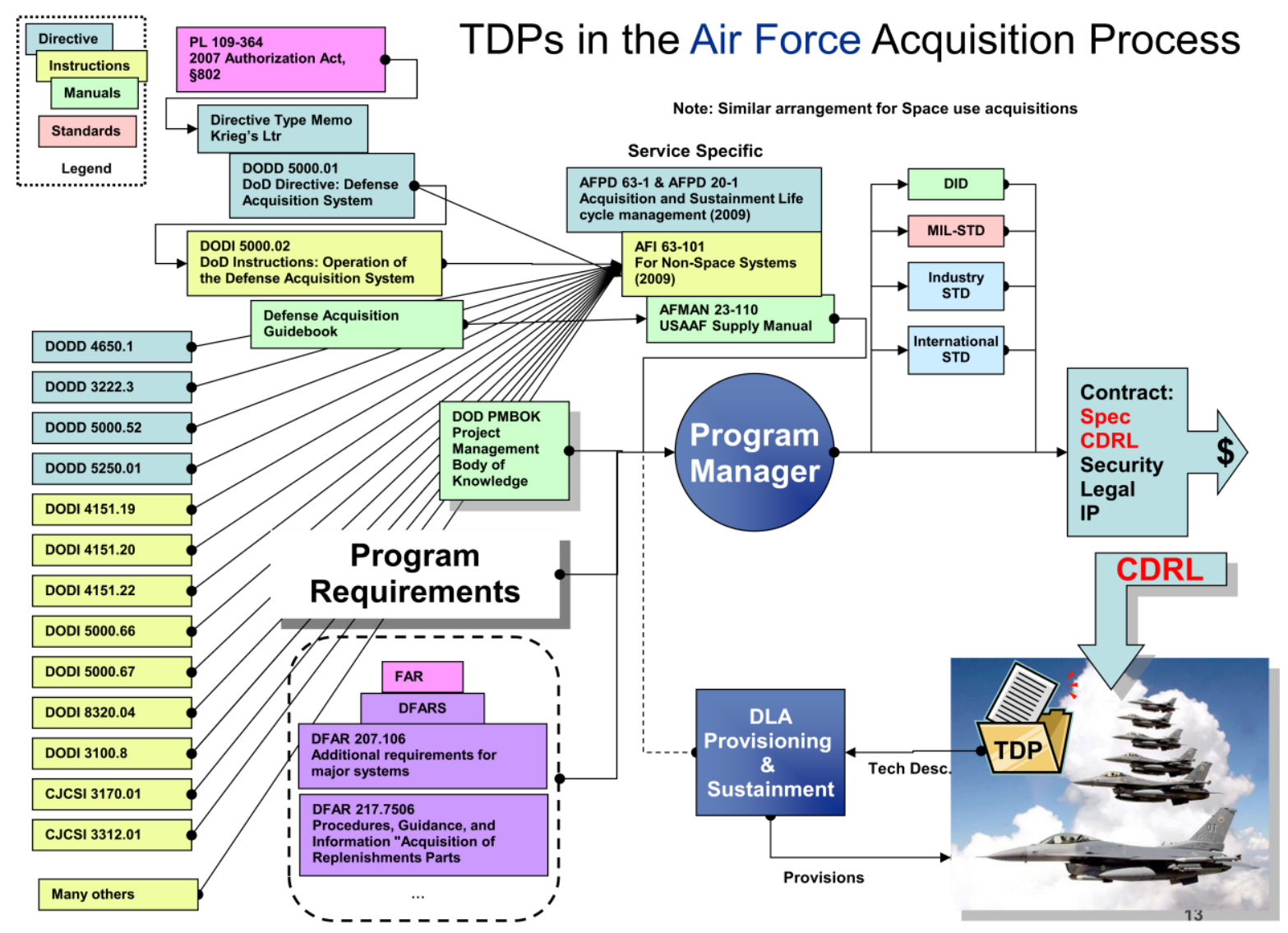



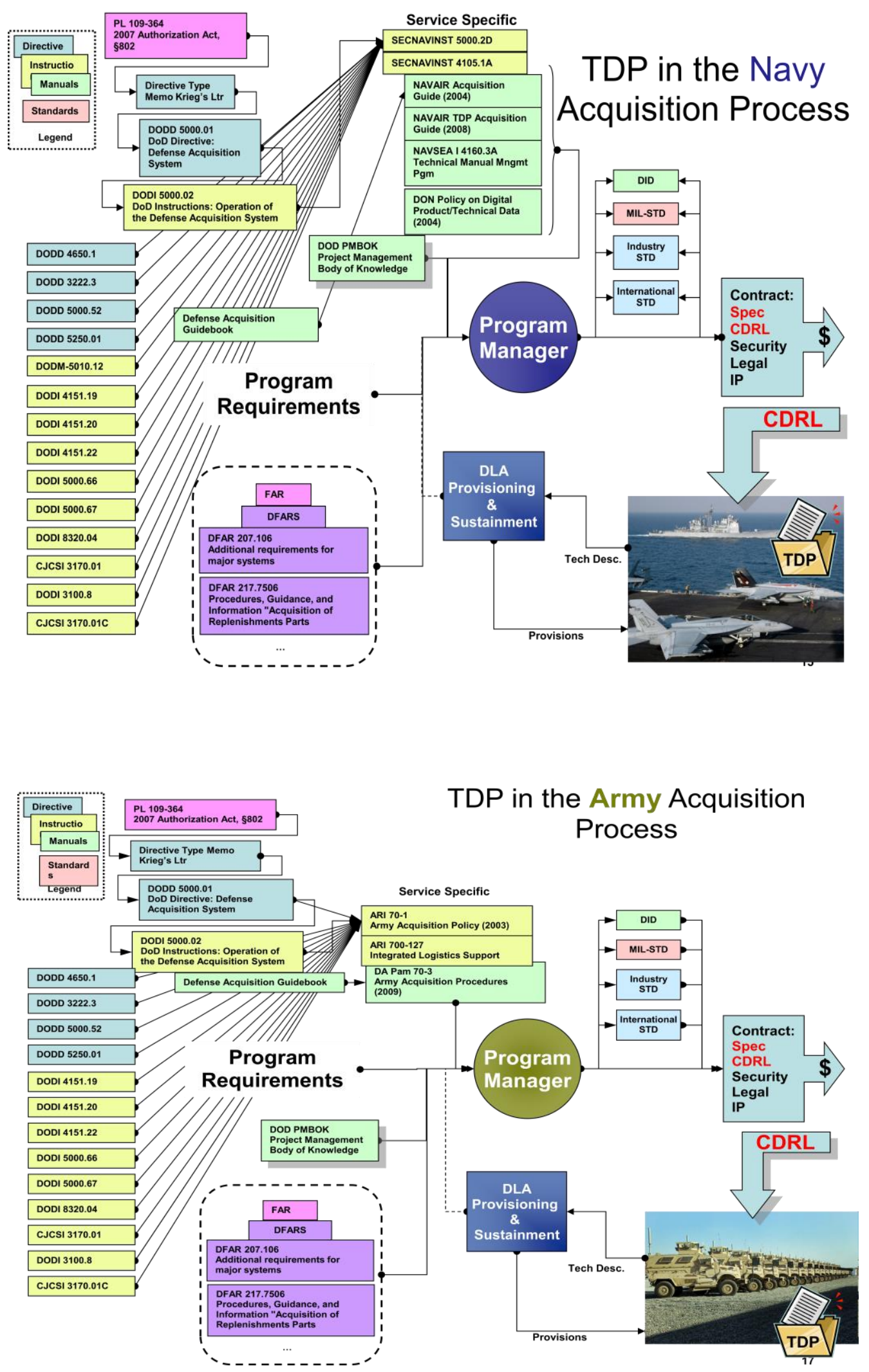


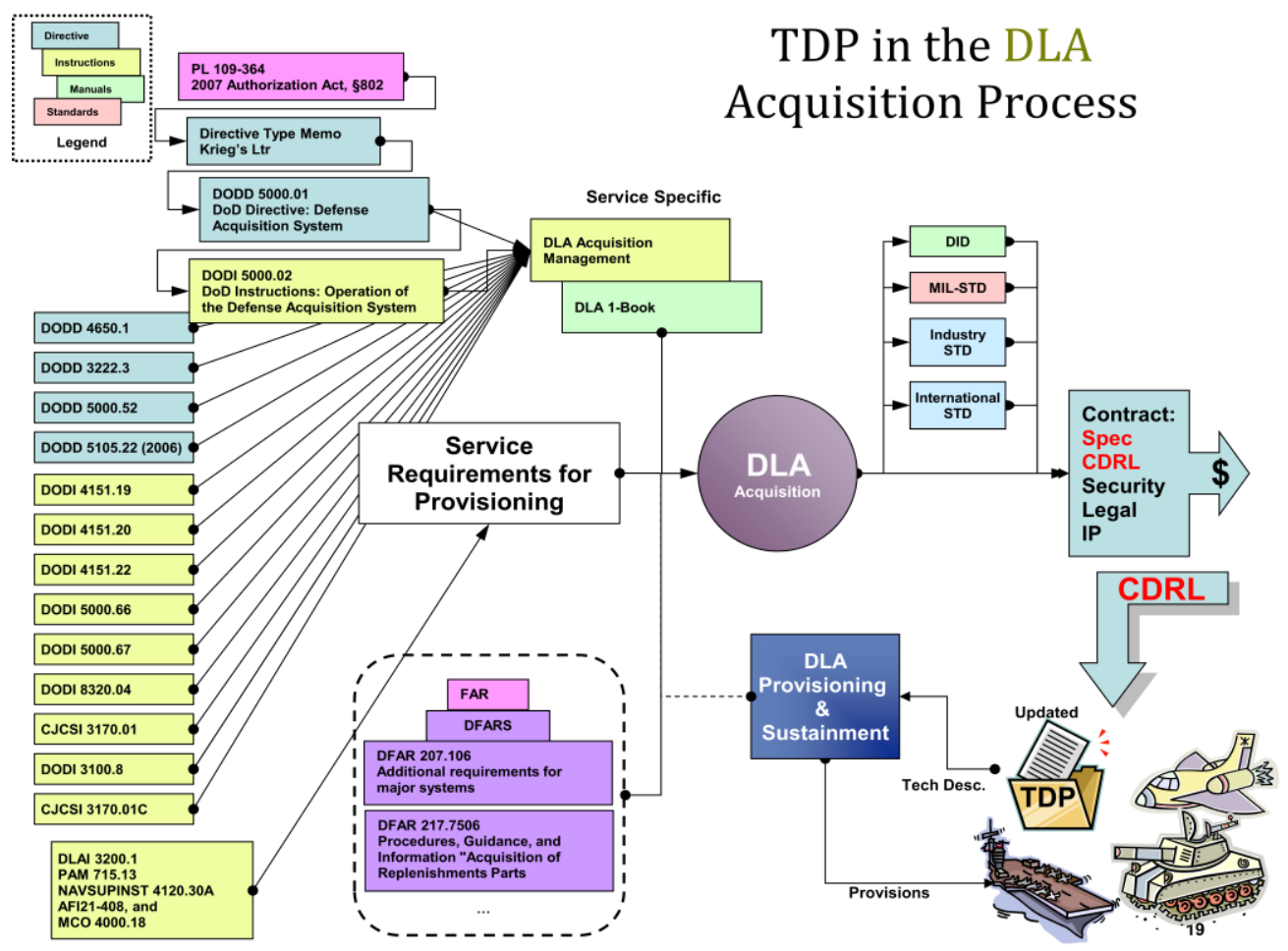

DLA provisions the services with required supplies and spare or replacement parts. They are subject to the same requirements in their acquisition process but are hampered in purchasing by the current lack of technical data on many of the systems they must provision. 